\title{
Climate Assessment for 1997
}

\author{
Gerald D. Bell and Michael S. Halpert \\ Climate Prediction Center, NCEP/NWS/NOAA, Washington, D.C.
}

\section{ABSTRACT}

The global climate during 1997 was affected by both extremes of the El Niño-Southern Oscillation (ENSO), with weak Pacific cold episode conditions prevailing during January and February, and one of the strongest Pacific warm episodes (El Niño) in the historical record prevailing during the remainder of the year. This warm episode contributed to major regional rainfall and temperature anomalies over large portions of the Tropics and extratropics, which were generally consistent with those observed during past warm episodes. In many regions, these anomalies were opposite to those observed during 1996 and early 1997 in association with Pacific cold episode conditions.

Some of the most dramatic El Niño impacts during 1997 were observed in the Tropics, where anomalous convection was evident across the entire Pacific and throughout most major monsoon regions of the world. Tropical regions most affected by excessive El Niño-related rainfall during the year included 1) the eastern half of the tropical Pacific, where extremely heavy rainfall and strong convective activity covered the region from April through December; 2) equatorial eastern Africa, where excessive rainfall during October-December led to widespread flooding and massive property damage; 3) Chile, where a highly amplified and extended South Pacific jet stream brought increased storminess and above-normal rainfall during the winter and spring; 4) southeastern South America, where these same storms produced above-normal rainfall during June-December; and 5) Ecuador and northern Peru, which began receiving excessive rainfall totals in November and December as deep tropical convection spread eastward across the extreme eastern Pacific.

In contrast, El Niño-related rainfall deficits during 1997 included 1) Indonesia, where significantly below-normal rainfall from June through December resulted in extreme drought and contributed to uncontrolled wildfires; 2) New Guinea, where drought contributed to large-scale food shortages leading to an outbreak of malnutrition; 3) the Amazon Basin, which received below-normal rainfall during June-December in association with substantially reduced tropical convection throughout the region; 4) the tropical Atlantic, which experienced drier than normal conditions during July-December; and 5) central America and the Caribbean Sea, which experienced below-normal rainfall during March-December.

The El Niño also contributed to a decrease in tropical storm and hurricane activity over the North Atlantic during August-November, and to an expanded area of conditions favorable for tropical cyclone and hurricane formation over the eastern North Pacific. These conditions are in marked contrast to both the 1995 and 1996 hurricane seasons, in which significantly above-normal tropical cyclone activity was observed over the North Atlantic and suppressed activity prevailed across the eastern North Pacific.

Other regional aspects of the short-term climate during 1997 included 1) wetter than average 1996/97 rainy seasons in both northeastern Australia and southern Africa in association with a continuation of weak cold episode conditions into early 1997; 2) below-normal rainfall and drought in southeastern Australia from October 1996 to December 1997 following very wet conditions in this region during most of 1996; 3) widespread flooding in the Red River Valley of the north-central United States during April following an abnormally cold and snowy winter; 4) floods in central Europe during July following several consecutive months of above-normal rainfall; 5) near-record to record rainfall in southeastern Asia during June-August in association with an abnormally weak upper-level monsoon ridge; and 6) near-normal rainfall across India during the Indian monsoon season (June-September) despite the weakened monsoon ridge.

Corresponding author address: Michael S. Halpert, Climate Prediction Center, NCEP/NOAA, W/NP52, NSC, Rm. 605, 5200

Auth Rd., Camp Springs, MD 20746 


\section{Table of Contents}

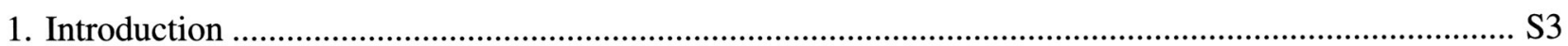

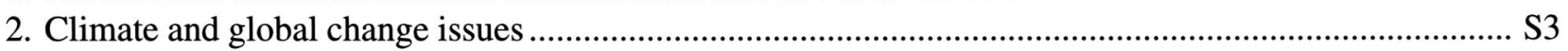

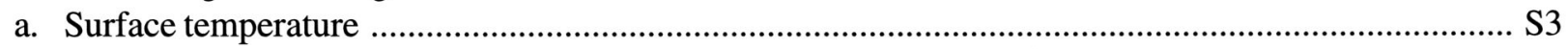

b. Tropospheric-stratospheric temperatures ………………....................................................... S6

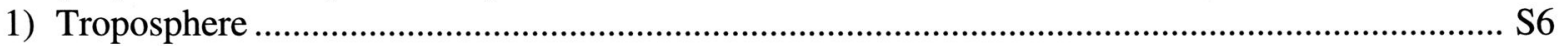

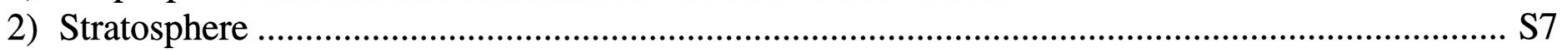

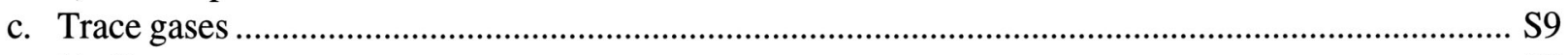

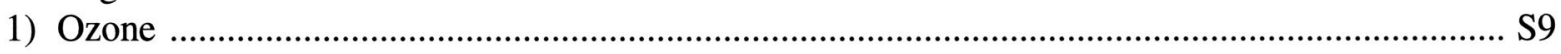

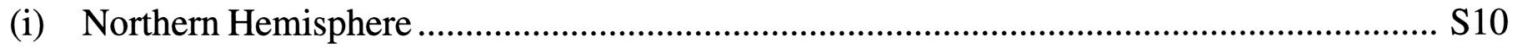

(ii) Southern Hemisphere ................................................................................................. $\mathrm{S} 10$

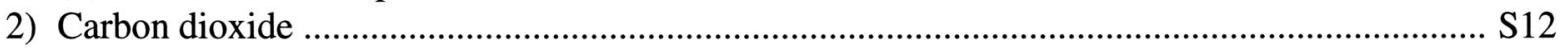

d. Northern Hemisphere snow cover ......................................................................................... S12

3. Atmospheric and oceanic circulation ............................................................................................... S13

a. Very strong 1997-98 Pacific warm episode (El Niño) .................................................................. S13

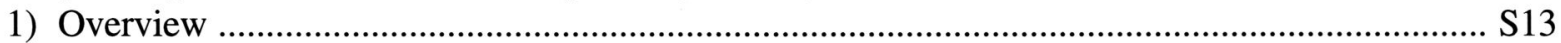

2) Evolution of the $1997 \mathrm{El} \mathrm{Niño} \mathrm{..............................................................................................} \mathrm{S14}$

3) Equatorial Walker circulation ........................................................................................... S20

4) South Pacific jet stream during July-September 1997 ............................................................. S20

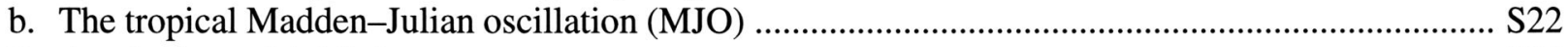

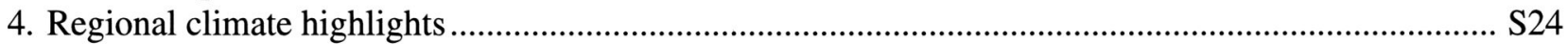

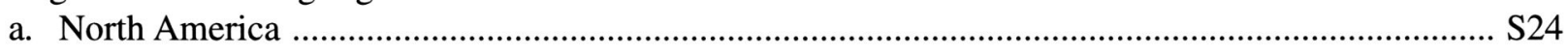

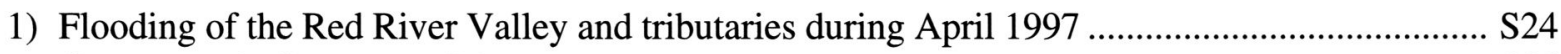

(i) Normal climate conditions ................................................................................................ S25

(ii) Contributing factors to the April 1997 record floods ..................................................... S25

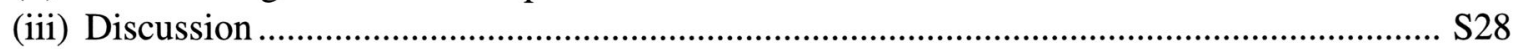

2) The 1997 North Atlantic and eastern North Pacific hurricane season ........................................ S28

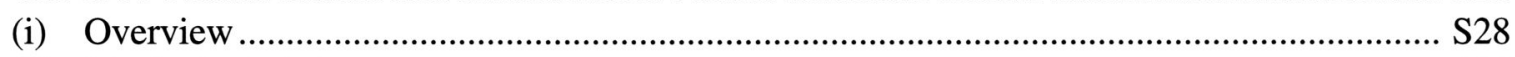

(ii) Vertical wind shear .................................................................................................... S29

(iii) The African easterly jet and African wave disturbances ................................................... S30

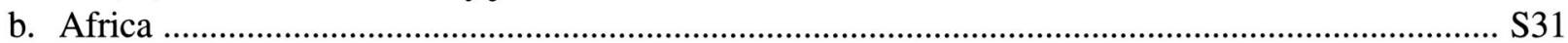

1) October-December 1997: Equatorial East Africa rainy season ............................................... S31

2) October 1996-April 1997: Southern Africa rainy season .......................................................... S33

3) June-September 1997: Western Africa rainy season .............................................................. S34

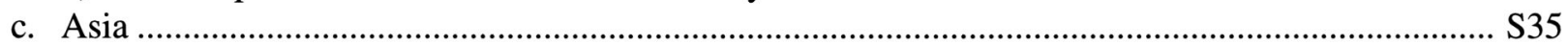

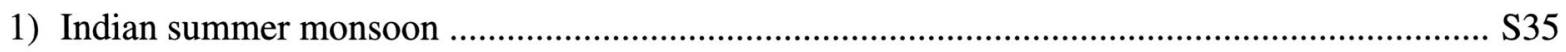

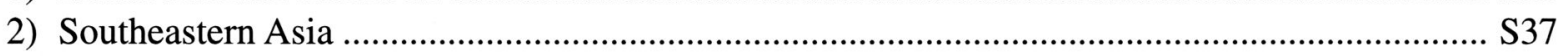

d. Europe: Cold winter, wet summer ................................................................................ S38

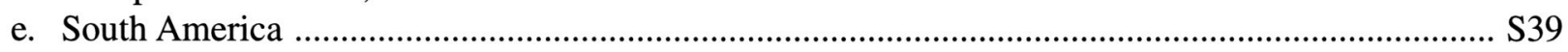

1) Brazil winter and spring highlights ................................................................................. S39

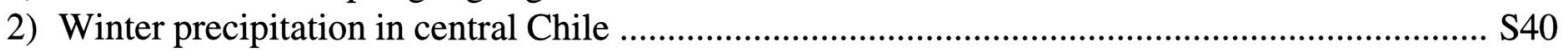

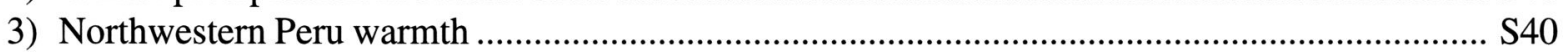

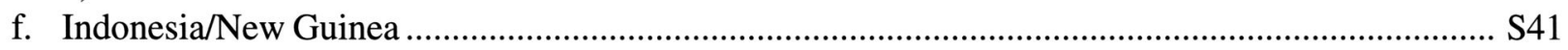

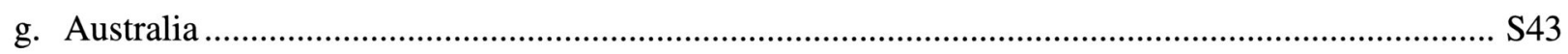

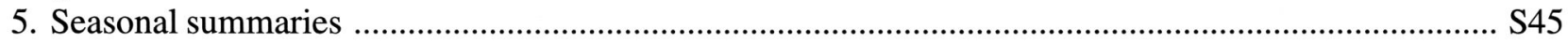

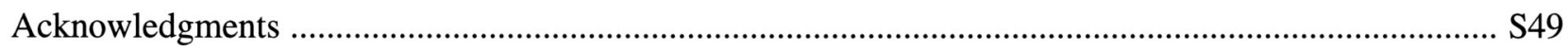

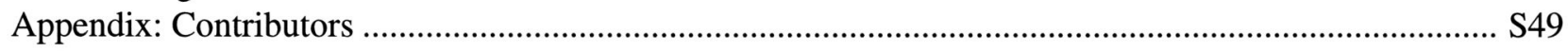

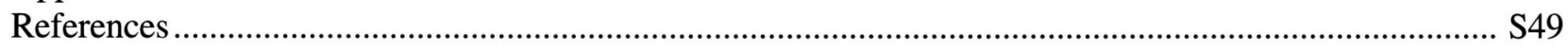




\section{Introduction}

This assessment is the eighth annual climate assessment in an ongoing series produced by the Climate Prediction Center. It is designed to provide a timely summary of the global climate system during 1997, and to document global climate variations, oceanic and atmospheric anomalies in the global Tropics and extratropics, and selected significant regional climate highlights.

Issues related to global and regional climate change, including atmospheric temperatures, ozone, carbon dioxide, and snow cover are addressed in section 2 . In section $3 \mathrm{a}$ an analysis of the very strong El NiñoSouthern Oscillation (ENSO) episode is presented, along with its effects on the atmospheric circulation throughout the tropical Pacific and over the Southern Hemisphere extratropics. Tropical intraseasonal (Madden-Julian oscillation) activity during the year is addressed in section 3b. Regional climate highlights and summaries of the major monsoon systems are discussed in section 4. Topics include flooding in the Red River basin of the north-central United States; a weakened North Atlantic hurricane season; a summary of the rainy seasons in southern, western, and eastern Africa; severe drought throughout Indonesia; temperature and precipitation highlights over South America; major flooding in the Czech Republic and eastern Germany during July; and widespread flooding throughout southern China. In section 5, seasonal maps of temperature anomalies, precipitation percentiles, and 500$\mathrm{hPa}$ heights and anomalies are presented. These maps are included for reference and to continue the set of maps that have appeared in previous annual climate assessments. Although each section is essentially selfcontained, there is liberal cross-referencing between sections to aid navigation through the document.

A variety of data sources were used in the compilation of this assessment, including 1) gridded analyses from the National Centers for Environmental Prediction-National Center for Atmospheric Research (NCEP-NCAR) Climate Data Assimilation System reanalysis project (Kalnay et al. 1996), 2) surface data obtained from the operational Global Telecommunications System, 3) satellites, 4) radiosondes, and 5) ship reports. Selected analyses were also obtained from international climate data centers. It should be noted that due to the variety of different data sources used in the assessment, it is not possible to maintain a consistent base period among all fields when computing anomalies.

\section{Climate and global change issues}

\section{a. Surface temperature}

Annual mean global surface temperatures for land and marine areas combined are based on data collected from over 1000 land-based weather stations, and from approximately 7000 ships and 1000 ocean buoys. The 1997 estimated global mean temperature anomaly over land and marine areas combined was $+0.43^{\circ} \mathrm{C}$ above the 1961-90 base period mean (Fig. 1a), with an approximate error of $0.06^{\circ} \mathrm{C}$ (Jones et al. 1997). This was the highest value recorded dating back to 1860 , which slightly surpassed the previous record estimate of $+0.38^{\circ} \mathrm{C}\left( \pm 0.06^{\circ} \mathrm{C}\right)$ set in 1995 . In the Northern Hemisphere, 1997 was the second warmest year on record, with annual mean temperatures reaching $+0.51^{\circ} \mathrm{C}$ above average (Fig. 1b). In the Southern Hemisphere, 1997 was the warmest year on record, with the annual mean temperature reaching $0.35^{\circ} \mathrm{C}$ above normal (Fig. 1c).

Six of the warmest 10 years in the historical record have been observed since 1990. During this period, the larger positive anomalies have been recorded in the Tropics $\left(30^{\circ} \mathrm{N}-30^{\circ} \mathrm{S}\right)$ (Fig. 2a) and in the Northern Hemisphere extratropics $\left(30^{\circ}-90^{\circ} \mathrm{N}\right)$ (Fig. 2b), where departures in both regions approximately doubled those observed in the Southern Hemisphere extratropics (Fig. 2c). The warmth in the Tropics has been strongly linked to recurring Pacific warm episode conditions. Since 1990, there have been four distinct periods of mature phase ENSO conditions, including the very strong 1997/98 warm episode. This latter episode was a major contributor to record 1997 warmth in the global Tropics, where temperatures averaged $0.6^{\circ} \mathrm{C}$ above the 1961-90 base period means, and was also an important contributor to the record global mean temperature set during the year (Fig. 1a). Annual mean temperatures during 1997 in both the Northern and Southern Hemisphere extratropics were also much above the 1961-90 base period means, with the 1997 anomaly in the Northern Hemisphere extratropics ranking third behind 1995 and 1990 (Fig. 2b), and the 1997 anomaly in the Southern Hemisphere extratropics equaling the previous record value set in 1993 (Fig. 2c).

The estimated global mean surface temperature during 1997 for land regions only was also well above the 1961-90 mean $\left(+0.31^{\circ} \mathrm{C}\right)$, resulting in the fifth warmest year in the historical record dating back to 1950 (Fig. 3a). All five of the warmest years have occurred during the $1990 \mathrm{~s}$. The tropical $\left(20^{\circ} \mathrm{S}-20^{\circ} \mathrm{N}\right)$ 

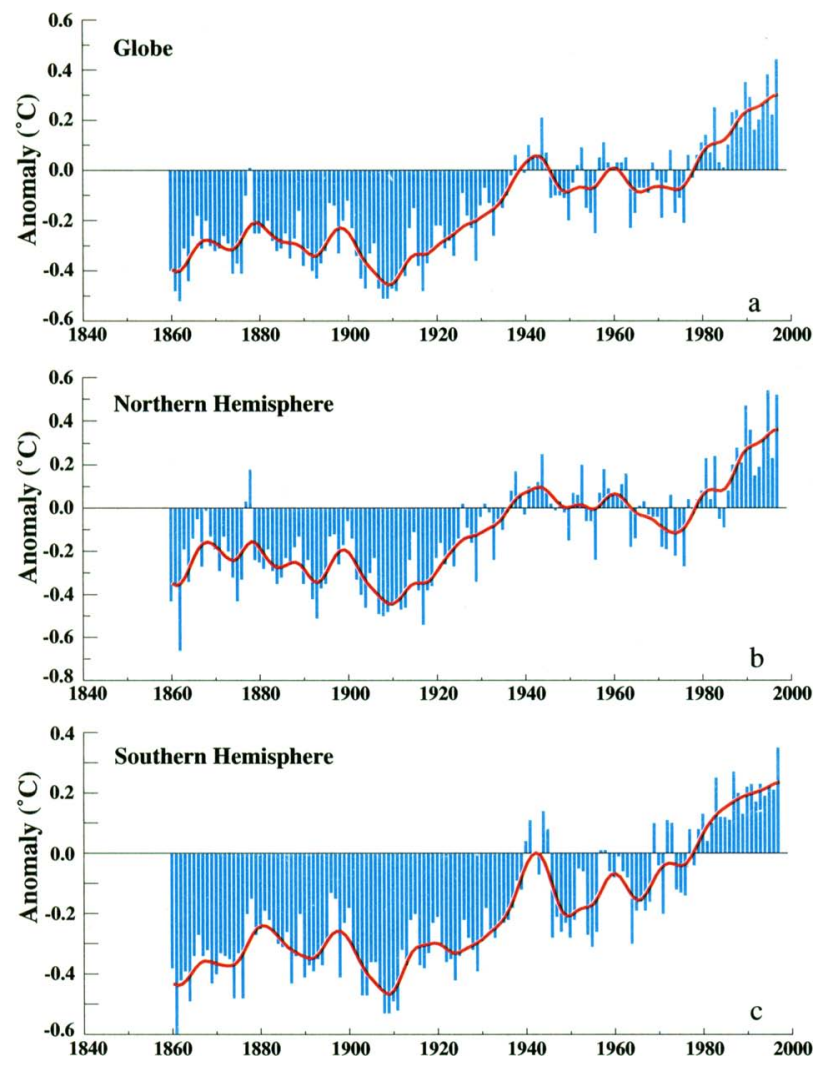

FIG. 1. Annual averages of combined land-air and SST anomalies (blue bars, ${ }^{\circ} \mathrm{C}$ ): (a) global, (b) Northern Hemisphere, and (c) Southern Hemisphere. Anomalies are departures from the 1961-90 base period means. Smoothed values (red curve) were obtained using a 13-term Gaussian filter designed to suppress variations on timescales less than 10 years. (Source: Hadley Centre for Climate Prediction and Research, United Kingdom, and Climatic Research Unit, University of East Anglia, United Kingdom.)

land areas during 1997 recorded their largest mean annual temperature anomaly $\left(+0.56^{\circ} \mathrm{C}\right)$ in the historical record dating back to 1950 (Fig. 3b), surpassing the previous record of $+0.50^{\circ} \mathrm{C}$ set in 1987 . Temperatures in the global Tropics were especially warm during October-December, when the three-month mean value averaged $+0.97^{\circ} \mathrm{C}$ above the $1961-90$ base period mean. In the Northern Hemisphere extratropics, annual mean land-only temperatures were the seventh warmest in the past 48 years (Fig. 3c), rebounding from the slightly negative anomaly observed during 1996. In the Southern Hemisphere extratropics, annual mean land-only temperatures during 1997 were $+0.28^{\circ} \mathrm{C}$ above normal, which is comparable to the largest values in the record dating back to 1950 (Fig. 3d).

The pattern of annual-average temperature anomalies during 1997 (Fig. 4) was dominated by well above
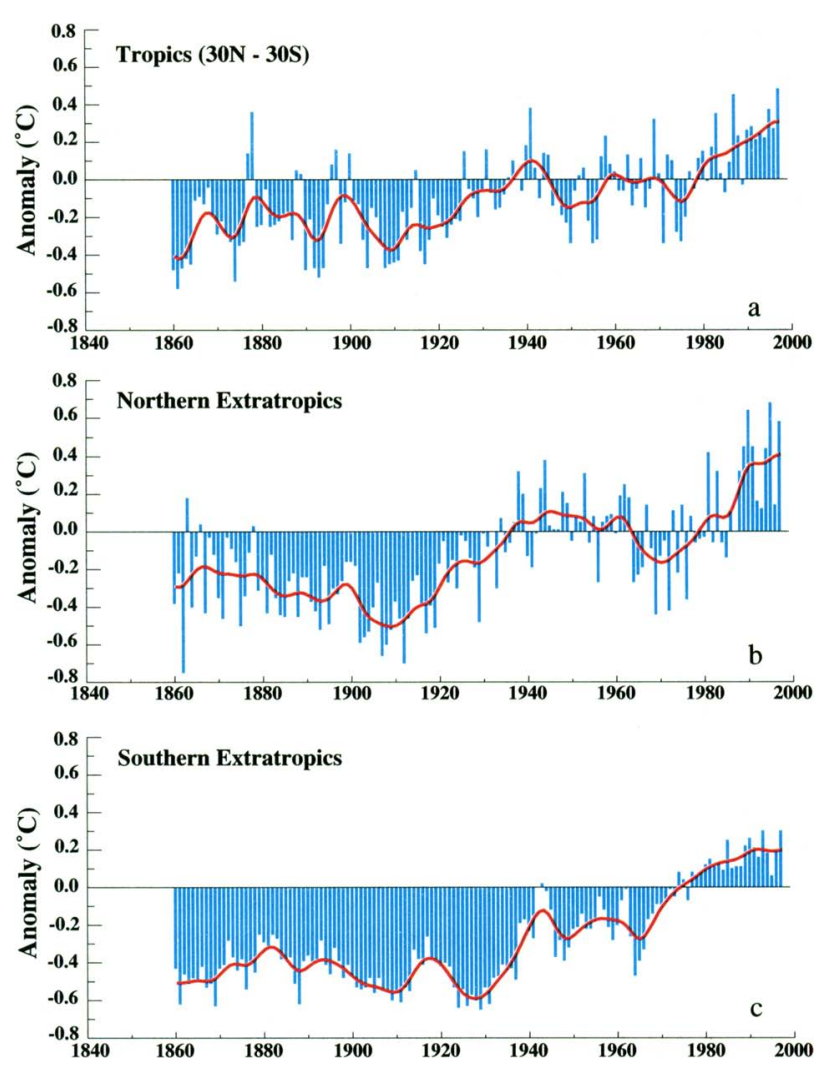

FIG. 2. Annual averages of combined land-air and SST anomalies (blue bars, ${ }^{\circ} \mathrm{C}$ ): (a) Tropics, (b) Northern Hemisphere extratropics, and (c) Southern Hemisphere extratropics. Anomalies are departures from the 1961-90 base period means. Smoothed values (red curve) were obtained using a 13-term Gaussian filter designed to suppress variations on timescales less than 10 years. (Source: Hadley Centre for Climate Prediction and Research, United Kingdom, and Climatic Research Unit, University of East Anglia, United Kingdom.)

normal temperatures across the tropical Pacific. Annual anomalies across the central and eastern tropical Pacific averaged $1^{\circ}-3.5^{\circ} \mathrm{C}$ above the $1961-90$ mean, with monthly anomalies exceeding $+5^{\circ} \mathrm{C}$ during October-December (not shown). These anomalies were larger than those recorded during the 1982/83 ENSO.

Abnormally warm SSTs were also observed across much of the tropical Indian Ocean during the year, where annual mean temperatures averaged $0.5^{\circ}-1.0^{\circ} \mathrm{C}$ above normal. Much of this warmth was observed during June-December, partly in association with a weaker than normal Indian monsoon circulation during JuneSeptember [see section 4c(1)], and with strong El Niño conditions throughout the period. During October-December these abnormally warm SSTs contributed to very large rainfall totals throughout equatorial eastern Africa and the western Indian Ocean [see section 4b(1)]. 

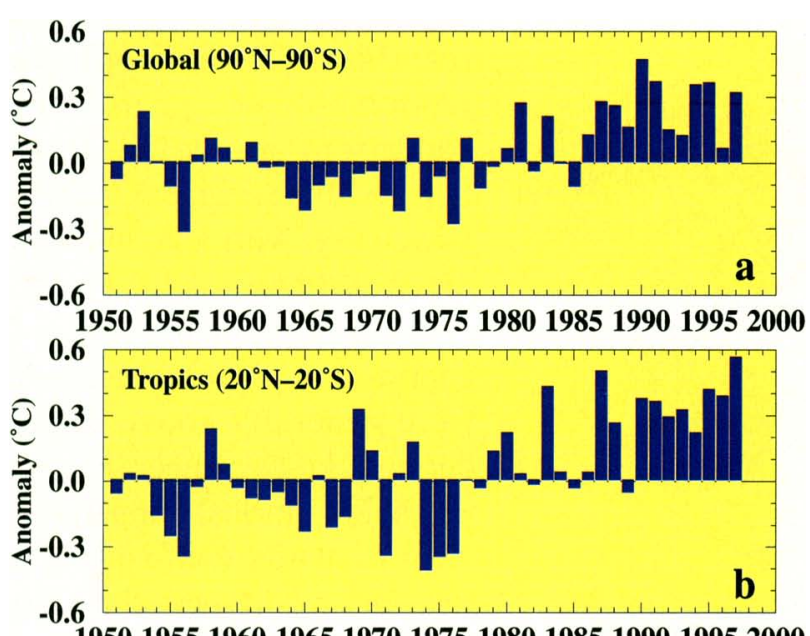

19501955196019651970197519801985199019952000

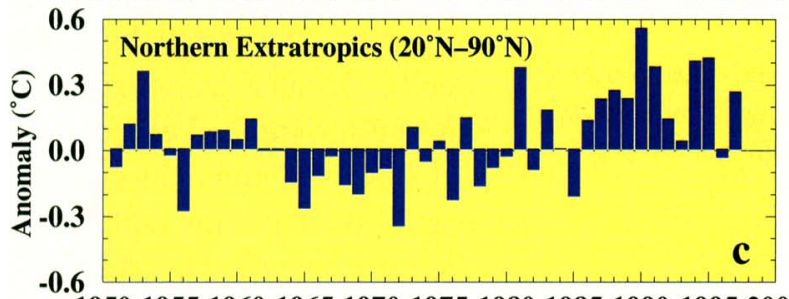

19501955196019651970197519801985199019952000

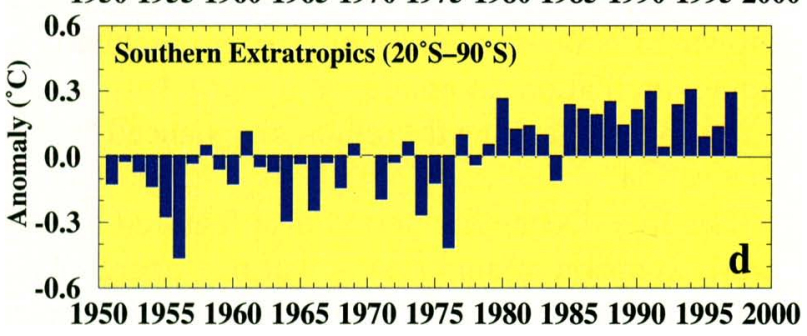

FIG. 3. Annual temperature anomalies (land only, ${ }^{\circ} \mathrm{C}$ ): (a) global, (b) Tropics, (c) Northern Hemisphere extratropics, and (d) Southern Hemisphere extratropics. Anomalies are departures from the $1961-90$ base period means.

In the Northern Hemisphere extratropics, the most prominent annual mean temperature anomalies during 1997 included above-normal temperatures over most of Siberia, over the eastern North Atlantic/western Europe, and across the eastern Pacific/western North America (including Alaska), and below-normal temperatures over the eastern two-thirds of North America, across the central North Pacific, northern India, and the Middle East (Fig. 4). The largest annual anomalies were observed over the eastern half of Russia and Siberia, where temperatures averaged $1^{\circ}-2.5^{\circ} \mathrm{C}$ above normal. In these regions, temperatures were above normal in all seasons except June-August (JJA), with the largest seasonal anomalies exceeding $+5^{\circ} \mathrm{C}$ during March-May (MAM) (see section 5, Fig. 69). This abnormal warmth was linked to an anomalous large-scale circulation pattern featuring above-normal heights and broad southwesterly flow throughout the region (see section 5, Fig. 70). A similar circulation pattern during January-May 1995 also resulted in excessive warmth (temperatures $6^{\circ}-8^{\circ} \mathrm{C}$ above average) and substantially reduced snow cover over Russia and Siberia (Halpert et al. 1996).

Elsewhere during 1997, a pattern of above-average temperatures over the eastern Atlantic/western Europe and below-average temperatures over eastern North America was observed during March-November (see section 5, Figs. 69, 71, 73). This temperature pattern was partly linked to a recurring negative phase of the North Atlantic oscillation (NAO). This negative NAO pattern was particularly prominent during April-June, as indicated by the largest negative NAO index for this three-month period dating back to 1950 (not shown). During this three-month period, temperatures averaged $1^{\circ}-3^{\circ} \mathrm{C}$ below normal across eastern North America and $1^{\circ}-2^{\circ} \mathrm{C}$ above normal across southwestern Europe (not shown). This anomalous circulation pattern also brought heavy rainfall to large parts of eastern Europe during April-June, and contributed to large-scale flooding throughout the region in July (see section 4d).

Over the Pacific sector, negative SST anomalies in the central north Pacific and positive temperature anomalies over Alaska and the eastern Pacific prevailed throughout much of the year (Fig. 4, also see section 5, Figs. 67, $69,71,73)$. In the Middle East and northern India, annual temperatures averaged near $1{ }^{\circ} \mathrm{C}$ below the 196190 means. In both of these regions temperatures during MAM and September-November (SON) were $0.5^{\circ}-$ $2^{\circ} \mathrm{C}$ below normal, with smaller negative anomalies observed during JJA. Temperatures over India were also below normal during December-February (DJF).

In the Southern Hemisphere extratropics, annual mean temperatures were above-normal over most of South America, Africa, and southeastern Australia, and below-normal over western Australia (Fig. 4). In South America the anomalous warmth was most evident during June-December in association with strong El Niño conditions (see section 5, Figs. 71 and 73). In Africa, temperatures were generally above normal in all four seasons. In Australia, seasonal temperatures were more variable, with above-normal temperatures observed in southern Australia during DJF (see section 5, Fig. 67) and over the eastern half of the continent during SON (see section 5, Fig. 73). Elsewhere, below-normal temperatures dominated northern and western Australia during the first three seasons of the year (see section 5, Figs. 67, 69, 71). 


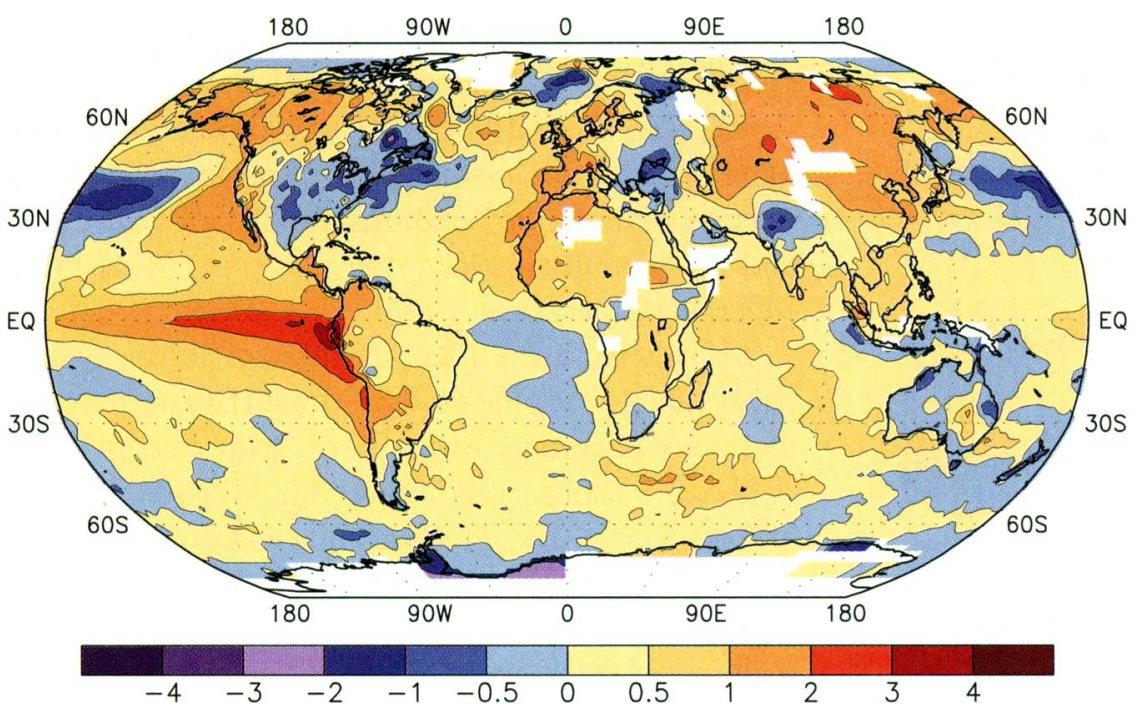

FIG. 4. Annual surface temperature anomalies $\left({ }^{\circ} \mathrm{C}\right)$ for 1997 . Analysis is based on station data over land and on SST data over the oceans. Anomalies are departures from the 196190 base period means. White areas are regions with insufficient data for analysis.

the first and second halves of the year (Fig. 6). In the Tropics and subtropics, colder than normal conditions prevailed during January-June (Fig. 6a), partly in association with a continuation of weak Pacific cold episode conditions into early 1997. In contrast, tropical temperatures were generally above normal during July-December (Fig. 6b), and below-normal temperatures were primarily confined to Africa. During this period the largest positive anomalies were found over the eastern half of the Pacific Ocean in association with an El Niño-related extension of deep tropical convection to well east of the date line (see section 3a, Figs. 26c,d). This warmth is

\section{b. Tropospheric-stratospheric temperatures}

1) Troposphere

Global fields of mean lower-tropospheric temperature are derived from channel-2R of the Microwave Sounding Unit (MSU) flown aboard the National Oceanic and Atmospheric Administration (NOAA) series of polar-orbiting satellites (Spencer et al. 1990). Most of the earth is sampled twice daily from each of two MSU instruments flying concurrently on different satellites. The MSU data record began in 1979 and has continued uninterrupted since that time. During 1997, the annual mean global lower-tropospheric temperature from the MSU (Fig. 5) was slightly below the $1979-95$ base period mean $\left(-0.15^{\circ} \mathrm{C}\right)$. This value is the seventh coldest in the 19-year record and is comparable to that observed in 1996. The MSU-derived temperatures have averaged below the 17-year average in five of the past six years. During this 6-year period temperatures averaged $0.2-0.4^{\circ} \mathrm{C}$ below the warmer period of 1987-91. Note that the very low temperatures recorded by the MSU instruments in 1992 and 1993 were strongly influenced by the eruption of Mount Pinatubo in June 1991. [In previous annual climate assessments lower-tropospheric temperatures derived from the MSU have been compared to estimates obtained from the global radiosonde network (e.g., Halpert and Bell 1997). However, radiosonde estimates for 1997 were unavailable for this assessment.]

The regional patterns of lower-tropospheric temperature anomalies show marked differences between thermodynamically consistent with another wellknown El Niño-related feature: subtropical anticyclonic circulation anomalies at upper levels of both hemispheres, flanking the region of enhanced tropical convection.

The July-December period also featured an eastward extension of abnormally warm temperatures to the northern half of South America and the tropical North Atlantic. This warmth was partly a result of advective processes, and in the Amazonian region was also the result of anomalous sinking motion in association with a weaker than normal upper-level anticyclonic circulation (see section 3a, Figs 27c,d).

In the extratropics, the January-June period featured below-normal temperatures over most of both

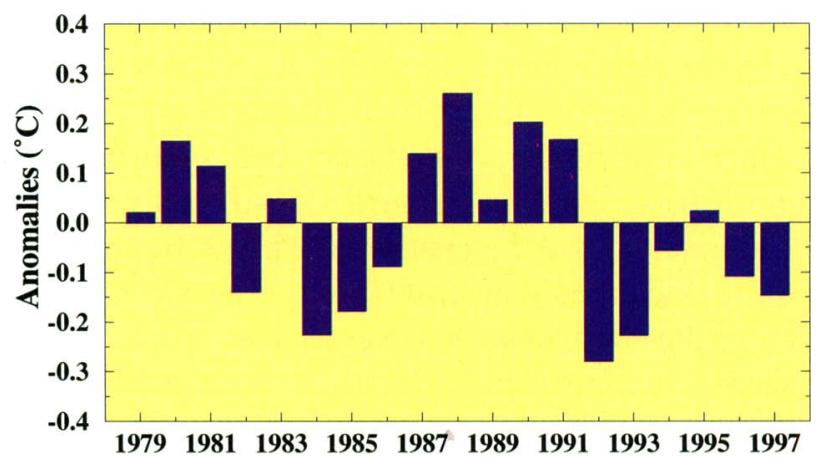

FIG. 5. Annual global-tropospheric temperature anomalies $\left({ }^{\circ} \mathrm{C}\right)$ derived from the MSU channel 2R. Anomalies are departures from the 1979-95 base period means. (MSU data provided by the University of Alabama in Huntsville.) 

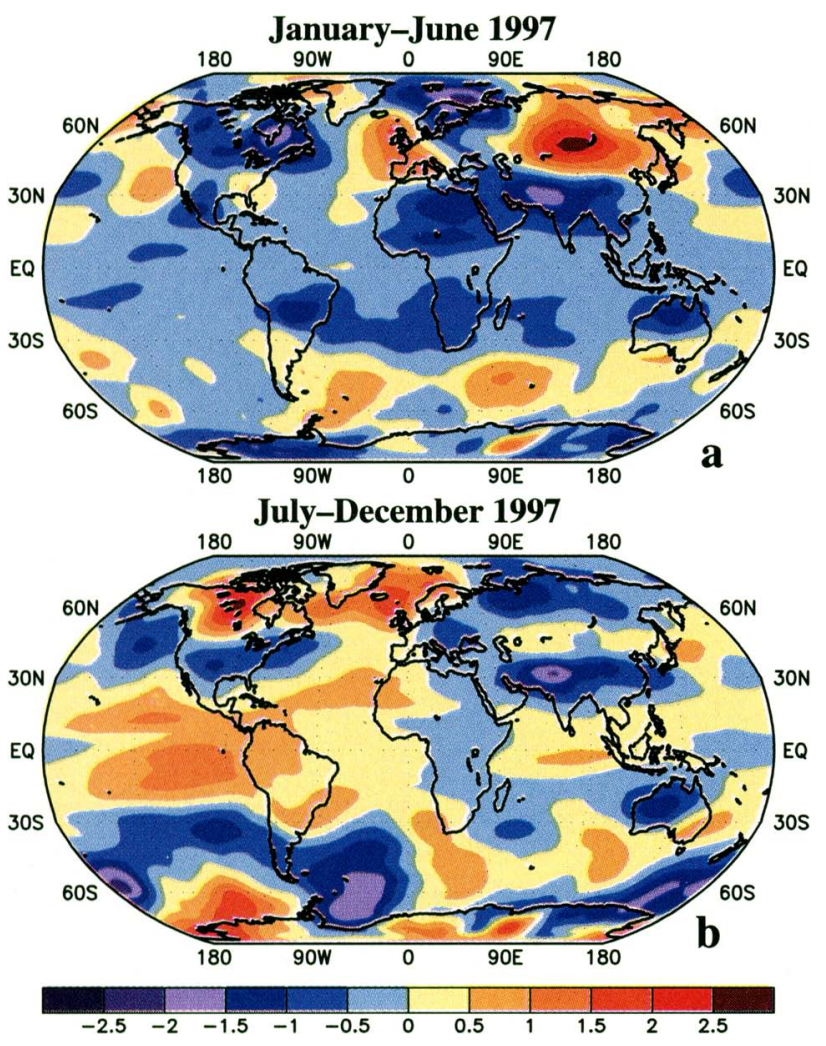

FIG. 6. Mean tropospheric temperature anomalies $\left({ }^{\circ} \mathrm{C}\right)$ for (a) January-June 1997 and (b) July-December 1997 derived from the MSU channel 2R. Anomalies are departures from the 197995 base period means. (MSU data provided by the University of Alabama in Huntsville.)

hemispheres, with positive anomalies confined to western Europe, central and eastern Asia, the eastern North Atlantic, and the high latitudes of the South Atlantic and South Indian Oceans (Fig. 6a). In Eurasia, the pattern of abnormally warm temperatures over central Russia and colder than normal conditions over northern Europe was also evident in the seasonal surface temperature and snow cover fields (see section 5 , Figs. 67, 69, and 19a,b). These conditions were associated with an anomalous atmospheric circulation, characterized by a pronounced upper-level trough throughout western Russia and broad southwesterly flow farther downstream (see section 5, Figs. 68 and 70).

In the Pacific-North America region, the pattern of below-normal lower-troposphere temperatures throughout Canada and the northern tier of the United States, and above-normal temperatures over the high latitudes of the North Pacific, reflected recurring highlatitude blocking over the central North Pacific. This blocking pattern contributed to increased storminess and a series of major cold-air outbreaks across central
North America. In contrast, the July-December period featured abnormally warm temperatures throughout Canada and abnormally cool conditions across most of the United States (Fig. 6b). These differences in temperature between the first and second halves of the year are consistent with the transition from Pacific cold to warm episode conditions.

Over the North Atlantic, lower-tropospheric temperatures during July-December were abnormally warm at high latitudes and in the subtropics, and close to normal in the middle latitudes. These conditions reflected recurring high latitude blocking activity during the period, and an overall southward shift of the main belt of westerlies to the central North Atlantic (see section 5, Figs. 72 and 74). These circulation features are consistent with a recurring negative phase of the NAO, especially during October-December. Farther east, temperatures were generally below normal across southeastern Europe during the period, in association with a persistent upper-level trough across the region. This trough was associated with an eastward extension of enhanced geostrophic westerlies across southern and central Europe, which contributed to increased storminess and above-normal rainfall throughout the region (see section $4 d$ ).

In the Southern Hemisphere extratropics, one of the most prominent features during July-December was persistent below-normal lower-tropospheric temperatures across the central latitudes of the South Pacific. This pattern is consistent with the presence of strong El Niño conditions throughout the period and, in combination with abnormally warm temperatures in the subtropics, was associated with a pronounced eastward extension of the South Pacific jet stream to well east of the date line [see section 3a(4)]. Farther south, above-normal temperatures covered the high latitudes of the eastern South Pacific during the period, in association with a persistent pattern of above-normal heights and recurring blocking activity. Increased coolseason blocking activity is also favored in this region during strong Pacific warm episodes (Karoly 1989).

\section{2) Stratosphere}

Global estimates of lower-stratospheric temperatures are derived from channel 4 of the MSU. During 1997, the estimated global mean temperature was $0.66^{\circ} \mathrm{C}$ below the $1979-95$ base period means (Fig. 7). This was the second lowest value in the 19-year historical record, surpassed only by the record low value recorded in 1996. Mean annual stratospheric temperatures have grown progressively colder during the 19- 


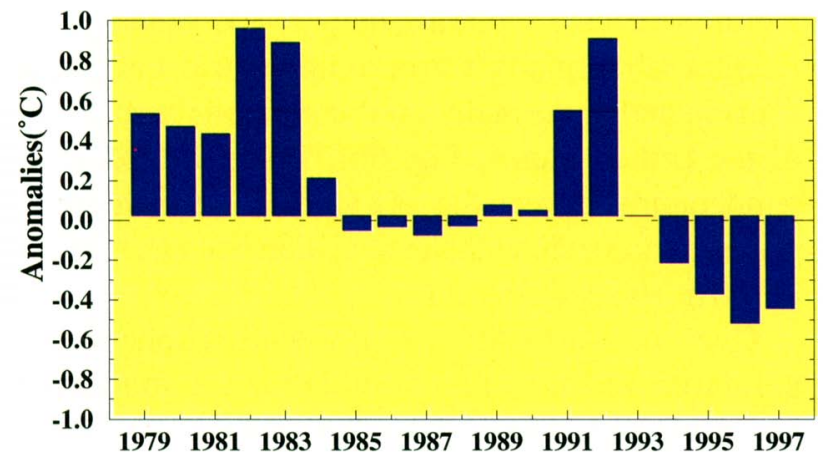

FIG. 7. Annual global-stratospheric temperature anomalies $\left({ }^{\circ} \mathrm{C}\right)$ derived from the MSU channel 4. Anomalies are departures from the 1979-95 base period means. (MSU data provided by the University of Alabama in Huntsville.)

year record, except for two 2-year periods in which temperatures were above normal. These periods coincide with the eruption of El Chichón in 1982 and the eruption of Mount Pinatubo in 1991. Also, global stratospheric temperatures have been below the longterm mean for the past five years, likely in response to an overall decrease in global ozone concentrations during the period.

During January-June, lower-stratospheric temperatures were below average over most of the globe (Fig. 8a). Regions with the largest negative temperature anomalies included the Northern Hemisphere polar region, the subtropical North Pacific extending eastward across the southern United States, and the Southern Hemisphere middle latitudes. Substantially warmer than normal temperatures during the period were confined to the high latitudes of the South $\mathrm{Pa}$ cific and portions of Antarctica.

Over the high latitudes of the Northern Hemisphere, wintertime temperatures have averaged well below normal for the past three years (Fig. 9). During 1997 extremely low temperatures were observed during February-April, when area-mean temperatures for the region north of $60^{\circ} \mathrm{N}$ averaged more than $9.0^{\circ} \mathrm{C}$ below normal. These below-normal temperatures were associated with below-normal geopotential heights at $50-\mathrm{hPa}$ everywhere north of $60^{\circ} \mathrm{N}$. The largest anomalies were centered directly over the polar region (Fig. 10a), where temperatures averaged more than $12.0^{\circ} \mathrm{C}$ below normal and heights averaged more than $600 \mathrm{~m}$ below normal. Collectively, these conditions were associated with an enhanced polar night jet (Fig. 10b). Features of this jet included an exceptionally strong gradient in the geopotential height field between $60^{\circ}$ and $80^{\circ} \mathrm{N}$ around the entire hemisphere, and

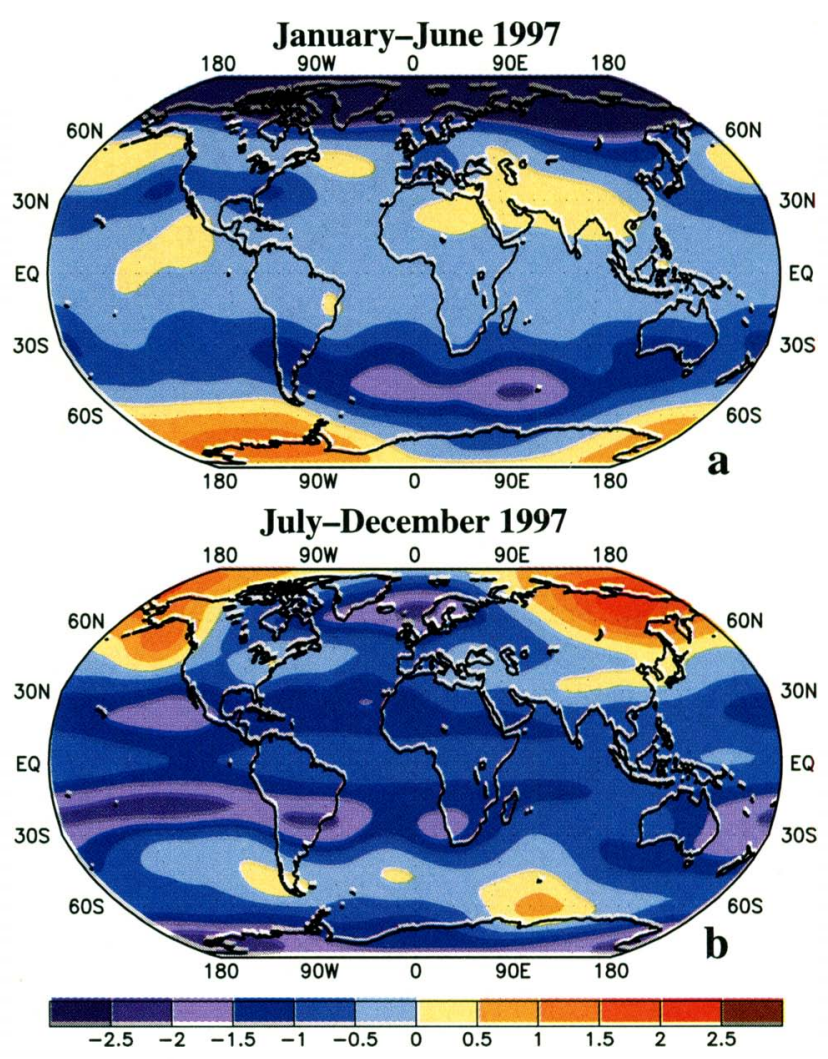

FIG. 8. Mean stratospheric temperature anomalies $\left({ }^{\circ} \mathrm{C}\right)$ for $(\mathrm{a})$ January-June 1997 and (b) July-December 1997 derived from the MSU channel 4. Anomalies are departures from the 1979-95 base period means. (MSU data provided by the University of Alabama in Huntsville.)

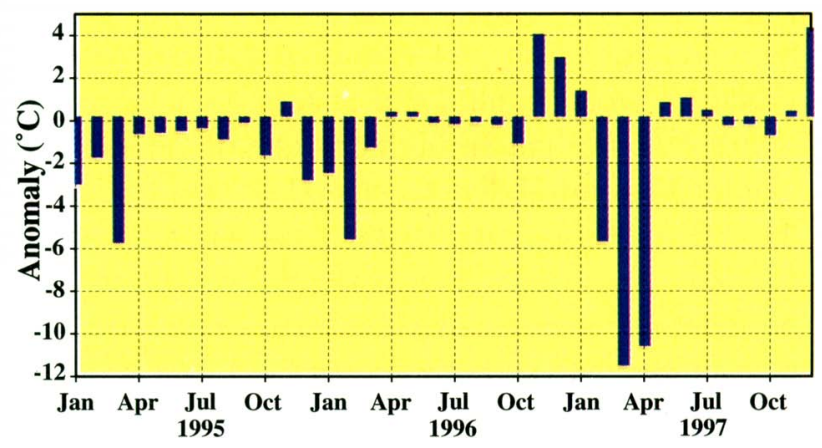

FIG. 9 Monthly Northern Hemisphere polar stratospheric temperature anomalies $\left({ }^{\circ} \mathrm{C}, 60^{\circ}-90^{\circ} \mathrm{N}\right)$ derived from the MSU channel 4. Anomalies are departures from the 1979-95 base period means. (MSU data provided by the University of Alabama in Huntsville.)

average zonal wind speeds of $25-35 \mathrm{~m} \mathrm{~s}^{-1}$. These conditions contrast with the relatively weak height gradient and ill-defined zonal wind maximum normally observed throughout the polar region at this time of the year (Fig. 10c). 

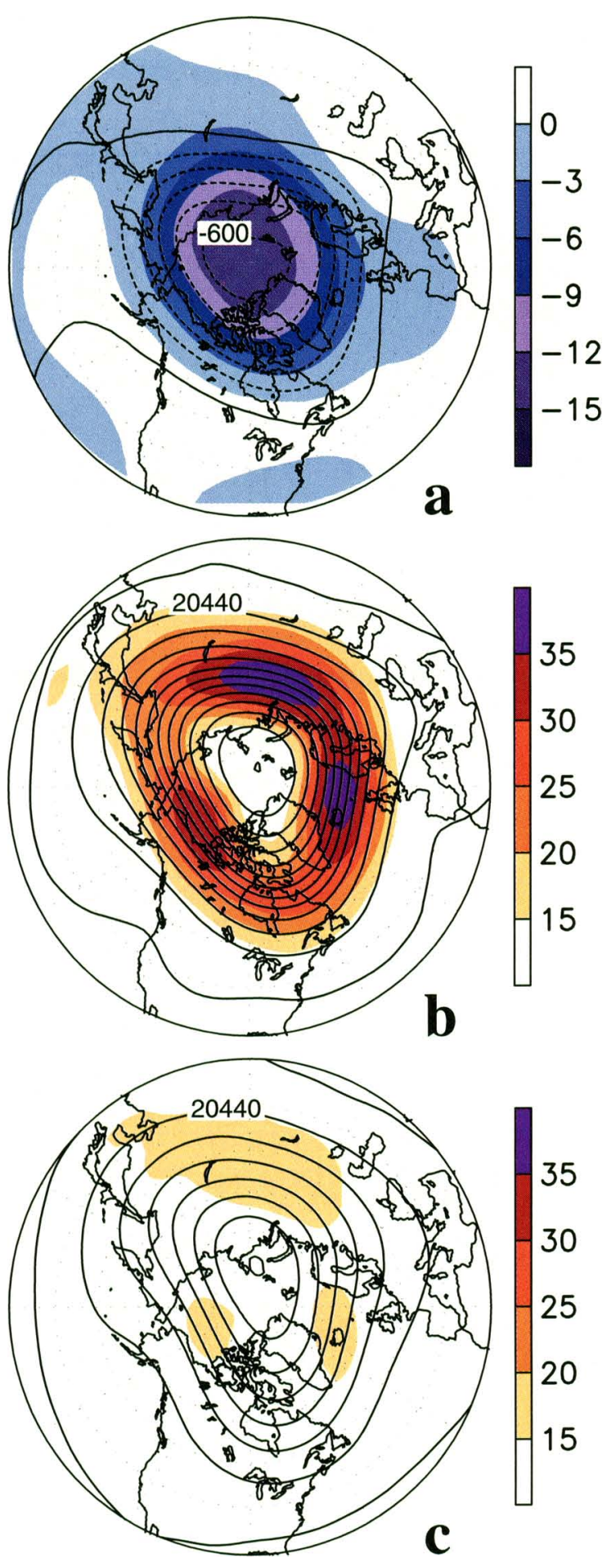

FIG. 10. February-April 1997 (a) stratospheric temperature anomalies (shaded, ${ }^{\circ} \mathrm{C}$ ) derived from the MSU channel 4 and 50$\mathrm{hPa}$ height anomalies (contours, m), (b) 50-hPa height (contours, $\mathrm{m}$ ) and zonal wind speed (shaded, $\mathrm{m} \mathrm{s}^{-1}$ ), and (c) mean FebruaryApril 50-hPa height (contours, $\mathrm{m}$ ) and zonal wind speed (shaded, $\mathrm{m} \mathrm{s}^{-1}$ ). Contour interval for height and height anomalies is $120 \mathrm{~m}$. Negative anomalies in (a) are indicated by dashed contours. Anomalies are departures from the 1979-95 base period means. (MSU data provided by the University of Alabama in Huntsville.)
An additional feature of the polar region during February-March was the large-scale formation of polar stratospheric clouds in response to extremely cold conditions temperatures. The presence of these clouds leads to the chemical destruction of stratospheric ozone, and during March contributed to below-normal ozone concentrations throughout the Arctic [see section 2c(1)].

During July-December, the primary features of the lower stratosphere included above-normal temperatures over much of the polar region of the Northern Hemisphere and below-normal temperatures over most of Antarctica. This anomaly pattern is nearly opposite in sign to that observed during January-June, and is consistent with increased ozone destruction due to polar stratospheric clouds in the Southern Hemisphere polar region, particularly during July-October.

In the extratropics, many of the anomaly features evident in the lower-stratospheric temperature field during July-December reflected the stratospheric signature of large-scale circulation anomalies that extended well into the middle and lower troposphere. For example, the very low temperatures over the high latitudes of the North Atlantic and Scandinavia, combined with above-average temperatures in the lower troposphere (Fig. 8b), reflected above-normal tropospheric heights and recurring high-latitude blocking activity throughout the region [see section $2 b(1)$ ]. Similarly, the patterns of above-normal temperatures in the lower stratosphere over the Gulf of Alaska and eastern Siberia reflected the high-altitude signature of persistent, largeamplitude troughs previously noted in these regions. This overall anomaly pattern across the higher latitudes of the Northern Hemisphere was remarkably similar to that observed during 1996, a year that also featured recurring blocking activity across the high latitudes of the North Atlantic (Halpert and Bell 1997, see their Fig. 9).

Over the subtropical North and South Pacific, negative temperature anomalies in the lower stratosphere during July-December were heavily linked to strong El Niño conditions, and were consistent with abnormally warm tropospheric temperatures and well-defined anticyclonic circulation anomalies at upper-tropospheric levels. In the Southern Hemisphere, the pattern of negative lower-stratospheric temperature anomalies also delineated the anticyclonic-shear side of a very strong and extended South Pacific jet stream throughout the period [see section 3a(4)].

c. Trace gases

1) Ozone

Total column ozone data were obtained from the 
National Aeronautics and Space Administration Nimbus-7 SBUV instrument from 1979 through 1988, from the NOAA-11 SBUV/2 instrument from January 1989 through August 1994, the NOAA-9 SBUV/2 instrument from September 1994 through June 1997, and from the NOAA-14 SBUV/2 beginning July 1997. Data from the SBUV instruments are only available during daylight viewing conditions; therefore no data are available over polar latitudes during winter. Other sources of ozone data include Dobson spectrophotometer readings and measurements from balloon-borne ozonesondes, both obtained from the NOAA Climate Monitoring and Diagnostics Laboratory (CMDL).

\section{(i) Northern Hemisphere}

Total column ozone in the Northern Hemisphere is generally lowest during December-March (DJFM). During the Northern Hemisphere winter of 1996/97, total column ozone over most of the hemisphere was substantially lower than the 1979-86 means. The drop in ozone was particularly prominent during March 1997 at high latitudes, when total ozone was 30\%40\% below mean 1979-86 levels (Fig. 11). Over the United States and northwest Europe ozone values during March 1997 averaged 10\%-20\% lower than the 1979-86 means.

At high latitudes, the large departures in total ozone during DJFM 1996/97 were partly related to extremely low temperatures during February-March, in association with a highly amplified polar vortex and polar night jet [see section $2 b(2)]$. Temperatures in the lower stratosphere are closely coupled to ozone through dynamics and photochemistry, with temperatures less than $-78^{\circ} \mathrm{C}$ believed to lead to ozone depletion. These low temperatures contribute to the formation of polar stratospheric clouds, which enhance the production and lifetime of reactive chlorine, leading to ozone depletion (WMO/UNEP 1994).

During March, ozone values at Point Barrow, Alaska $\left(71.3^{\circ} \mathrm{N}\right)$, the closest U.S. territory to the polar low-ozone region, averaged 388 Dobson units (DU) (Fig. 12). This value is approximately $6 \%$ below the previous 10-year average of 413 DU. During the month record low daily total ozone totals were observed on 17-18 March, with values dropping below 320 DU each day. These values surpass the previously record low value of $326 \mathrm{DU}$ observed on 22 March 1993, and contrast with a normal year in which Alaska is spared the very low springtime ozone totals typically found throughout northern Europe and Siberia.

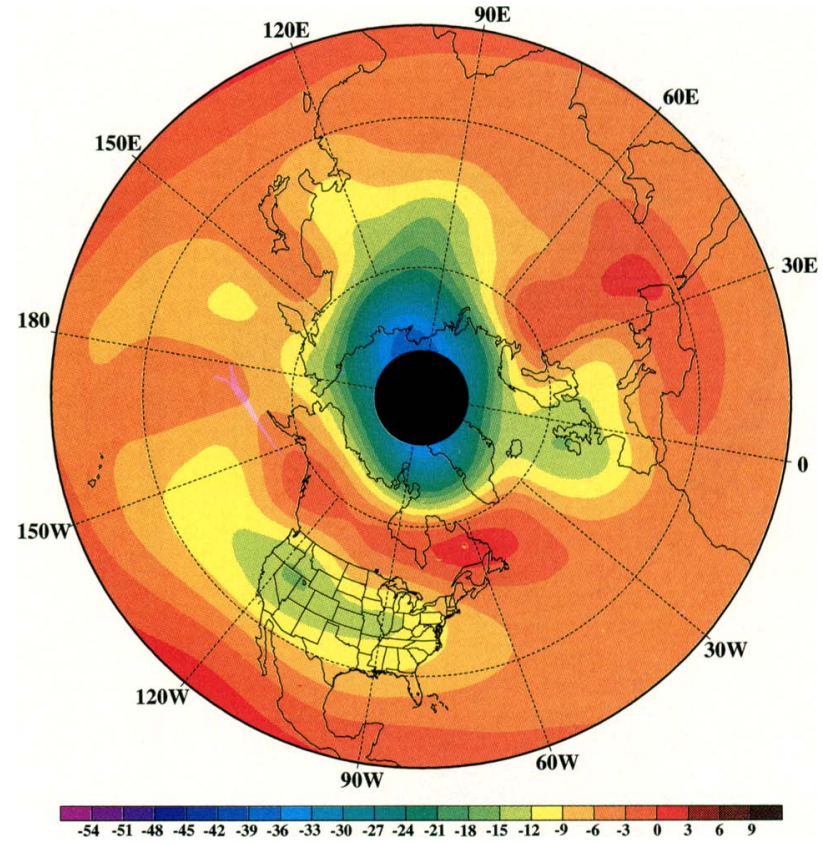

FIG. 11. Total ozone percent difference between March 1997 and the March 1979-86 based period means. Regions with no data are shown in black.

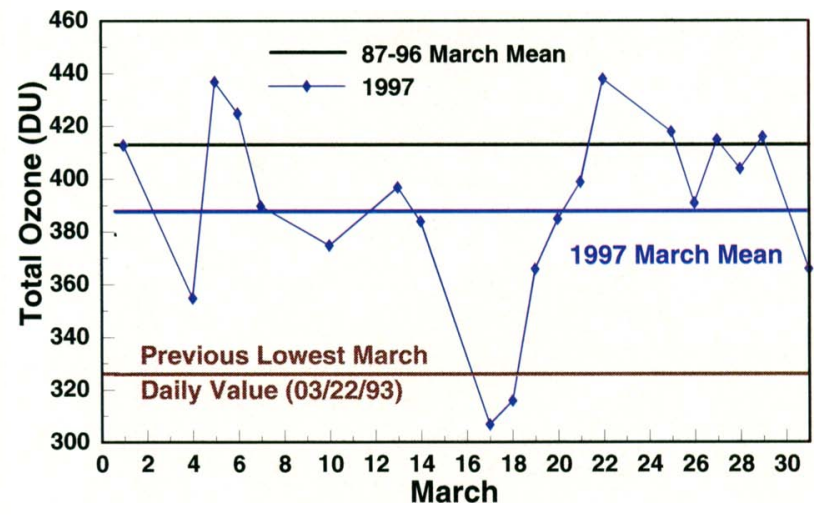

FIG. 12. Dobson spectrophotometer total ozone measurements at Point Barrow, AK, during March 1997. Values (blue) are daily averages for days when weather permitted observations. The 1987-96 March mean is drawn in black with the previous March daily low value shown in red.

\section{(ii) Southern Hemisphere}

Total column ozone exhibits a well-defined annual cycle in the Southern Hemisphere, with the lowest values typically observed over Antarctica during September-November. During October 1997, almost all areas of the hemisphere showed total ozone decreases compared to levels observed during the 1979-86 period (Fig. 13). The largest decreases occurred over Antarctica and the South Atlantic polar region, where 


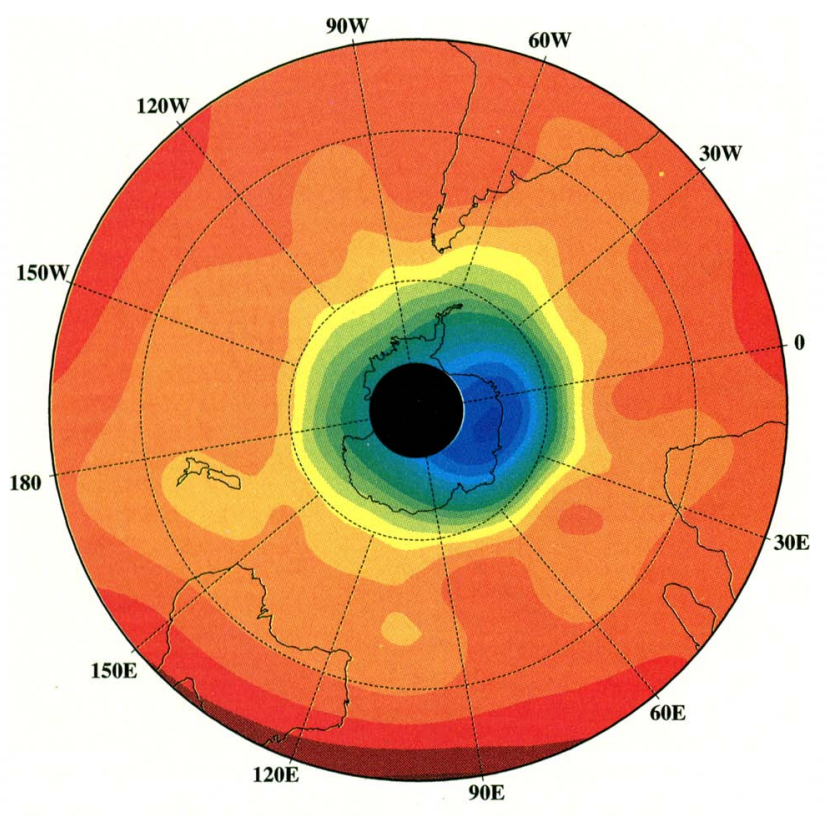

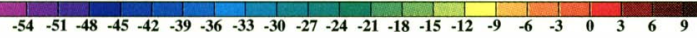

FIG. 13. Total ozone percent difference between October 1997 and the October 1979-86 based period means. Regions with no data are shown in black.

totals averaged $25 \%-40 \%$ lower than the $1979-86$ means.

The "ozone hole," denoted by total ozone concentrations less than 220 DU, is most pronounced over the polar region and typically reaches maximum areal extent during late September-early October. During 1997, the ozone hole developed in late August, with total ozone values dropping to near $100 \mathrm{DU}$ by early October. The areal coverage of the ozone hole exceeded $16 \times 10^{6} \mathrm{~km}^{2}$ during all of September and October, and reached a maximum of nearly $22 \times 10^{6}$ $\mathrm{km}^{2}$ in late September and early October (Fig. 14). This extent of the ozone hole was comparable to that observed throughout the mid-1990s, and was substantially larger than that observed in earlier years such as 1989 and 1990. During 1997, the areal extent of the ozone hole began to diminish in early November and disappeared rapidly during mid-November. This evolution coincided with an increase in daily minimum polar temperatures at $50 \mathrm{hPa}$ (approximately $19 \mathrm{~km}$ ) from the record and near-record low values observed in late September and October (Fig. 15). This rapid return to higher ozone concentrations during November 1997 contrasted with most other recent years, in which the ozone hole persisted into late November and early December.

A further inspection of ozone concentrations dur-

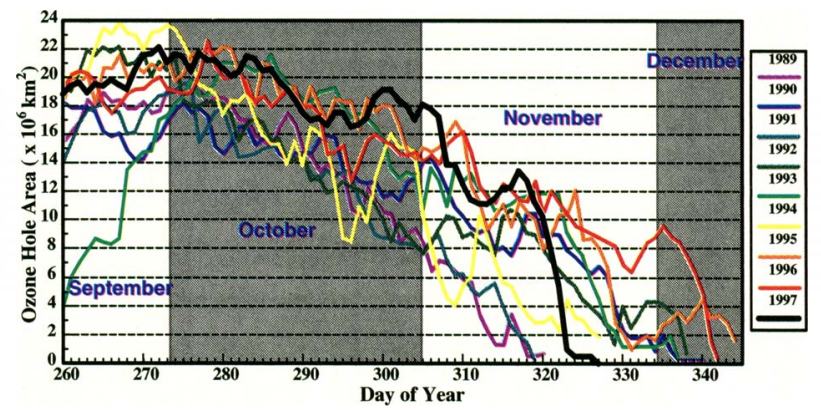

FIG. 14. Daily areal coverage $\left(10^{6} \mathrm{~km}^{2}\right)$ of the ozone hole, denoted by values less than $220 \mathrm{DU}$, as measured by the SBUV/2 sensor.

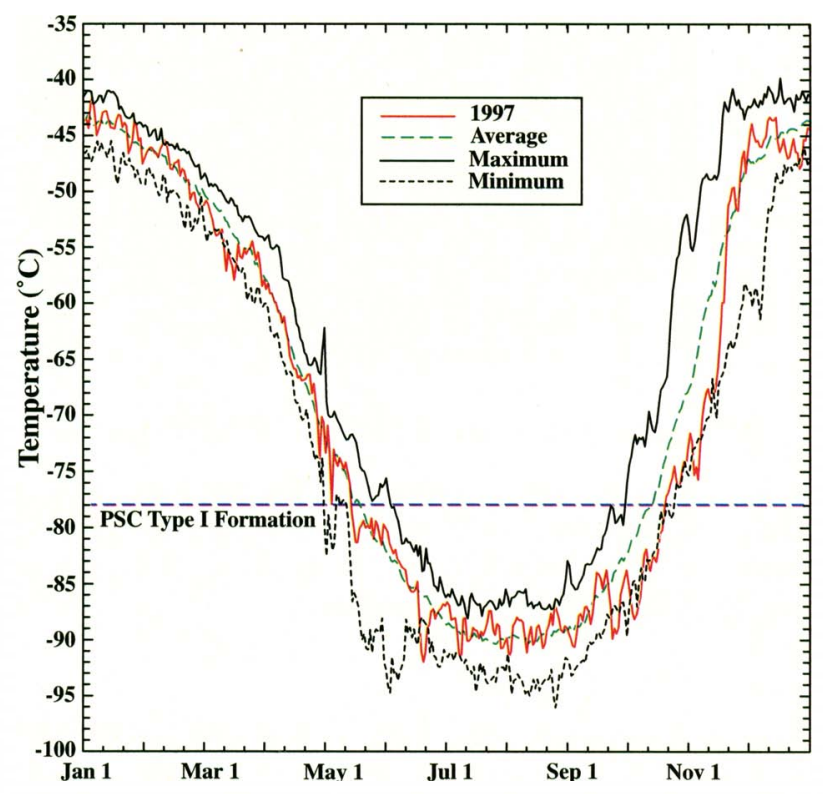

FIG. 15. Daily minimum temperatures at $50 \mathrm{hPa}(19 \mathrm{~km})$ in the region $65^{\circ}-90^{\circ} \mathrm{S}$ for 1997 (red line). Mean daily values for the period 1979-96 are shown in green. Daily extreme maxima (solid) and minima (dashed) for any year are also shown.

ing 1997 obtained from a sounding at the South Pole on 8 October 1997 (Fig. 16) reveals total column ozone concentrations of 112 DU. The sounding also shows a nearly complete destruction of ozone between 14 and $20 \mathrm{~km}$, the largest vertical extent of total depletion observed in the historical record. These conditions contrast with the "pre-ozone hole" period of 1967-71 when no ozone depletion was detected between 15 and $20 \mathrm{~km}$, and with conditions 15 years later (October 1986) when only partial ozone depletion was observed at these levels.

The record vertical extent of ozone depletion during 1997 likely resulted from the continued increase in stratospheric total reactive halogen, termed "effec- 


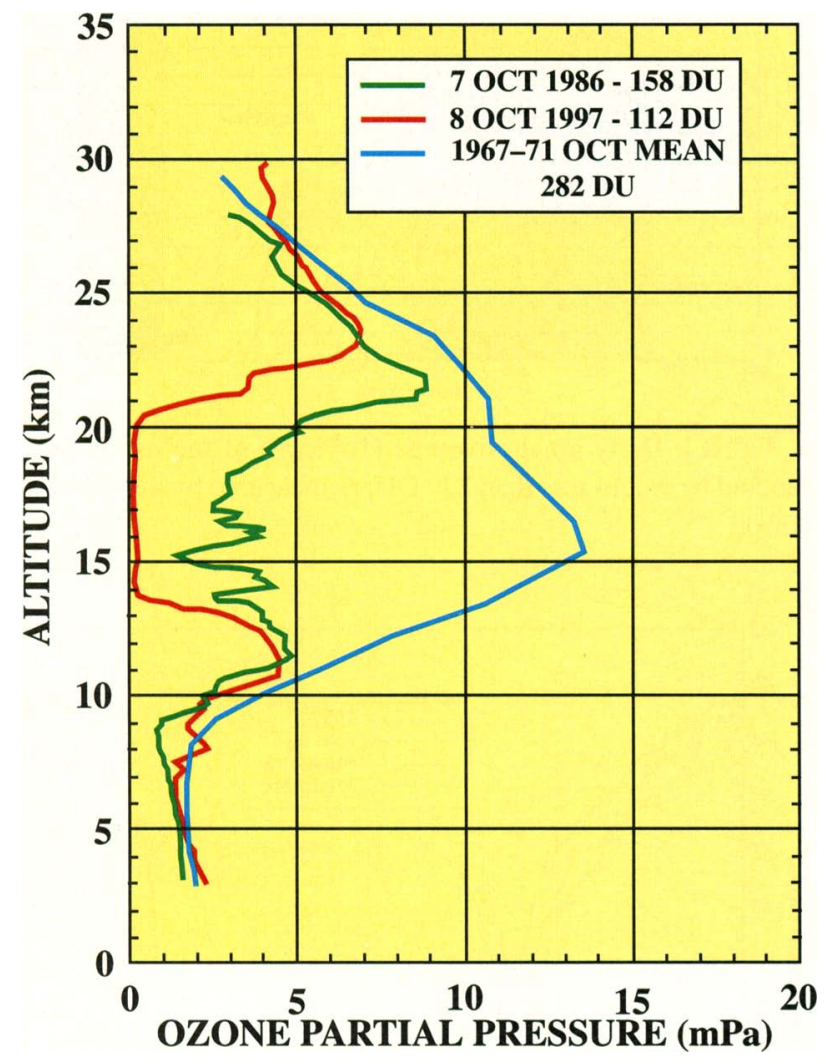

FIG. 16. Ozone profile (partial pressure, $\mathrm{mPa}$ ) measured by balloon-borne ozonesonde at the South Pole on 8 October 1997 (red line) and comparisons to the October 1967-71 mean (blue line) and to 7 October 1986 (green line).

tive equivalent chlorine" (EECl) (Montzka et al. 1996). That study indicates that although $\mathrm{EECl}$ has already peaked at the surface, it is not expected to peak in the stratosphere until 1998-99. Thereafter, the decrease in stratospheric EECl levels is expected to contribute to larger total ozone values over Antarctica, and thus to an overall reduction in the areal extent of the ozone hole during the first decades of the twenty-first century (Hofmann et al. 1997).

\section{2) CARBON DIOXIDE}

The atmospheric carbon dioxide $\left(\mathrm{CO}_{2}\right)$ measurements made at Mauna Loa Observatory, Hawaii since 1958 provide strong evidence for human alteration of the environment (Fig. 17). The data through 1973 are from Keeling et al. (1982), while data since 1973 are from the NOAA program (Thoning et al. 1989).

Mauna Loa Observatory is located at an elevation of $3350 \mathrm{~m}$ on the flank of Mauna Loa volcano and is an ideal site for carbon dioxide measurements. There is no nearby vegetation, and the prevailing nighttime downslope winds give a representative sampling of

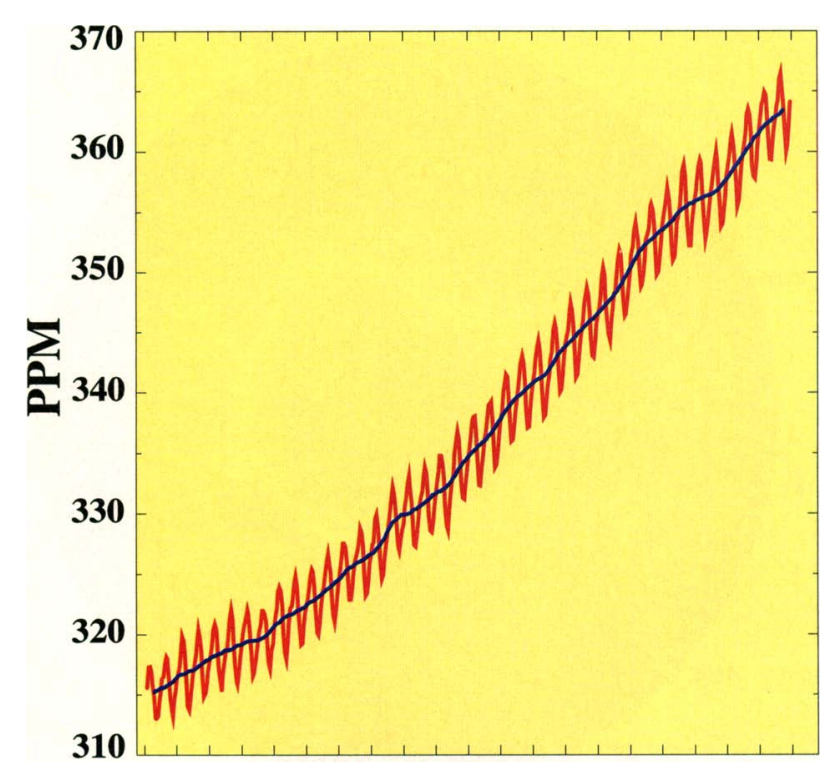

586062646668707274767880828486889092949698

FIG. 17. Monthly mean carbon dioxide concentrations (red curve, ppm) measured at Mauna Loa, HI. Blue line is the 12-month running mean. The data through 1973 are from C. D. Keeling at Scripps Institute of Oceanography. [Analysis provided by CMDL.]

midtropospheric air from the central North Pacific Ocean. Thus, this record is taken as a reliable index of long-term carbon dioxide growth.

The average $\mathrm{CO}_{2}$ concentration increase at Mauna Loa during the 1980s and 1990s has been about 1.4$1.5 \mathrm{ppm} \mathrm{yr}^{-1}$, but with significant year-to-year variability in the growth rate (Fig. 17). These fluctuations in growth rate appear to be strongly influenced by the state of the Southern Oscillation, with increases in the growth rate evident during cold episodes (e.g., $1988 / 89,1995 / 96$ ) and decreases evident during warm episodes (e.g., 1982/83, 1991/92). The very strong $1997 / 98$ El Niño appears to have slowed the rate of increase by the middle of 1997 .

\section{d. Northern Hemisphere snow cover}

The annual average snow cover in the Northern Hemisphere during 1997 was more than $3 \%$ below the long-term (1972-96) mean, and was the third lowest value in the historical record of satellite data dating back to 1972 . Only 1990 and 1988 recorded less annual mean snow cover than was observed in 1997. Northern Hemisphere snow cover has been below normal during 9 of the past 10 years, with only the 1996 value being above normal during this period.

Northern Hemisphere snow cover extent during 1997 was below normal in all months except August 
and September (Fig. 18). This contrasts with heavy snow years (such as 1996) in which above-normal snow cover is typically recorded in 8-10 months of the year. During 1997, monthly snow cover deficits exceeded $2 \times 10^{6} \mathrm{~km}^{2}$ during February and March. The March mean snow cover extent was the second lowest value in the historical record for that calendar month, with only March 1990 recording a lower value. The February mean snow cover extent was the fourth lowest value in the record for that month.

Over Eurasia, snow cover extent was below normal throughout much of the year (Fig. 19), consistent with abovenormal annual mean temperatures

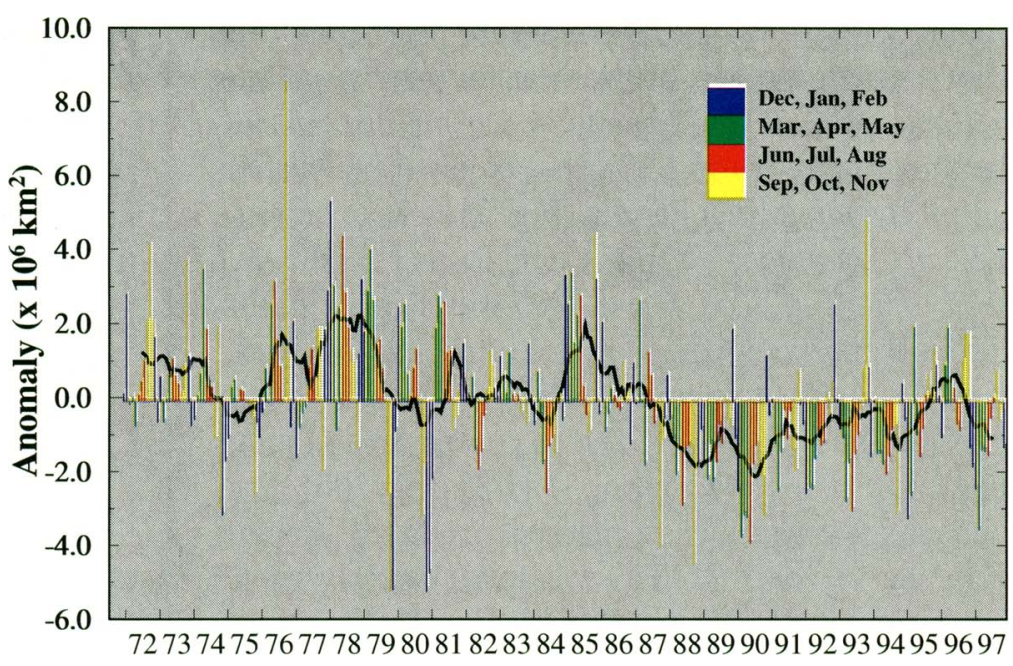

FIG. 18. Anomalies of monthly snow cover extent over the Northern Hemisphere. Smoothed curve is a 12-month running mean. Anomalies are departures from the 1972-96 base period means. (Analysis provided by Rutgers University.) throughout the region (Fig. 4). Snow cover deficits reached $0.8 \times 10^{6} \mathrm{~km}^{2}$ during DJF in response to a reduced southward extent of the snowpack across central Europe, most of southern Russia and northwestern China (Fig. 19a). These conditions were associated with abnormally warm surface temperatures $\left(2^{\circ}-3^{\circ} \mathrm{C}\right.$ above average) across the region (see section 5, Fig. 67), and are consistent with previous studies relating snow cover extent to surface air temperatures (Groisman et al. 1994).

Even larger snow cover deficits $\left(1.4 \times 10^{6} \mathrm{~km}^{2}\right)$ were observed over Eurasia during MAM (Fig. 19b), in response to an early-season snowmelt over central Siberia, northern Mongolia, and western China. This early melt was also associated with much warmer than normal surface temperatures $\left(4^{\circ}-6^{\circ} \mathrm{C}\right.$ above average) throughout the region (see section 5, Fig. 69). As previously noted, this anomalous warmth was heavily linked to a persistent pattern of broad southwesterly geostrophic flow throughout the region, in association with an anomalous large-scale trough over northern Europe and Scandinavia and a persistent ridge across central Siberia (see section 5, Fig. 70). Similar circulation features contributed to significantly above-normal surface temperatures in central Siberia during January-May 1995, also resulting in a notable reduction in the areal extent of snow cover during that period (Halpert et al. 1996).

The SON 1997 season featured an abnormally late development of the cool-season snowpack and a continuation of below-normal snow cover over much of central Siberia (Fig. 19c). These conditions were associated with a continuation of abnormally warm tem-

peratures throughout the region (see section 5, Fig. 73), in response to the reestablishment of the pattern of broad southwesterly geostrophic flow and above-normal geopotential heights throughout the region (see section 5, Fig. 74).

In North America, the DJF and MAM seasons featured above-normal snow cover across the northwestern United States and southwestern Canada. These conditions resulted from repetitive winter storms and cold-air outbreaks, in response to two prominent, and sometimes related, atmospheric phenomena: 1) recurring high-latitude blocking and block evolution in the vicinity of the Bering Sea and Alaska, and 2) substantial variability in the eastward extent of the East Asian jet stream over the eastern North Pacific. The abnormal melt of this snowpack contributed to significant flooding in the Columbia and Willamette River Gorges in the Pacific Northwest section of the United States during late 1996/early 1997 (Halpert and Bell 1997), and to massive flooding of the Red River Valley and its tributaries (located in the northern plains states) during April [see section 4a(1)].

\section{Atmospheric and oceanic circulation}

\section{a. Very strong 1997-98 Pacific warm episode (El Niño)}

1) OVERVIEW

The global climate during 1997 was affected by one of the strongest Pacific warm episodes on record. These warm episode conditions developed rapidly in 
March, with strong ENSO conditions persisting from May through the end of the year (and subsequently well into 1998) (Figs. 20 and 21). During this episode the abnormally warm SSTs that covered the eastern half of the equatorial Pacific (Fig. 21a) were comparable in magnitude and areal extent to the famed 1982/ 83 El Niño (Fig. 20a). These 1997 warm episode conditions were accompanied by a strong negative phase of the Southern Oscillation, with the equatorial Southern Oscillation index (SOI) also comparable in magnitude to that observed during 1982/83 (Fig. 20b). Also evident since April was a markedly reduced strength of the low-level (850-hPa) equatorial easterly winds across the eastern tropical Pacific (Fig. 21c). At times these anomalies indicated a complete disappearance of the easterlies across the entire eastern Pacific, along with a complete collapse of the normal equatorial Walker circulation. These anomalies were also comparable to those observed during the $1982 / 83 \mathrm{El} \mathrm{Niño}$ (Fig. 20c).

The above conditions were associated with a dramatic alteration of the global pattern of tropical rainfall and deep tropical convection, as indicated by above-normal rainfall across the eastern half of the tropical Pacific and by significantly below-normal convection across Indonesia and the western equatorial Pacific (Fig. 22). The combined zonal extent of these rainfall anomalies covered a distance more than one-half the circumference of the earth.

Selected impacts associated with these warm episode conditions included 1) excessive rainfall across the eastern half of the tropical Pacific; 2) significantly below-normal rainfall and drought across Indonesia and the western tropical Pacific; 3) below-normal hurricane activity over the North Atlantic during AugustOctober, with a simultaneously expanded region of conditions favorable for tropical cyclone formation over the eastern subtropical North Pacific [see section $4 \mathrm{a}(2)$ ]; 4) excessive rainfall and flooding in equatorial eastern Africa during October-December [see section $4 \mathrm{~b}(1)$ ]; 5) a dramatic eastward extension of the South Pacific jet stream to well east of the date line during June-December [see section 3a(4)], which resulted in enhanced storminess across southeastern South America and central Chile [see section 4e(2)]; and 6) abnormally dry conditions across the Amazon Basin, central America, the Caribbean Sea, and the subtropical North Atlantic throughout the period.

\section{2) Evolution of the 1997 El NiÑo}

The year began with a continuation of weak cold
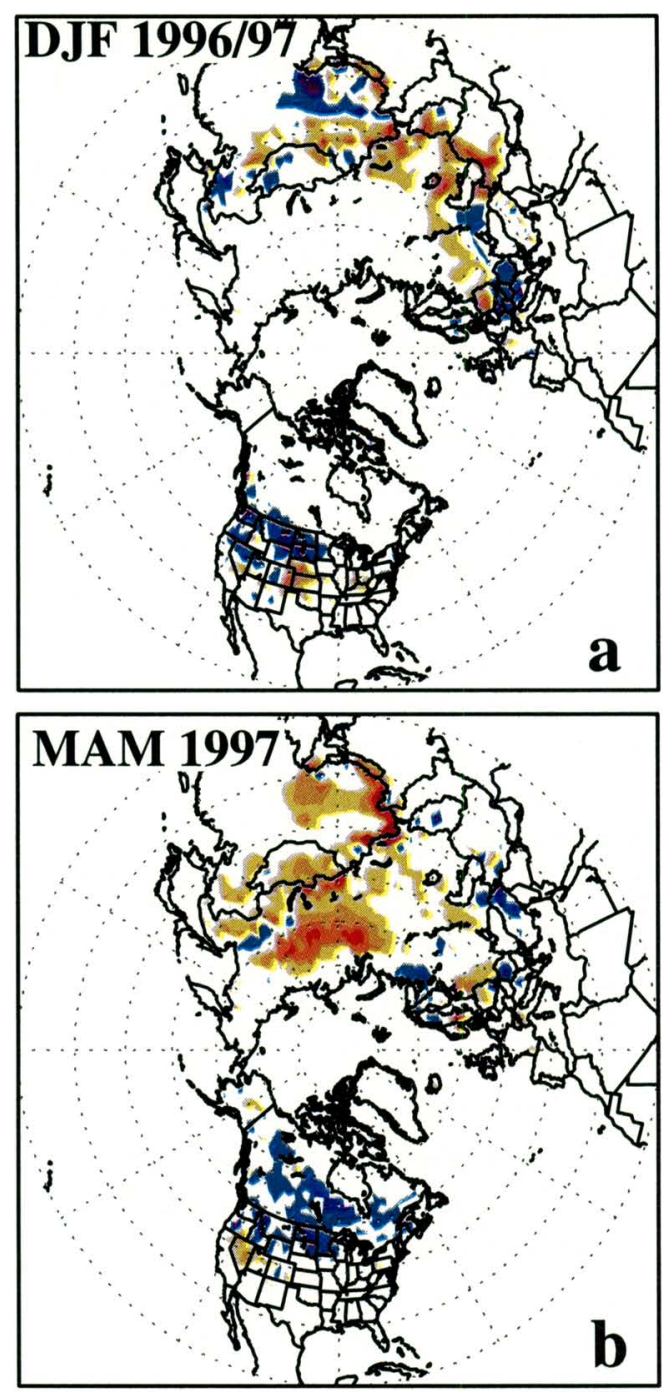

4

3

2

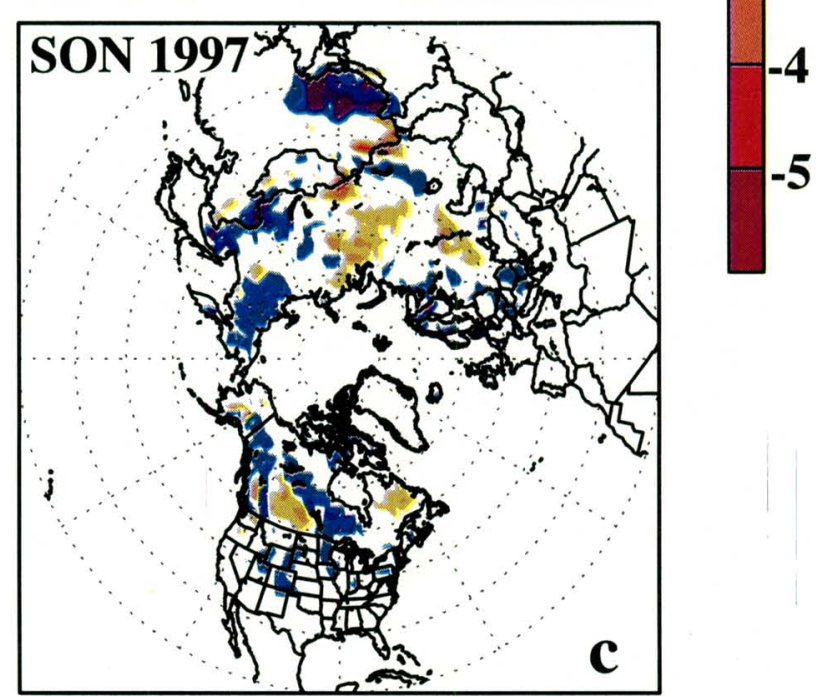

FIG. 19. Snow cover duration anomaly in weeks derived from operational analysis of visual imagery by NOAA/NESDIS: (a) December 1996-February 1997, (b) March-May 1997, and (c) September-November 1997. 

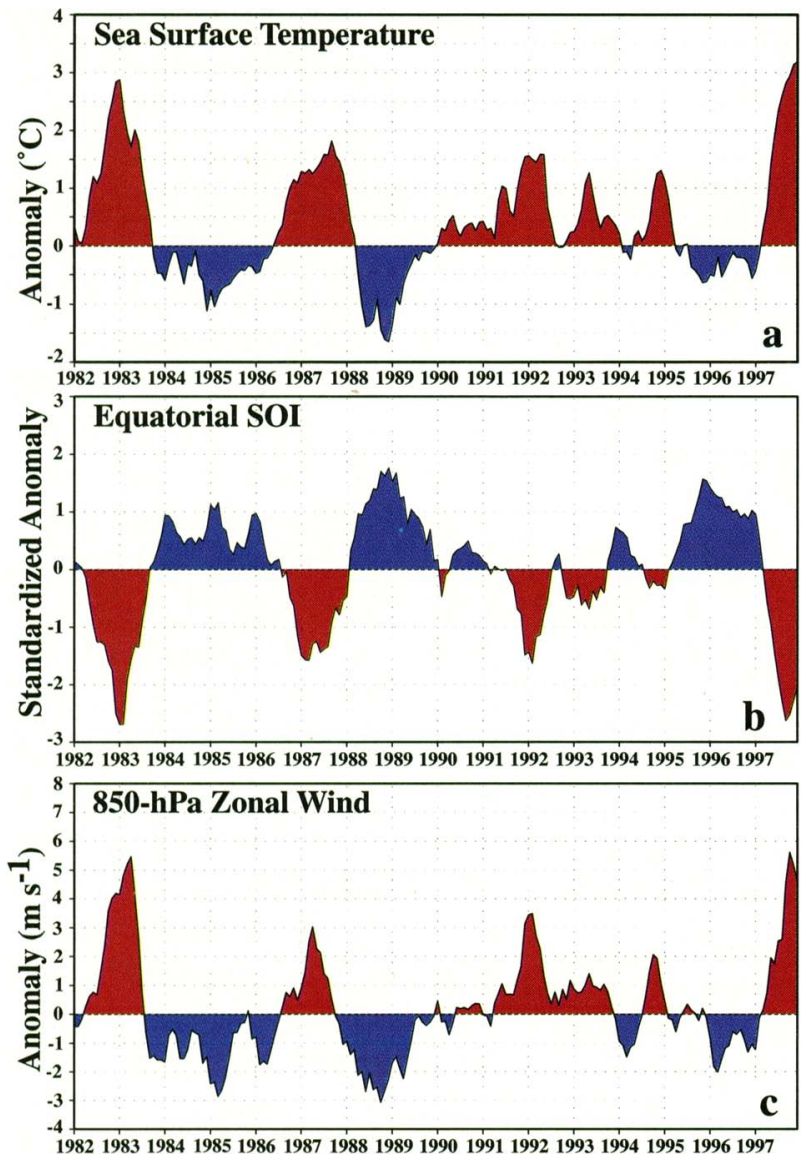

FIG. 20. Time series of monthly (a) SST anomalies $\left({ }^{\circ} \mathrm{C}\right)$, (b) standardized equatorial index of the Southern Oscillation (SO), and (c) 850 -hPa zonal wind anomalies $\left(\mathrm{m} \mathrm{s}^{-1}\right)$. SST and wind anomalies are area-averaged values for the region bounded by $5^{\circ} \mathrm{N}-5^{\circ} \mathrm{S}$ and $180^{\circ}-80^{\circ} \mathrm{W}$. The equatorial index of the $\mathrm{SO}$ is calculated as the standardized difference of the standardized sealevel pressure anomalies between the Indonesia region (bounded by $5^{\circ} \mathrm{N}-5^{\circ} \mathrm{S}$ and $90^{\circ}-140^{\circ} \mathrm{E}$ ) and the eastern tropical Pacific (bounded by $5^{\circ} \mathrm{N}-5^{\circ} \mathrm{S}$ and $130^{\circ}-80^{\circ} \mathrm{W}$ ) [ i.e., Indonesia minus eastern Pacific].

episode conditions in the tropical Pacific during December 1996-February 1997 (DJF 1996/97). These conditions included a well-defined tongue of abnormally cold SSTs extending across the eastern tropical Pacific (Fig. 23b), with equatorial SSTs greater than $28^{\circ} \mathrm{C}$ confined to the area west of the date line (Fig. 23a). SSTs were slightly below normal in the Niño $1+2$ region (Fig. 24a), the Niño 3 region (Fig. 24b), and the Niño 3.4 region (Fig. 24c), and substantially below the $28^{\circ} \mathrm{C}$ threshold for convection (Gadgil et al. 1984) in all three regions.

The colder than normal conditions were accompanied by a strongly sloping equatorial oceanic thermocline (Fig. 25a), with increased thermocline depths
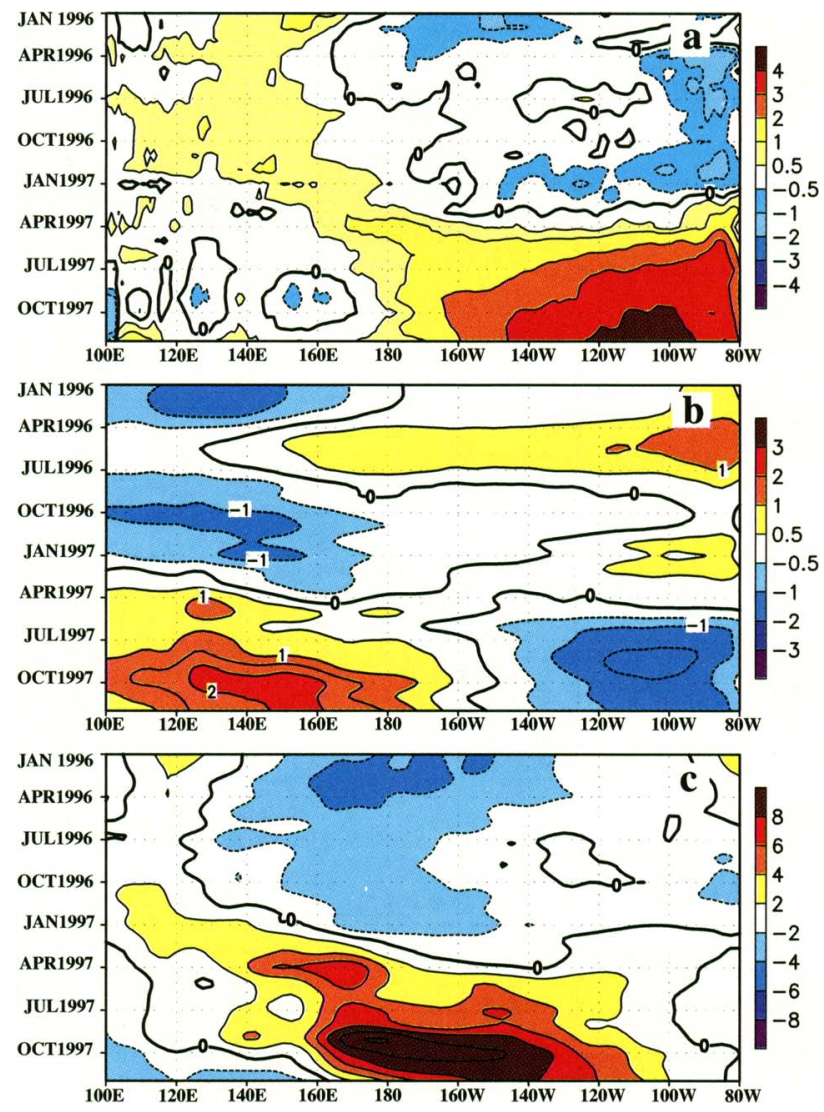

FIG. 21. Time-longitude sections $\left(5^{\circ} \mathrm{N}-5^{\circ} \mathrm{S}\right)$ of anomalous (a) SST $\left({ }^{\circ} \mathrm{C}\right)$, (b) SLP (hPa), and (c) zonal wind ( $\left.\mathrm{m} \mathrm{s}^{-1}\right)$. SST anomalies are departures from the 1950-79 adjusted OI climatology (Reynolds and Smith 1995); SLP and wind anomalies are departures from the 1979-95 base period monthly means. A three-month running mean smoother has been applied to the SLP and wind data.

across the western Pacific and reduced depths over the extreme eastern Pacific. (The center of the thermocline is approximated by the $20^{\circ} \mathrm{C}$ isotherm.) These variations in thermocline depth were accompanied by abnormally warm ocean temperatures in the western and central tropical Pacific between 50- and 200-m depth and by abnormally cold water in the eastern tropical Pacific between the surface and 50-100-m depth. During this period, the atmosphere featured 1) a positive phase of the Southern Oscillation, with below-normal sea level pressure (SLP) across the western tropical $\mathrm{Pa}-$ cific (Fig. 21b); 2) a broad area of slightly enhanced low-level easterlies across the central tropical Pacific (Figs. 21c and 26a); 3) enhanced tropical convection over Indonesia and the western tropical Pacific [indicated by negative values of anomalous outgoing 

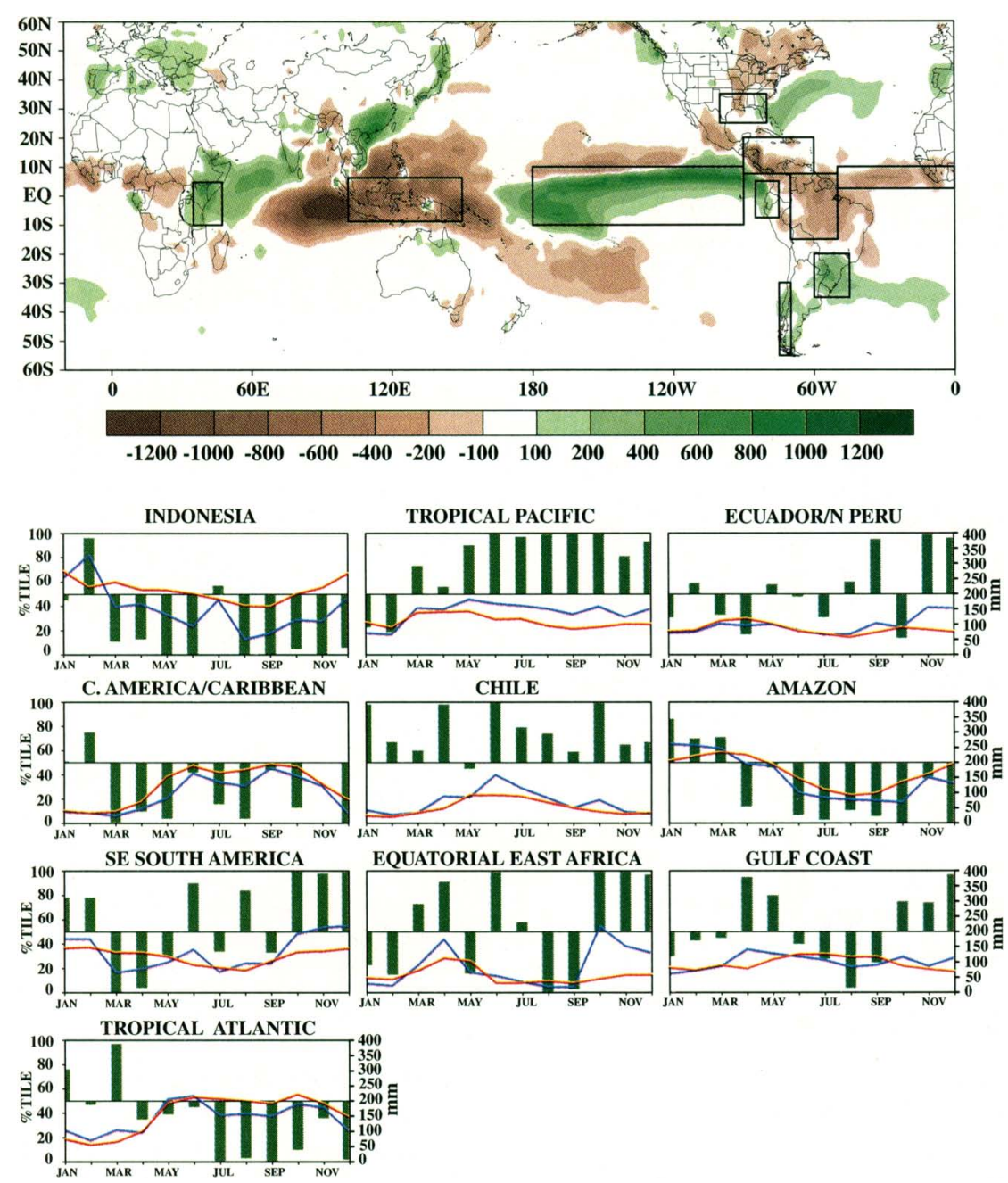

FIG. 22. June-December 1997 accumulated precipitation anomaly (top), and regional area-averaged estimates of monthly mean precipitation amounts ( $\mathrm{mm}$, blue lines) and precipitation percentiles (\%, bars) during 1997 for the 10 boxed regions shown in top panel. The monthly precipitation climatology ( $\mathrm{mm}$, red lines) is from the 1979-95 base period monthly means. Values are obtained by merging rain guage observations and satellitederived precipitation estimates. The satellite estimates are generated by the outgoing longwave radiation precipitation index technique (Xie and Arkin 1998), and are merged with rain guage data via a method adapted from Xie and Arkin (1996). Monthly percentiles are not shown if the monthly mean is less than $5 \mathrm{~mm}$. Percentiles are labeled on the lefthand vertical axis and totals are labeled on the right-hand vertical axis. normal annual cycle in the Niño 1+2 region during March (Fig. $24 \mathrm{a}$ ), and nearly $1.0^{\circ}-1.5^{\circ} \mathrm{C}$ over the annual cycle in the Niño 3 , Niño 3.4, and Niño 4 regions. In the Niño 4 region this increase occurred during a two-week period and was greater than the entire annual cycle of SST for that region. A second period of very rapid SST increases in the eastcentral Pacific then occurred during April, as SSTs in both the Niño 3 and Niño 3.4 regions climbed an additional $1^{\circ} \mathrm{C}$ over that expected from the normal annual cycle. Thus, by mid-April SSTs exceeded $28^{\circ} \mathrm{C}$ across the central and east-central equatorial Pacific (Figs. 24b-d), with values averaging $1^{\circ}-3^{\circ} \mathrm{C}$ above normal in all four Niño regions. Area-averaged SSTs in the Niño 3, Niño 3.4 , and Niño 4 regions then remained nearly constant at values greater than $28^{\circ} \mathrm{C}$ throughout the remainder of the year. This warming reflected a nearly complete elimination of the annual cycle in SSTs across most of the equatorial Pacific, which is normally characterized by a peak in temperatures during MarchApril and a minimum during September-October.

For the MAM season as a whole, mean SSTs greater than $29^{\circ} \mathrm{C}$ extended to east of the date line, and values greater than $28^{\circ} \mathrm{C}$ extended to approximately longwave radiation (OLR)] and suppressed convection in the vicinity of the date line (Fig. 26a); and 4) westerly wind anomalies at upper levels across the eastern tropical Pacific (Fig. 27a). Collectively, these conditions reflected an enhanced equatorial Walker circulation [see section $3 \mathrm{a}(3)$ ], and a continued coupling between the positive phase of the Southern Oscillation and below-normal SSTs across the eastern tropical Pacific.

In contrast, March and April featured an extremely rapid transition to one of the strongest warm episodes of the century. SSTs increased nearly $1.5^{\circ} \mathrm{C}$ over the $160^{\circ} \mathrm{W}$ (Fig. 23c). These temperatures averaged $0.5^{\circ}-$ $2.0^{\circ} \mathrm{C}$ above normal across the central and east-central tropical Pacific (Fig. 23d). This warming was accompanied by increased depths of the oceanic thermocline everywhere east of the date line (Fig. 25b), and by a flattening of the thermocline across the region. In the eastern tropical Pacific, this suppressed thermocline reflected substantially reduced oceanic upwelling in association with a weakening of the lowlevel equatorial easterly winds (westerly wind anomalies) (Fig. 26b). These conditions were accompanied 

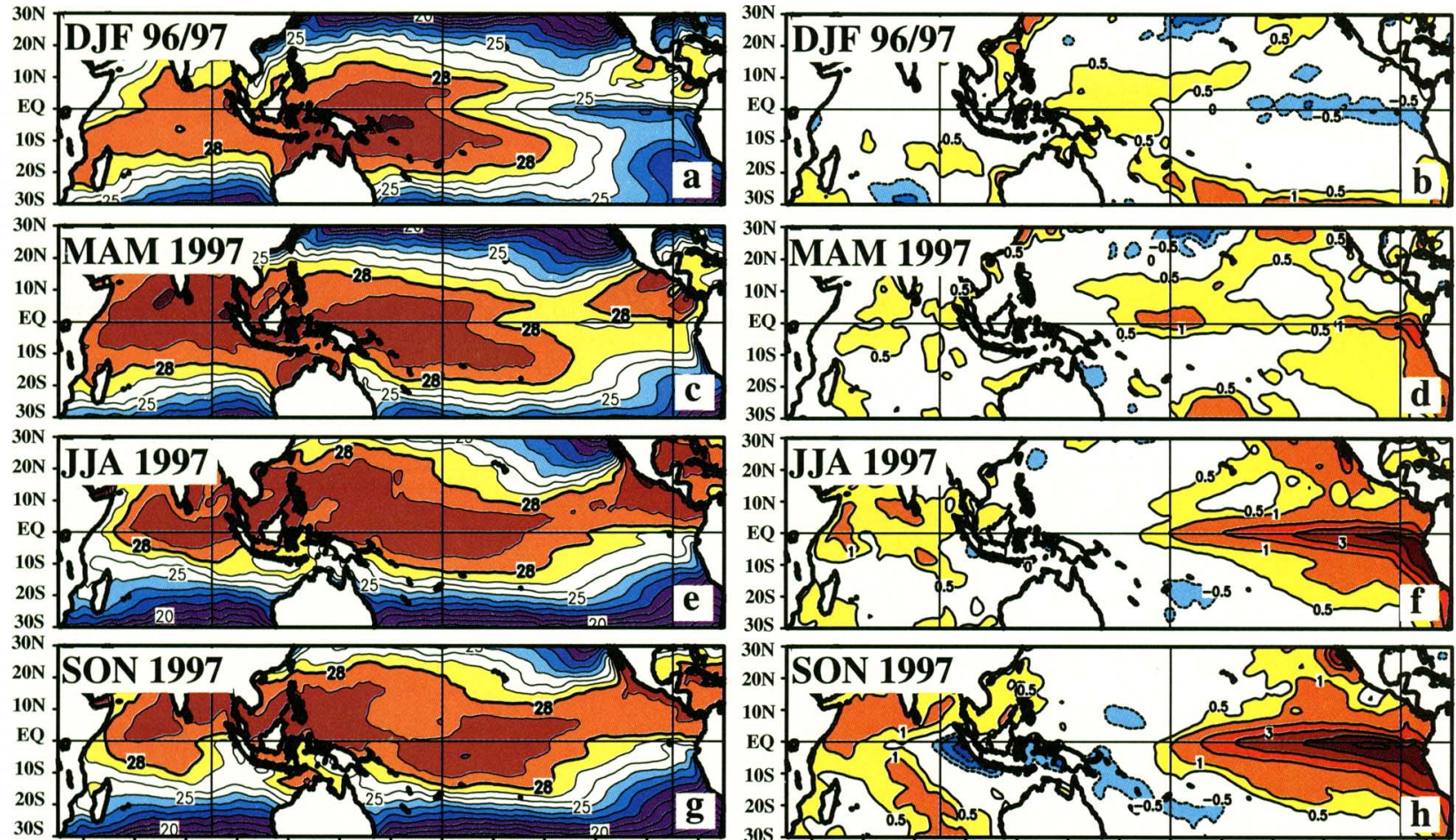

$40 \mathrm{E} \quad 60 \mathrm{E} \quad 80 \mathrm{E} \quad 100 \mathrm{E} 120 \mathrm{E}$ 140E $160 \mathrm{E} \quad 180$ 160W 140W 120W 100W 80W
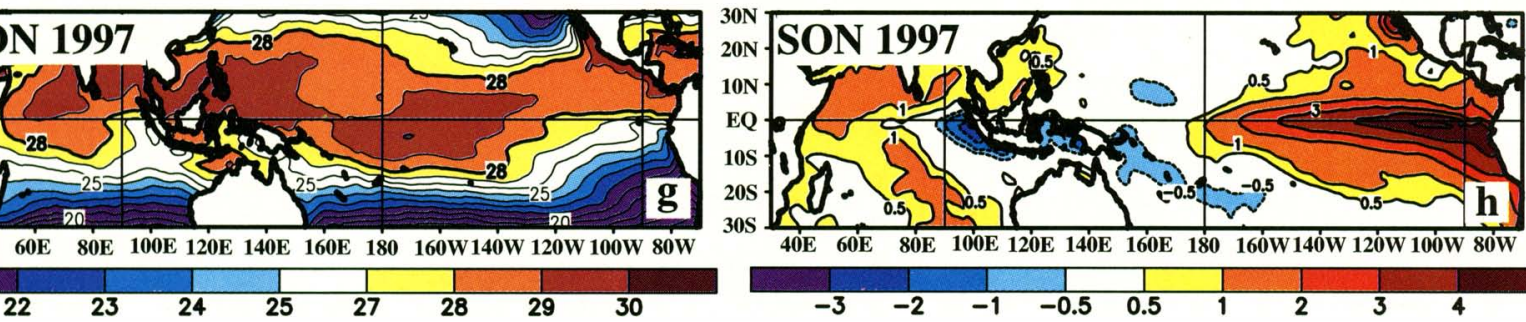

FIG. 23. Seasonal SST (left) and anomaly (right) for (a),(b) DJF 1996/97, (c),(d) MAM 1997, (e),(f) JJA 1997, and (g),(h) SON 1997. Contour interval is $1{ }^{\circ} \mathrm{C}$, with the $0.5^{\circ} \mathrm{C}$ anomaly contour included. Anomalies are departures from the 1950-79 adjusted OI climatology (Reynolds and Smith 1995).
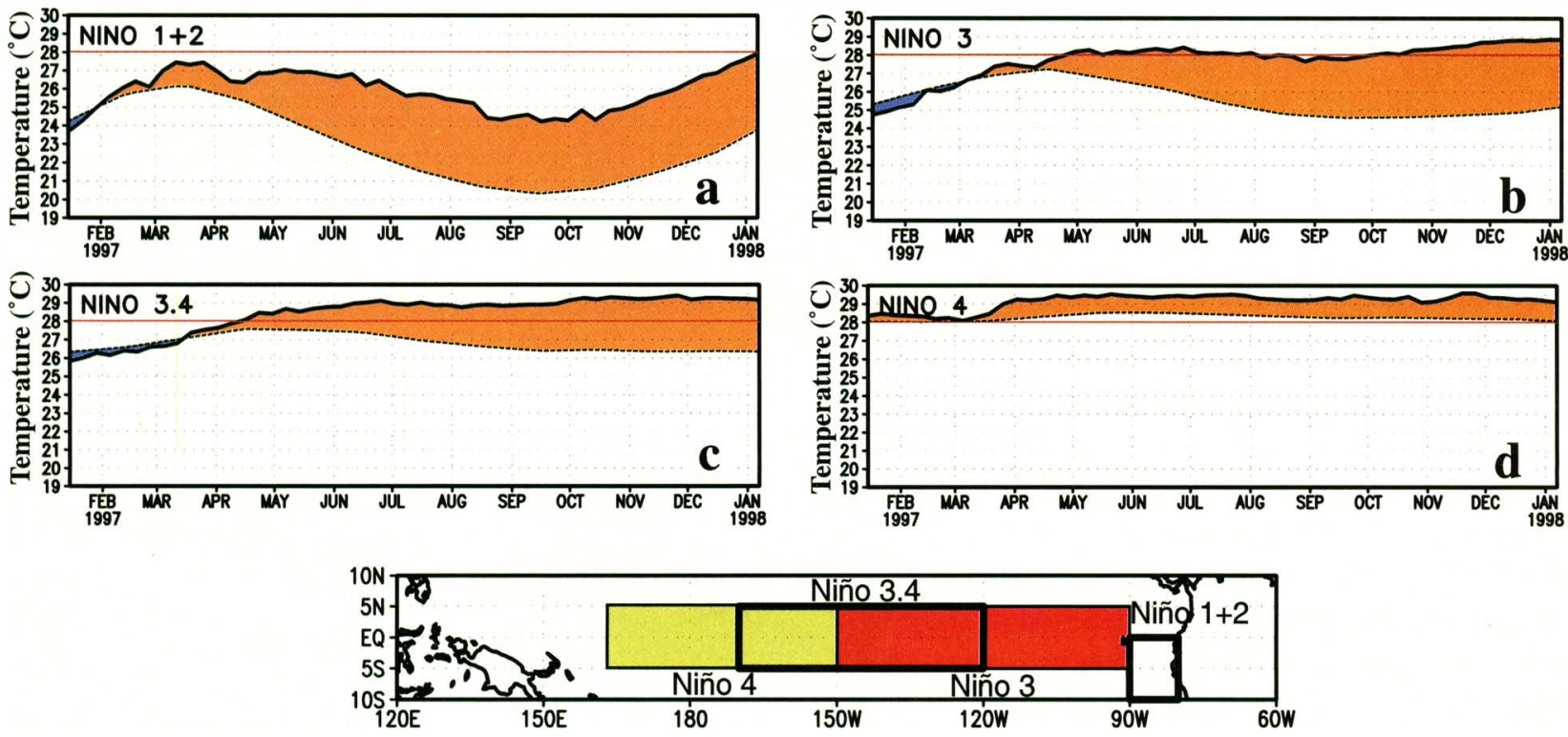

FIG. 24. Pentad (five-day averages) time series of tropical Pacific SSTs averaged over the following regions: (a) the Niño 1+2 region, (b) the Niño 3 region, (c) the Niño 3.4 region, (d) the Niño 4 region. In all panels, solid curve shows observed SST and dashed curve shows climatological mean SST. Orange shading indicates positive anomalies and blue shading indicates negative anomalies. The Niño regions are depicted in bottom panel. Climatological SSTs are derived from the 1950-79 adjusted OI climatology (Reynolds and Smith 1995). 

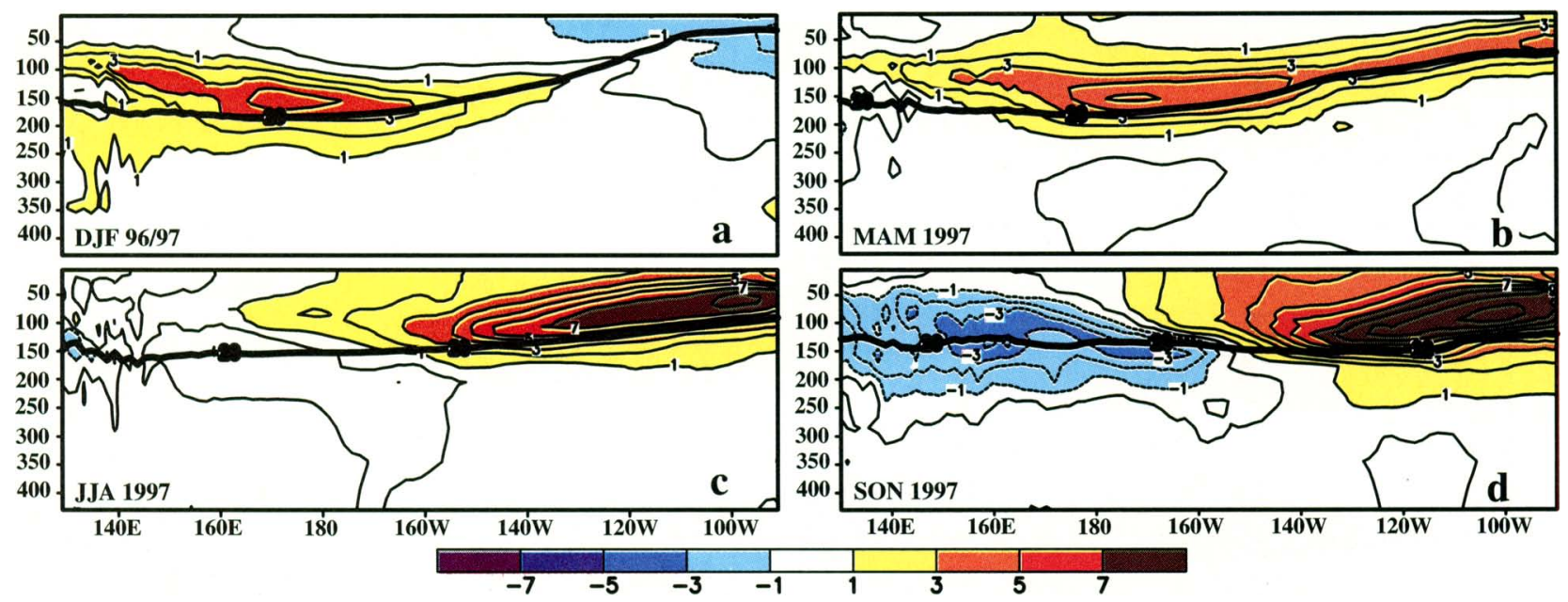

FIG. 25. Equatorial depth-longitude section of ocean temperature anomalies for (a) DJF 1996/97, (b) MAM 1997, (c) JJA 1997 and (d) SON 1997. Contour interval is $1^{\circ} \mathrm{C}$. The dark line is the $20^{\circ} \mathrm{C}$ isotherm. Data are derived from an analysis system that assimilates oceanic observations into an oceanic GCM (Ji et al. 1995). Anomalies are departures from the 1983-92 base period means.

by suppressed convection throughout Indonesia and enhanced convection in the vicinity of the date line, which is opposite to the pattern observed the previous season.

During JJA, SSTs remained very warm throughout the entire eastern half of the tropical Pacific, with the $29^{\circ} \mathrm{C}$ isotherm expanding eastward to approximately $150^{\circ} \mathrm{W}$, and the $28^{\circ} \mathrm{C}$ isotherm extending eastward to approximately $125^{\circ} \mathrm{W}$ (Fig. 23e). These extremely warm waters are highly abnormal for that time of year (Fig. 23f), a period normally characterized by a marked decrease in SSTs across the eastern tropical Pacific. As a result, SST anomalies increased substantially throughout the region, and exceeded $3^{\circ}-4^{\circ} \mathrm{C}$ between $130^{\circ} \mathrm{W}$ and the west coast of South America (Fig. 23f). This increase in anomalies was accompanied by a further flattening of the oceanic thermocline across the eastern Pacific (Fig. 25c), as the $20^{\circ} \mathrm{C}$ isotherm dropped to more than 100-m depth and ocean temperatures increased to more than $7^{\circ} \mathrm{C}$ above normal between 50 - and 125-m depth.

The JJA period also featured an increasingly negative phase of the Southern Oscillation, and a further decrease in the strength of the $850-\mathrm{hPa}$ easterly
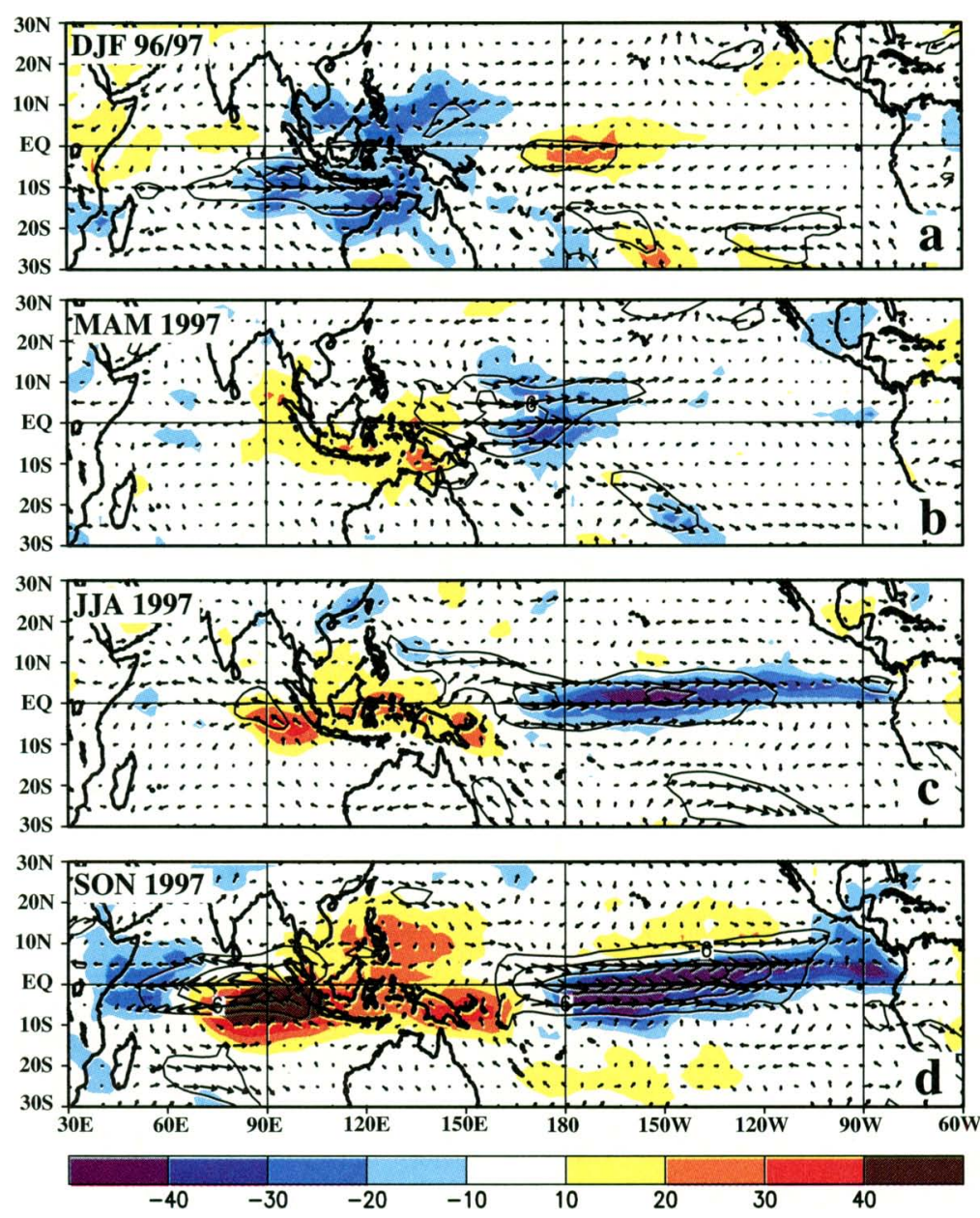

FIG. 26. OLR anomalies (shaded) and 850-hPa vector wind anomalies and isotachs for (a) DJF 1996/97, (b) MAM 1997, (c) JJA 1997, and (d) SON 1997. Contour interval for isotachs is $3 \mathrm{~m} \mathrm{~s}^{-1}$. Shading interval for OLR anomalies is 10 $\mathrm{W} \mathrm{m}{ }^{-2}$. Anomalies are departures from the $1979-95$ base period monthly means. 
winds (3-6 $\mathrm{m} \mathrm{s}^{-1}$ below normal) across most of the central and eastern tropical Pacific (Fig. 26c). These conditions were accompanied by increased tropical convection (Fig. 26c) and rainfall across the entire eastern half of the Pacific, and by decreased rainfall across the western tropical Pacific and Indonesia (see section 4f). These changes in tropical convection reflected 1) a pronounced eastward extension of the primary area of tropical convection to well east of the date line, and at times an actual shift of the main region of tropical convection to the eastern half of the tropical Pacific (not shown), and 2) a strengthening and equatorward shift of the intertropical convergence zone (ITCZ) in the Northern Hemisphere (not shown).
Also observed during JJA was the development of an anomalous upper-level anticyclonic circulation in the Southern Hemisphere subtropics between the date line and $90^{\circ} \mathrm{W}$ (Fig. 27c). This feature is a recurring aspect of the winter hemisphere circulation during strong warm episodes (Arkin 1982), and reflects several important changes in the flow occurring in the Tropics, the subtropics, and the extratropics. In the Tropics, the equatorward flank of the circulation anomaly reflects anomalous upperlevel easterly flow across the eastern Pacific, and thus comprises important structural elements of the much weaker-than-normal equatorial Walker circulation observed during the period [see section $3 a(3)$ ]. In the subtropics, above-normal heights (not shown) accompanying the anticyclonic circulation anomaly reflect an eastward extension of the mean subtropical ridge to well east of the date line, in response to the increase in tropical convection and deep tropospheric heating across the eastern tropical Pacific. In the extratropics, the anomalous anticyclonic circulation is an integral component of the coupling process between changes in tropical convection and changes in the wintertime jet stream across the South Pacific [see section 3a(4)]. The Southern Hemisphere circulation was also characterized by recurring high-latitude blocking over the high latitudes of the eastern South Pacific, a feature typical of strong warm episode conditions (Karoly 1989).

Strong warm episode conditions continued during SON (Figs. 23g,h), with SSTs greater than $28^{\circ} \mathrm{C}$ extending eastward from Indonesia to $125^{\circ} \mathrm{W}$ and greater than $29^{\circ} \mathrm{C}$ extending eastward to approximately $140^{\circ} \mathrm{W}$ (Fig. $23 \mathrm{~g}$ ). The normal cold tongue that typically occupies the eastern half of the tropical Pacific at this time of the year was notably absent, consistent with the collapse of the normal annual cycle in SSTs throughout the region (Figs. 24b,c). A nearly isothermal temperature structure was also observed from the surface to $150-\mathrm{m}$ depth, with ocean temperatures exceeding $9^{\circ} \mathrm{C}$ above normal at 50-150-m depth in the eastern Pacific (Fig. 25d). 
Also during SON, El Niño-related enhanced rainfall and heavy tropical convection developed across equatorial eastern Africa [see section $4 b(1)$ ]. This rainfall was associated with low-level easterly wind anomalies across the tropical Indian Ocean (Fig. 26d), and with a continuation of extremely suppressed convection throughout Indonesia. Also observed was a continuation of enhanced upper-level westerlies and an extended jet stream across the subtropical South $\mathrm{Pa}-$ cific (Fig. 27d), resulting in continued heavy precipitation across Chile and southeastern South America. Elsewhere, above-normal rainfall and increased storminess developed across the gulf coast of the United States (Fig. 22), in association with enhanced upper-level westerlies across the southern tier of the country.

\section{3) Equatorial Walker circulation}

Over the equatorial Pacific the divergent component of the atmospheric circulation is intimately related to the distribution of tropical convection, which in turn is an integral part of the still larger Southern Oscillation (Bjerknes 1969). This divergent circulation is often partitioned into its zonal and meridional components, respectively called the equatorial Walker circulation and the tropical Hadley circulation.

The equatorial Walker circulation is characterized by ascending motion over Indonesia and the western tropical Pacific, and descending motion over the eastcentral equatorial Pacific, with upper-level westerly (low-level easterly) flow completing the "direct" circulation cell. Following Halpert and Bell (1997), we illustrate the equatorial Walker circulation using pressure-longitude plots of the vector field whose horizontal component is the divergent zonal wind and whose vertical component is the scaled pressure vertical velocity. The pressure vertical velocity was subjectively scaled to give a sense of the relative vertical motion in the equatorial plane. The seasonal mean equatorial Walker circulation and anomalies during 1997, along with the accompanying seasonal relative humidity anomalies, are shown in Fig. 28.

During DJF 1996/97, a well-defined equatorial Walker circulation was present (Fig. 28a), with ascending motion over the western tropical Pacific, descending motion over the eastern Pacific, and a circulation center near $170^{\circ} \mathrm{W}$. These conditions reflected a slight strengthening and an overall westward shift of the circulation center compared to normal (Fig. 28b), consistent with weak cold episode conditions and a positive phase of the Southern Oscillation. These condi- tions dissipated rapidly during MAM 1997, as a nearnormal strength and location of the Walker circulation prevailed (Figs. 28c,d).

By JJA 1997, ascending motion and deep tropical convection encompassed the tropical Pacific between $140^{\circ} \mathrm{E}$ and $120^{\circ} \mathrm{W}$ (Fig. 28e), while no well-defined pattern of vertical motion was evident over Indonesia. This anomalous vertical motion field (Fig. 28f) reflected a nearly complete disappearance of the equatorial Walker circulation. The pattern was also accompanied by enhanced relative humidity everywhere east of the date line, and by reduced relative humidity across the western tropical Pacific and Indonesia. These conditions strengthened during SON 1997, with the equatorial Walker circulation again nearly absent (Figs. 28g,h).

\section{4) South Pacific Jet Stream during July- SEPTEMBER 1997}

In both the Northern and Southern Hemisphere, the extratropical wintertime jet stream over the western and central Pacific is intimately related to the distribution of tropical convection across Indonesia and the tropical Pacific. Thus, the interannual variability of these jet streams is strongly influenced by the ENSO. During strong El Niño conditions the wintertime jet stream extends eastward to well east of the date line, and over the eastern Pacific is shifted well equatorward from normal. These changes in the jet stream reflect a deep baroclinic jet structure often extending across the entire Pacific Basin, along with a pronounced eastward shift of the normal jet exit region to well east of the date line. These conditions then contribute to enhanced storminess and above-normal precipitation at lower latitudes of both North and South America.

During 1997, the South Pacific jet stream was particularly impacted during July-September by the ongoing strong El Niño conditions, while the primary impacts on the North Pacific jet stream did not occur until early 1998. Thus, this analysis focuses on the wintertime South Pacific jet stream, which extended across the entire South Pacific and brought enhanced storminess and above-normal precipitation throughout Chile and southeastern South America [see section 4e(2)].

The core of the South Pacific jet stream (approximated by wind speeds greater than $50 \mathrm{~m} \mathrm{~s}^{-1}$ ) during July-September is typically located between $22.5^{\circ}$ and $32.5^{\circ} \mathrm{S}$ and extends eastward from eastern Australia to approximately $150^{\circ} \mathrm{W}$ (Fig. 29a). The jet entrance region is normally located over eastern Australia, and is characterized by a local maximum in alongstream 

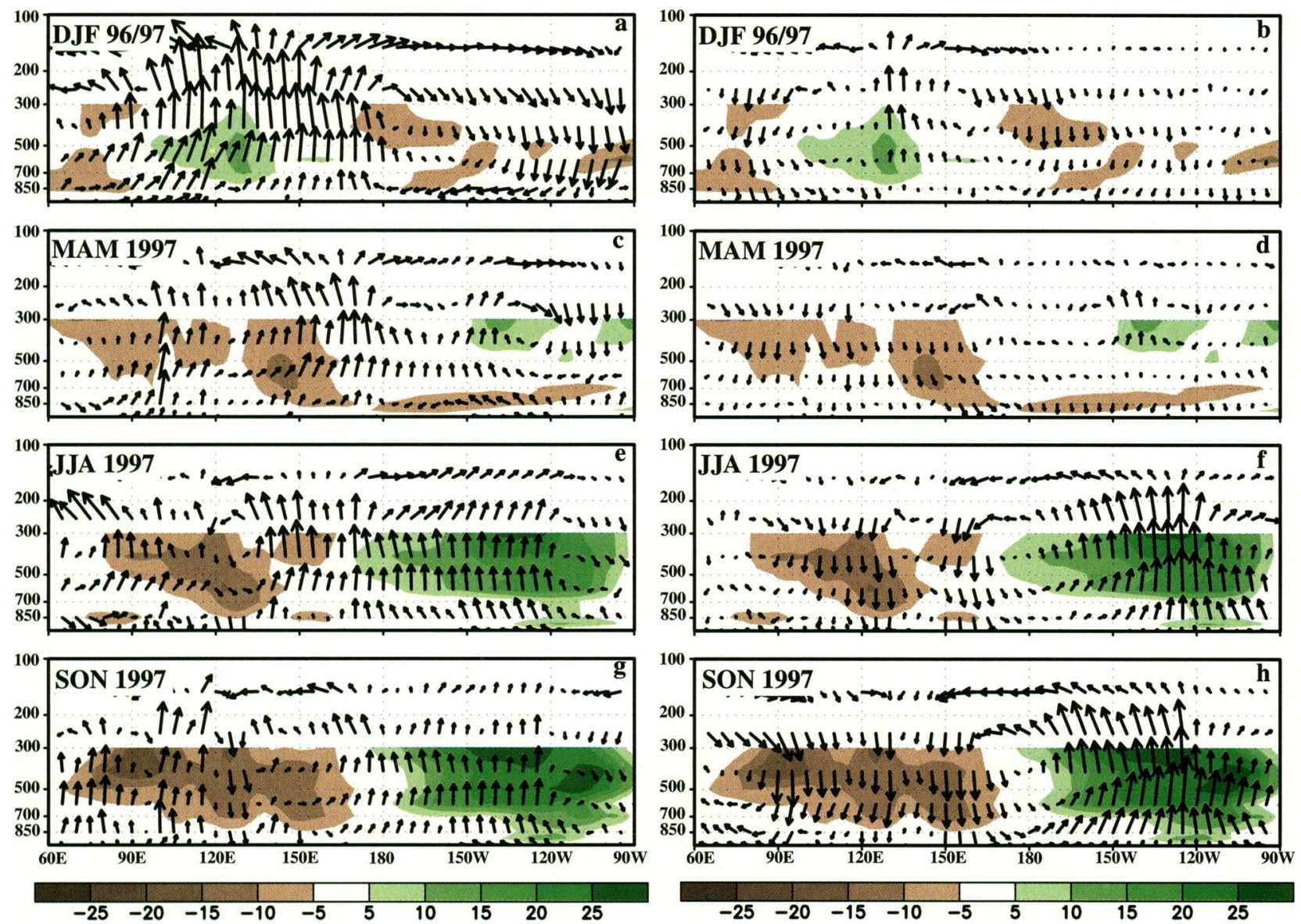

FIG. 28. Mean (left) and anomalies (right) pressure-longitude sections of the equatorial Walker circulation for (a),(b) DJF 1996/ 97, (c),(d) MAM 1997, (e),(f) JJA 1997, and (g),(h) SON 1997. Vertical component of vectors is the scaled pressure vertical velocity, and horizontal component is the zonal component of the divergent wind. The pressure vertical velocity was subjectively scaled to give a sense of the relative vertical motion in the equatorial plane. Shading in all panels shows relative humidity anomalies (\%). Note that the relative humidity in the NCEP-NCAR reanalysis extends upward to only the 300-hPa level.

increases in geostrophic wind speed. Additional characteristics of the entrance region include confluent geostrophic flow at upper levels and a strong poleward component of the horizontal ageostrophic flow directed toward lower geopotential height. This ageostrophic flow is one component of the thermodynamically direct, transverse ageostrophic circulation typical of any midlatitude jet entrance region (Palmen and Newton 1969, sections 1.5 and 8.3; Hoskins et al. 1978; Keyser and Shapiro 1986), and produces the required westerly momentum and kinetic energy increases that air parcels experience as they approach the jet core.

Farther downstream, the jet exit region is normally found between the date line and approximately $125^{\circ} \mathrm{W}$, and is characterized by a local maximum in alongstream decreases in geostrophic wind speed. Characteristic features of this exit region include dif- fluent geostrophic flow at upper levels and a strong equatorward component of the ageostrophic flow directed toward higher geopotential height. This ageostrophic flow is one component of the required thermodynamically indirect, transverse ageostrophic circulation typical of any midlatitude jet exit region, and produces the required westerly momentum and kinetic energy decreases that air parcels experience as they exit the jet.

The July-September 1997 period featured an eastward extension of the jet stream across the entire South Pacific (Fig. 29b), and an extension of the jet core to $105^{\circ} \mathrm{W}$ (nearly $45^{\circ}$ east of normal). This extension was accompanied by a pronounced eastward shift in the regions of alongstream decreases in geostrophic wind speed and strong diffluent geostrophic flow, and by a nearly complete elimination of these features in the vicinity of the climatological mean jet exit region. Col- 
lectively, these conditions reflected an eastward shift in the location of the jet exit region to between $130^{\circ}$ and $90^{\circ} \mathrm{W}$. This dramatic structural change in the jet stream was accompanied by a dynamically consistent eastward shift in the primary region of equatorwarddirected ageostrophic flow at upper levels to the observed jet exit region, indicating a corresponding shift in the entire thermodynamically indirect, transverse ageostrophic circulation that characterizes the jet exit region.

This jet extension and eastward shift of the jet exit region were intimately related to an eastward extension of the subtropical ridge to well east of the date line, which is identified by a well-defined anticyclonic circulation anomaly across the entire eastern subtropical South Pacific during JJA and SON (Figs. 27c,d). Additional aspects of this link between the two features are revealed by examining their common attributes. One common feature is the region of enhanced westerlies over the eastern South Pacific, which comprises both the poleward flank of the anticyclonic circulation anomaly and the extended South Pacific jet stream (compare Figs. 27c, and 29b,c). Two additional common features are the poleward flow and equatorward flow along the western and eastern flanks of the anticyclonic anomaly, respectively, which contain important dynamical information regarding links between the anomalous subtropical ridge and changes in the jet entrance and exit regions.

The anomalous poleward flow comprises several important structural changes occurring in the exit region of the climatological mean Pacific jet. First, it contributes to anomalous geostrophic confluence throughout the region (Fig. 29c), which also coincides with the entrance region of the anomalous westerly wind maximum. Second, it comprises a dynamically consistent pattern of anomalous ageostrophic flow at upper levels, directed toward lower geopotential heights at an angle nearly orthogonal to the jet axis. This ageostrophic flow reflects an anomalous thermodynamically direct, transverse ageostrophic circulation, and results in abnormally strong Lagrangian increases in kinetic energy throughout the region (Fig. 30a). In this particular case, both the rotational (Fig. 30b) and divergent (Fig. 30c) components of the ageostrophic flow contributed strongly to these kinetic energy tendencies. Collectively, these anomalies are consistent with an almost complete elimination of the normal jet exit region in the vicinity of the date line, and with a reduced strength of its attendant transverse ageostrophic circulation.
A similar examination indicates that the equatorward flow along the eastern flank of the anticyclonic circulation anomaly comprises important structural and dynamical features of the observed jet exit region. For example, this equatorward flow contributes to geostrophic diffluence in the observed jet exit region (Fig. 30c), an area that also coincides with the exit region of the anomalous westerly wind maximum. The equatorward flow also comprises a coherent pattern of ageostrophic flow directed toward higher geopotential heights at upper levels, at an angle nearly orthogonal to the jet axis. This ageostrophic component of the flow reflects the well-defined thermodynamically indirect, transverse ageostrophic circulation previously noted in the jet exit region, and results in Lagrangian decreases in kinetic energy throughout the area (Fig. 30a). In this case, the rotational component of the ageostrophic flow contributes more to these kinetic energy tendencies (Fig. 30b) than does the divergent component (Fig. 30c).

Thus, in this case the anomalous poleward and equatorward flow found respectively along the western and eastern flanks of the anticyclonic circulation anomaly are strongly linked to jet dynamical processes through El Niño-related changes in the subtropical ridge. These flow features also highlight the jetlike character of the anomalous westerly wind maximum found along the poleward flank of the anticyclonic circulation anomaly.

\section{b. The tropical Madden-Julian oscillation (MJO)}

In addition to the ENSO, low-frequency variability in the Tropics is heavily influenced by the MJO (e.g., Madden and Julian 1971, 1972, 1994). These oscillations are characterized by a strong eastward propagation of atmospheric features, with a typical period of 30-60 days. The oscillation is associated with variations in deep tropical convection, with the largest anomalies typically observed over the relatively warm ocean waters (greater than $28^{\circ} \mathrm{C}$ ) of the Indian Ocean, Indonesia, and the western Pacific. The MJOrelated tropical convection can be masked to some degree by extreme phases of ENSO. For example, during cold episodes enhanced convection associated with the MJO is often more evident over Indonesia while suppressed convection is more evident in the vicinity of the date line. In contrast, during warm episodes enhanced convection associated with the MJO is often more evident in the vicinity of the date line while suppressed convection is more evident over Indonesia. 


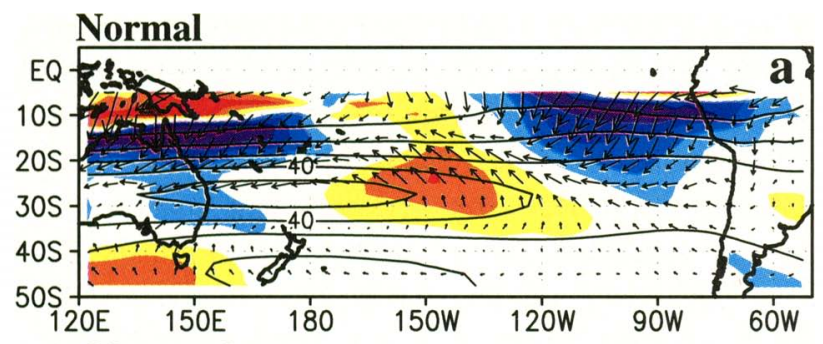

Observed
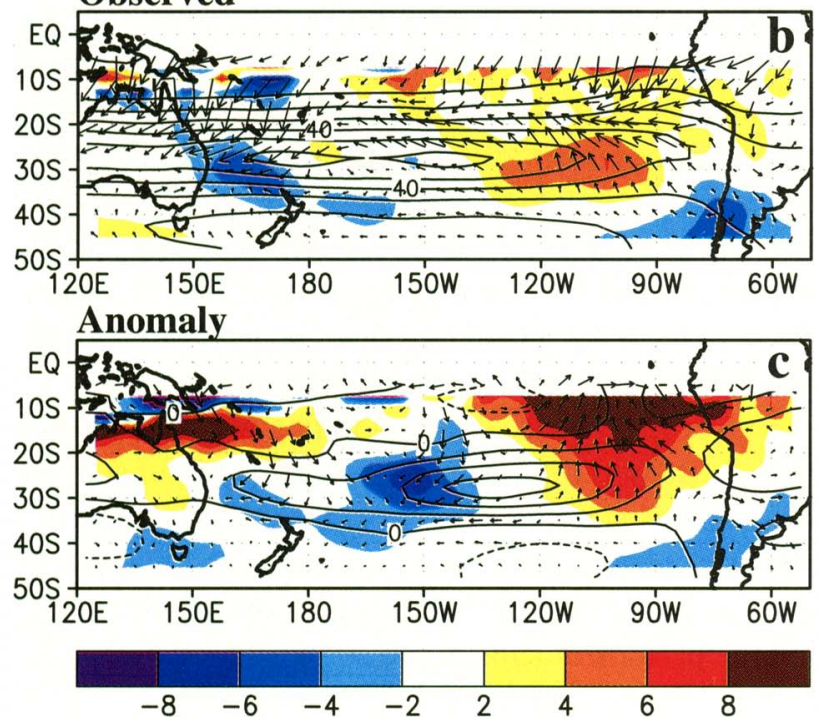

FIG. 29. Analysis of the South Pacific jet stream at $200 \mathrm{hPa}$ during July-September 1997 showing geostrophic wind speed (contours), geostrophic diffluence/ confluence (shading, interval is $2 \times 10^{-6} \mathrm{~s}^{-1}$ ), and horizontal component of the ageostrophic wind vector for (a) climatological mean and (b) observed, and (c) anomaly. Contour interval for isotachs in (a),(b) is $10 \mathrm{~m} \mathrm{~s}^{-1}$ and in (c) is $5 \mathrm{~m} \mathrm{~s}^{-1}$. Diffluence and confluence are indicated by positive and negative values, respectively. Diffluence is calculated in Cartesian coordinates based on the transformation equations from the natural coordinate system provided by Bell and Keyser (1993). Anomalous diffluence is calculated as the numerical difference between the observed and the climatological mean. Climatology is the 1979-95 base period monthly means.

There is also substantial interannual variability in MJO activity, with long periods (e.g., February 1996 -July 1997) of increased activity followed by periods (e.g., August-December 1997) in which the oscillation is weak or absent (Figs. 31 and 32). During March-July 1997, the active MJO was sometimes strong enough to mask the ENSO-related pattern of anomalous tropical convection (Fig. 31), and to also affect the atmospheric wind and pressure indices used to monitor the developing warm episode. Subsequently, the diminished MJO activity during AugustDecember 1997 was presumably linked to a continued strengthening of the warm episode and its even-

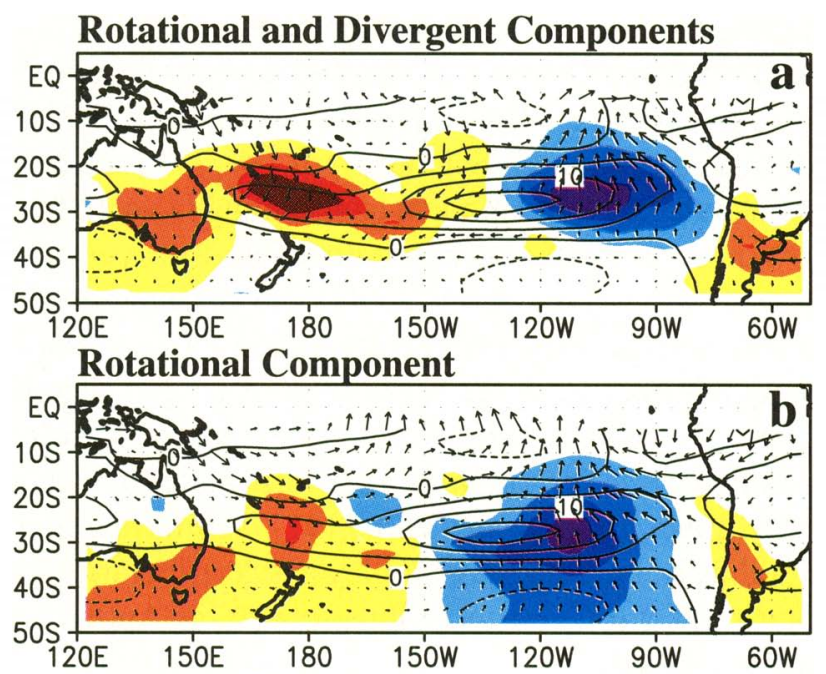

Divergent Component

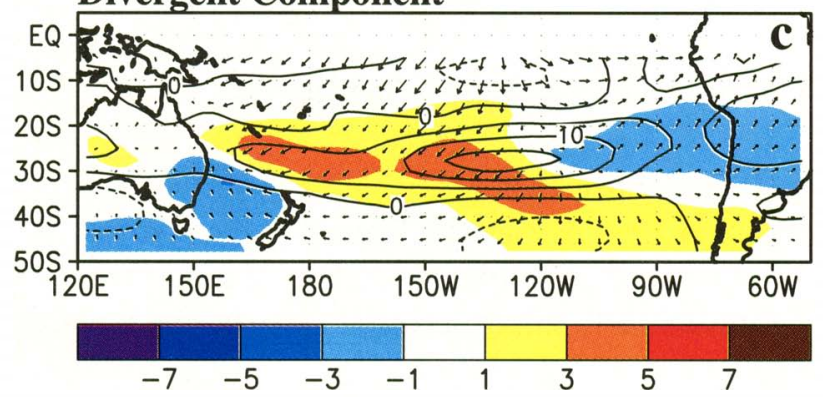

FIG. 30. Anomalous Lagrangian tendency of kinetic energy (shading, interval is $1 \times 10^{-3} \mathrm{~m}^{2} \mathrm{~s}^{-3}$ ) and ageostrophic wind vector during July-September 1997, associated with (a) both the rotational and divergent components of the horizontal ageostrophic flow, (b) the rotational component of the horizontal ageostrophic flow, and (c) the divergent component of the horizontal ageostrophic flow. Also shown in all panels is the anomalous geostrophic wind speed (contours, interval is $5 \mathrm{~m} \mathrm{~s}^{-1}$ ). Lagrangian kinetic energy tendency results from the ageostrophic flow directed across the geopotential height contours. Anomalous tendencies are calculated as the difference between the observed and the climatological mean. Climatology is the 1979-95 base period monthly means.

tual control over the distribution of convection throughout the tropical Pacific and Indonesia.

As a consequence of the large-scale changes in tropical convection accompanying the MJO, the jet streams over both the North Pacific and South Pacific can be heavily impacted during the respective hemisphere's winter season (Higgins and Mo 1997). For example, the jets often exhibit a westward retraction during periods of enhanced convection over Indonesia, and an eastward extension as the enhanced convection moves over the central equatorial Pacific. In the Northern Hemisphere, these east-west modulations of the Pacific jet stream can contribute to re- 
curring blocking activity over the high latitudes of the North Pacific (Higgins and Mo 1997), as was observed during September-December 1996 (Halpert and Bell 1997) and continued well into April 1997. This blocking activity was an important contributing factor to below-normal surface temperatures across western Canada throughout the 1996/97 cold season, and to below-normal surface temperatures and above-normal precipitation across the northwestern United States during the period. These conditions contributed to flooding in the Pacific Northwest during late 1996 and early 1997 (Halpert and Bell 1997), and to massive flooding of the Red River Valley and its tributaries in North Dakota and western Minnesota during April [see section $4 \mathrm{a}(1)]$.

\section{Regional climate highlights}

\section{a. North America}

1) Flooding of the Red River Valley AND TRIBUTARIES DURING APRIL 1997

Substantial flooding occurred in the northern plains

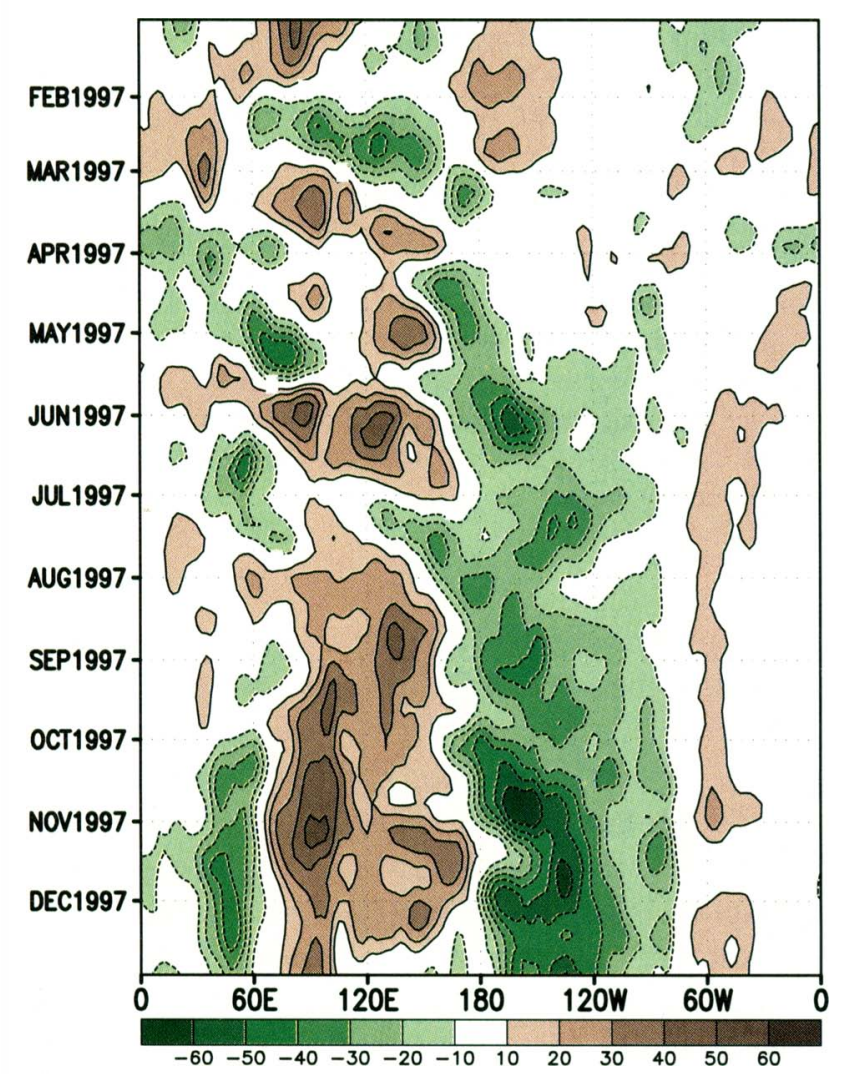

FIG. 31. Time-longitude section $\left(5^{\circ} \mathrm{N}-5^{\circ} \mathrm{S}\right)$ of OLR anomalies $\left(\mathrm{W} \mathrm{m}^{-2}\right)$. Anomalies are departures from the 1979-95 base period pentad means. of the United States and southern Manitoba, Canada, during April 1997, with many rivers reaching record high levels during the month (Fig. 33). In the Red River Valley of eastern North Dakota and west-central Minnesota flooding persisted from early April through mid-May. At Fargo, North Dakota, the Red River peaked at more than $6.6 \mathrm{~m}$ above flood stage during this period, a level reached only once previously in the past 100 years. Farther north, river levels at East Grand Forks also peaked at more than $6.6 \mathrm{~m}$ above flood stage, slightly exceeding the 500-year statistical recurrence interval at that site. Record flooding also occurred in all major tributaries of the Red River during April, including the Wild Rice River and the Maple River (a record $1.8 \mathrm{~m}$ above flood stage), the Sheyenne River (a record $2.5 \mathrm{~m}$ above flood stage) and the Buffalo River (a record $1.1 \mathrm{~m}$ above flood stage).

The primary cause of this flooding was a highly abnormal thaw during March and April of substantial winter snow and river ice. Abnormal characteristics of the thaw included its timing, duration, and areal extent, as well as the diurnal temperature changes during the periods of substantial snow and ice melt.

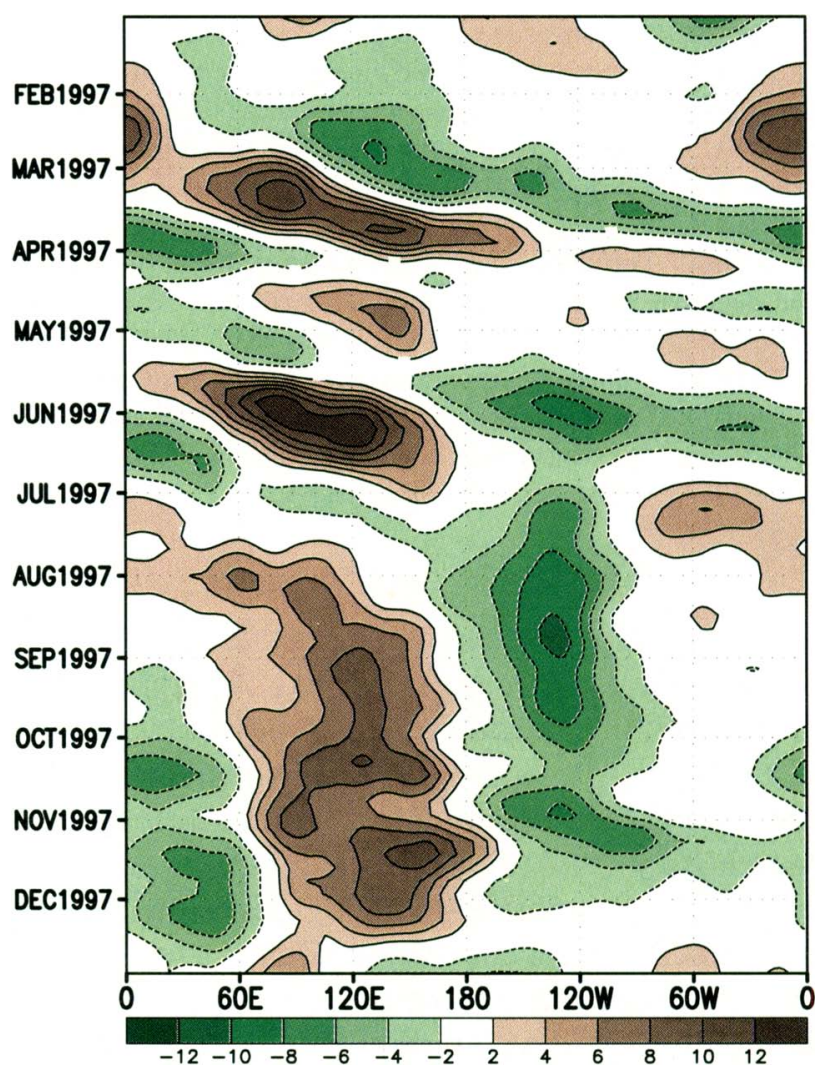

FIG. 32. Time-longitude section $\left(5^{\circ} \mathrm{N}-5^{\circ} \mathrm{S}\right)$ of 200 -hPa velocity potential anomalies $\left(10^{6} \mathrm{~m}^{2} \mathrm{~s}^{-1}\right)$. The period mean anomalies have been removed at each longitude. 


\section{(i) Normal climate conditions}

The atmospheric conditions that contributed to the record flooding of the Red River and its tributaries are best appreciated by first reviewing the geographic and normal climate conditions for the region. The Red River flows slowly northward within a broad, gently sloping flood plain from its source region in northeastern South Dakota/west-central Minnesota to Lake Winnipeg in southern Manitoba, Canada. In the southern part of the Red River Basin, daily mean temperatures normally remain below freezing from mid-November through late February/early March, and then increase to almost $10^{\circ} \mathrm{C}$ by the end of April. In the northern part of the basin, daily mean temperatures throughout the winter and spring typically average $3^{\circ}-$ $6^{\circ} \mathrm{C}$ lower than those in the south, remaining below freezing from late October to early April, then increasing to $7^{\circ}-8^{\circ} \mathrm{C}$ by the end of April.

This unique relationship between climate and geography makes the Red River Valley particularly susceptible to flooding during March and April (A. Voelker, National Weather Service meteorologist, Grand Forks, ND, 1977, personal communication). In particular, the normal annual cycle in air temperature favors a south-to-north progression of the spring thaw, which is characterized by the melting of snow and river ice in the south during March while the downstream river channel remains frozen. These conditions favor flooding of the Red River and a backfill of the runoff into the river's tributaries.

The springtime thaw is particularly sensitive to modest departures from normal in the annual cycle of air temperature, with increased flooding typically observed during heavy snow years in which the thaw is delayed and confined to the southern part of the basin. In contrast, less flooding is typically observed during years in which the thaw is well established by March throughout the entire basin. Flooding is also influenced by the diurnal freeze/ thaw cycle. A more gradual thaw, and therefore reduced flooding, occurs when daily high temperatures during March are above freezing and daily minimum temperatures continually drop below freezing.

\section{(ii) Contributing factors to the April 1997 record floods}

The important factors that set the stage for potential significant flooding of the Red River and its tributaries during April 1997 included greatly enhanced snowfall during the winter and a substantial buildup of river ice throughout the northern half of the Red River. These conditions resulted from a series of major cold-air outbreaks and winter storms from September 1996 to April 1997. During this period more than $200 \%$ of normal snowfall was observed over most of North Dakota, western Minnesota, and northeastern South Dakota, with $125 \%-200 \%$ of normal snow covering the remainder of the upper Midwest, the northern plains, Montana, and most of Wyoming (Fig. 34). The floods were then directly initiated by a highly abnormal thaw of this snowpack and river ice.

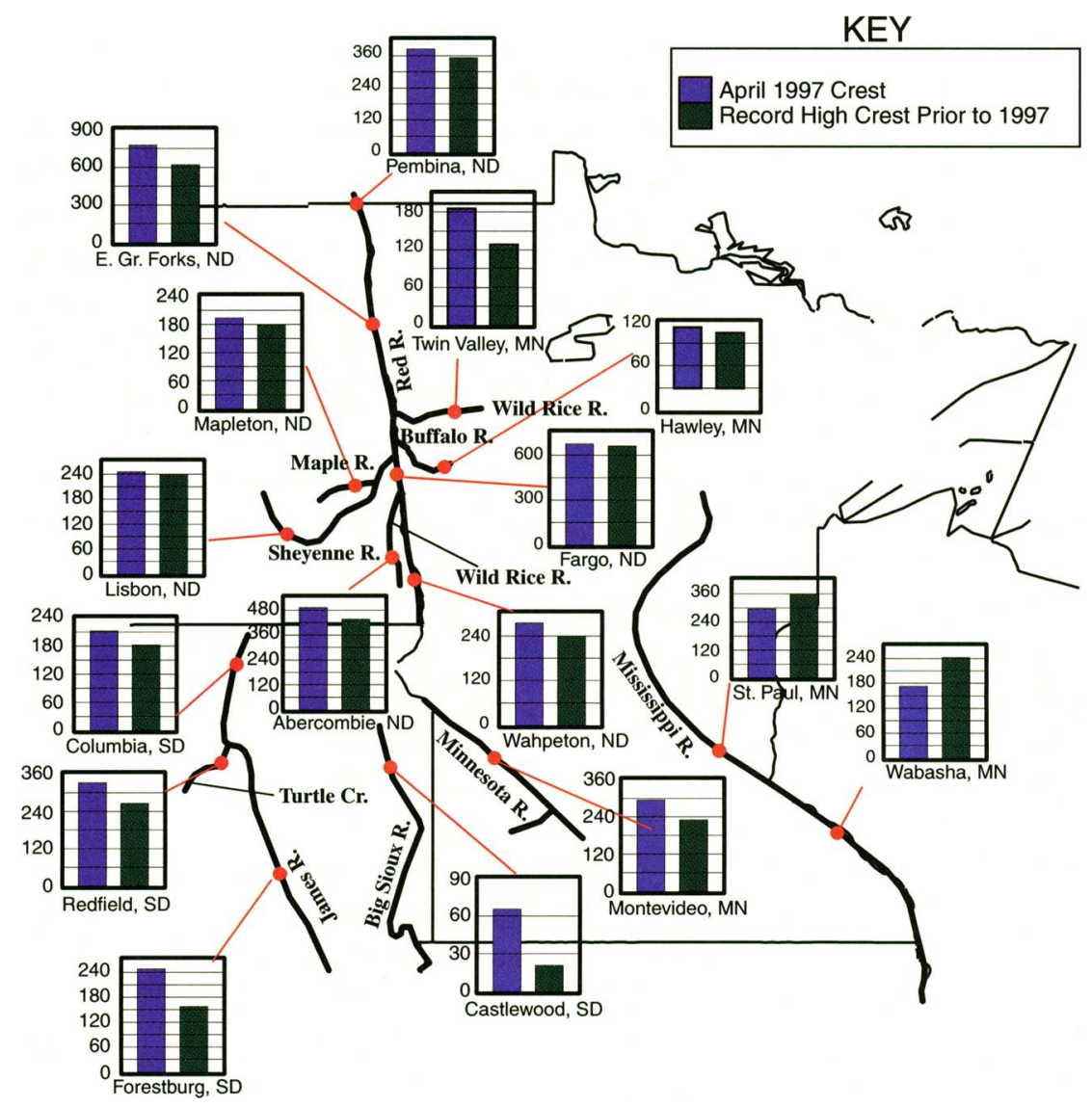

FIG. 33. Crests above flood stage (cm) for selected rivers in the north-central United States for April 1997 (purple) and for the previous record high crest (green). State abbreviations are North Dakota, ND; South Dakota, SD; and Minnesota, MN. 


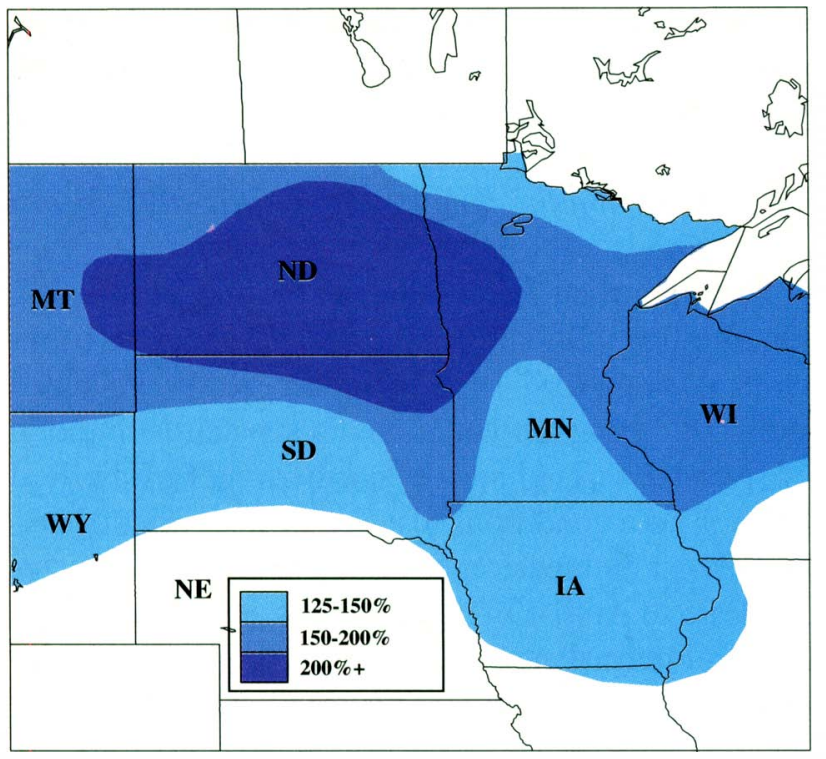

FIG. 34. Percent of normal accumulated snowfall during 1 September 1996-12 April 1997, compared to the 1961-90 base period means.

This abnormal thaw occurred during March-April, and is highlighted using time series of estimated daily maximum and minimum temperatures in both the northern (Fig. 35a) and southern portions of the basin (Fig. 35b). The period 1-20 March featured a continuation of freezing conditions throughout the basin, with daily minimum temperatures often dropping below $-10^{\circ} \mathrm{C}$ in the south and below $-15^{\circ} \mathrm{C}$ in the north. These abnormally cold temperatures reflected a large influx of polar air into central North America in response to an amplified ridge and blocking anticyclone over the Bering Sea (Fig. 36a).

The first major melt of snow and ice then occurred in the southern part of the basin during 21 March-5 April, with daily maximum temperatures reaching $15^{\circ} \mathrm{C}$ on many days during the period and minimum temperatures remaining above freezing on one-half of the nights (Fig. 35b). Also during this period temperatures averaged $2^{\circ}-4^{\circ} \mathrm{C}$ above average across the central United States and northern plains states (Fig. 36b), which also contributed to significant snowmelt and flooding in other river basins across North Dakota, South Dakota and Minnesota (Fig. 33). This largescale warming resulted from a strong transport of mild Pacific air into central North America, in association with the breakdown of the high-latitude block and the establishment of broad westerly flow throughout the region (Fig. 36b). Farther north, freezing conditions and significant river ice persisted in the northern portion of the Red River Basin throughout the period, as
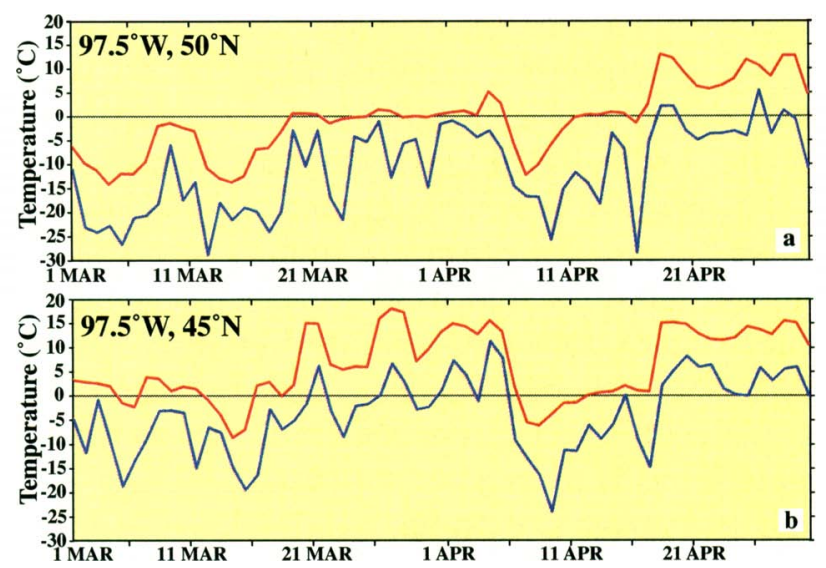

FIG. 35. Estimated daily maximum (red curve) and minimum (blue curve) temperatures $\left({ }^{\circ} \mathrm{C}\right)$ during March and April 1997 over (a) the northern part of the Red River in southern Canada $\left(50^{\circ} \mathrm{N}\right.$, $\left.97.5^{\circ} \mathrm{W}\right)$, and (b) eastern North Dakota near the central part of the Red River $\left(45^{\circ} \mathrm{N}, 97.5^{\circ} \mathrm{W}\right)$. Temperatures are from the NCEPNCAR reanalysis dataset.

daily maximum temperatures remained near freezing and daily minimum temperatures averaged $-5^{\circ}$ to $-10^{\circ} \mathrm{C}$. These conditions exacerbated flooding in the south by significantly impeding the normal northward flow of the river and allowing runoff to backfill into the river's tributaries across eastern North Dakota and western Minnesota.

This warm period was followed by a major storm and cold frontal passage on 5-6 April, which brought heavy rainfall to the Red River Basin. These conditions were followed during 6-17 April by a return to abnormally cold temperatures (Fig. 36c), which froze standing water throughout the southern portion of the basin. This drop in temperatures occurred in association with a large influx of polar air throughout central North America, in response to the redevelopment of an amplified ridge and blocking anticyclone over Alaska (Fig. 36c).

A second major warming then occurred throughout the entire Red River basin during 17-30 April (Figs. $35 a, b)$, which resulted in further snow and ice melt and to a second period of substantial rises in river levels. This warming was also associated with a large-scale pattern of above-normal temperatures throughout the western half of the United States and south-central Canada (Fig. 36d), and was similar to the previous thaw (20 March-5 April) in that it was linked to a strong transport of mild Pacific air into central North America. These conditions also followed the breakdown of a high-latitude block and the establishment 

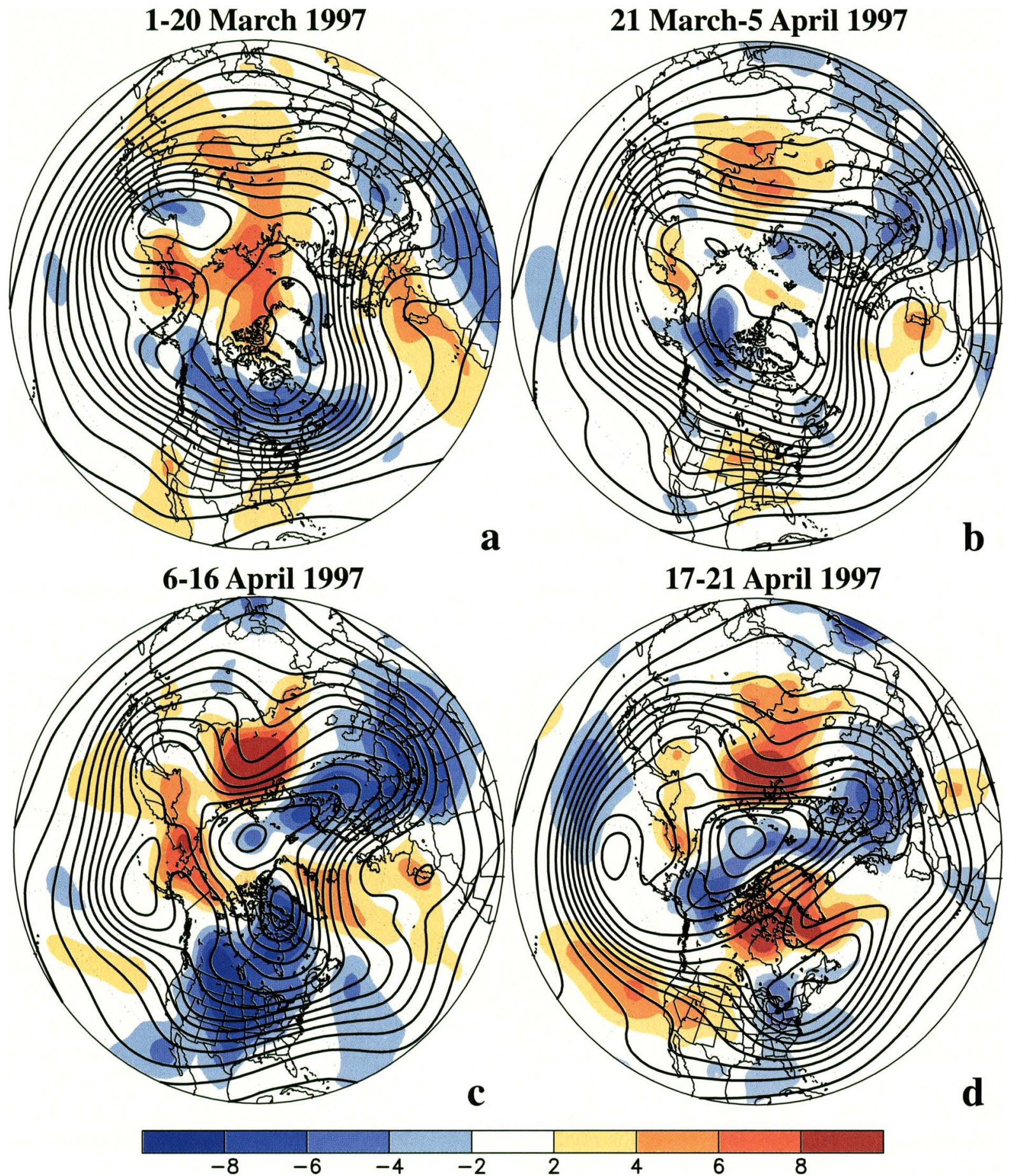

FIG. 36. Northern Hemisphere analyses of 300-hPa height (contours, interval is $90 \mathrm{~m}$ ) and 925 -hPa temperature anomalies (shading, ${ }^{\circ} \mathrm{C}$ ) for (a) 1-20 March, (b) 21 March-5 April, (c) 6-16 April, and (d) 17-21 April. Analysis times coincide with significant temperature transitions shown in Fig. 35. Temperature anomalies are departures from the 1979-95 base period daily means.

of broad westerly/southwesterly flow throughout the eastern North Pacific and western North America.

This highly unfavorable March-April 1997 thaw in the Red River Basin can be put into perspective by comparing it with the very favorable or "ideal" thaw of 1994 (Fig. 37), a year in which there was only minor flooding despite record or near-record snowfall at many locations during October 1993-February 1994. The 1994 thaw featured four periods of substantial basin-wide warming during March, along with signifi- 
cant refreezing at night. These conditions produced a much more uniform melt of snow and river ice throughout the basin, and resulted in a substantial reduction of the winter snowpack prior to the onset of the major April warming.

\section{(iii) Discussion}

A combination of atmospheric conditions spanning many time and space scales generally contributes to most major climate events, and the same is true of the record Red River flooding of April 1997. The primary cause of the 1997 flooding was a highly abnormal thaw of winter snow and river ice, following a winter season that featured much above normal snowfall across the northern plains. The buildup of snow and river ice resulted from repetitive winter storms and cold-air outbreaks that were heavily controlled by two prominent and sometimes related atmospheric phenomena: 1) recurring high-latitude blocking and block evolution in the vicinity of the Bering Sea and Alaska (see section 3b; see also Halpert and Bell 1997), and 2) substantial variability in the eastward extent of the East Asian jet stream over the eastern North Pacific.

Similar atmospheric circulation features prevailed throughout the 1995/96 cold season, which resulted in abnormally cold temperatures and above-normal snowfall throughout the Red River Valley. This combination of recurring high-latitude blocking and abnormally cold air temperatures tends to be more prevalent during tropical Pacific cold episodes (La Niña), and much less prevalent during tropical Pacific warm episodes (El Niño) (Chen and Van den Dool 1997). Also, it is likely that the blocking activity and increased intensity of the undercutting flow observed throughout the cool season was influenced by the strong MJO activity across the tropical Pacific. The strong undercutting coincided with periods of eastward propagating convection from Indonesia to the central equatorial Pacific (see section 3b). These observations are consistent with previous analyses of the relationship between strong MJO activity and changes in both the wintertime East Asian jet stream and the occurrence of blocking activity over the high latitudes of the North Pacific (Higgins and Mo 1997).

Despite the apparent external influence on the extratropical atmospheric circulation features by the La Niña and the MJO, it is evident that the timing of both the block evolution and the undercutting jet stream was a crucial contributing factor to the abnormal 1997 thaw and subsequent flooding. Thus, predicting the magnitude and areal extent of future Red River flooding is

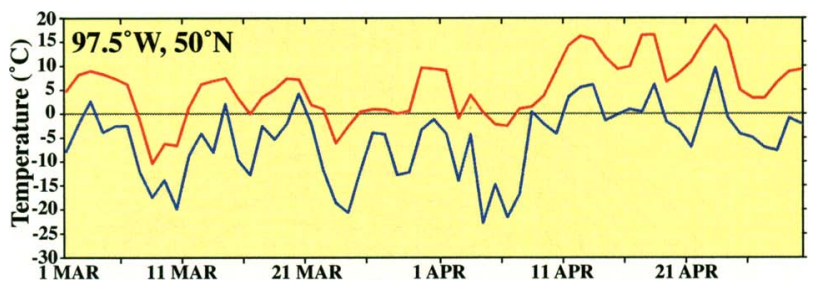

FIG. 37. Estimated daily maximum (red curve) and minimum (blue curve) temperatures $\left({ }^{\circ} \mathrm{C}\right)$ during March and April 1994 over the northern part of the Red River in southern Canada $\left(50^{\circ} \mathrm{N}\right.$, $\left.97.5^{\circ} \mathrm{W}\right)$. Temperatures are from the NCEP-NCAR reanalysis dataset.

strongly dependent on forecasts of the timing of the March-April thaw. Unfortunately, long-lead (monthly) predictions of blocks and their life cycles, as well as reliable predictions of the extratropical atmospheric response to the $\mathrm{MJO}$, are presently not possible.

2) The 1997 North Atlantic and eastern North PACIFIC HURRICANE SEASON

(i) Overview

The North Atlantic hurricane season runs from June through November, with peak activity between August to October primarily linked to systems developing from African easterly wave disturbances. Overall, 910 tropical storms are observed over the North Atlantic in an average season, with 5-6 becoming hurricanes and 2-3 reaching intense hurricane status [measured by a category 3,4 , or 5 on the Saffir-Simpson scale (Simpson 1974)]. The suppressed 1997 hurricane season featured seven named storms (Fig. 38), with three of these systems becoming hurricanes and one reaching intense hurricane status. This latter system, Erica, developed in September and remained intense for only two days. Interestingly, Hurricane Erica was the only tropical cyclone to form over the North Atlantic basin during August-September, a record low number for the period since the beginning of the aircraft reconnaissance era in 1944.

In contrast, the 1995 and 1996 Atlantic hurricane seasons were very active (Fig. 38), with a high percentage of tropical storms becoming hurricanes in each year (Halpert and Bell 1997; Halpert et al. 1996). During 1995, 11 of 19 tropical systems became hurricanes, with 5 reaching intense hurricane status. During 1996, 9 of 13 tropical storms became hurricanes, with 6 reaching intense hurricane status. A significant majority of these tropical cyclones and hurricanes in both years (16 of 19 systems in 1995 and 9 of 13 systems 
in 1996) developed from African easterly wave disturbances during August-October.

Over the eastern North Pacific, the 1997 hurricane season featured 17 named storms (normal is 16), 9 of which became hurricanes (normal is 9) with 7 becoming major hurricanes (normal is 5). The season also featured an expanded area of tropical cyclone activity compared to normal, with four systems moving well west of $135^{\circ} \mathrm{W}$ and two major hurricanes affecting southwestern North America. In contrast, the 1995 and 1996 seasons featured well below normal tropical storm and hurricane activity across the eastern North Pacific.

\section{(ii) Vertical wind shear}

Tropical storm and hurricane activity over the North Atlantic and eastern North Pacific ocean basins is strongly affected by the vertical wind shear between the upper (200-hPa) and lower (850-hPa) levels of the atmosphere. Strong vertical shear inhibits tropical cyclogenesis while weak vertical shear (less than approximately $8 \mathrm{~m} \mathrm{~s}^{-1}$ ) favors tropical cyclone development. Climatologically, strong vertical wind shear during the hurricane season is observed throughout the Caribbean, large portions of the subtropical North Atlantic, and the northern Gulf of Mexico. In contrast, weak vertical shear is normally observed over the tropical eastern North Atlantic and over a large area of the eastern North $\mathrm{Pa}$ cific between $10^{\circ}$ and $17.5^{\circ} \mathrm{N}$ (Fig. 39a). Thus, tropical cyclone formation is normally favored over the eastern tropical Atlantic and North Pacific basins, while comparatively less activity is favored in the Caribbean region.

The ENSO can substantially influence the year-to-year variability of vertical wind shear over both the North Atlantic and eastern North Pacific ocean basins and, thus, the interannual variability of hurricane activity in these regions. Gray (1984) has shown that $\mathrm{Pa}$ cific warm episodes (El Niño) often favor suppressed tropical storm activity and a reduction in intense hurricane accyclone formation.

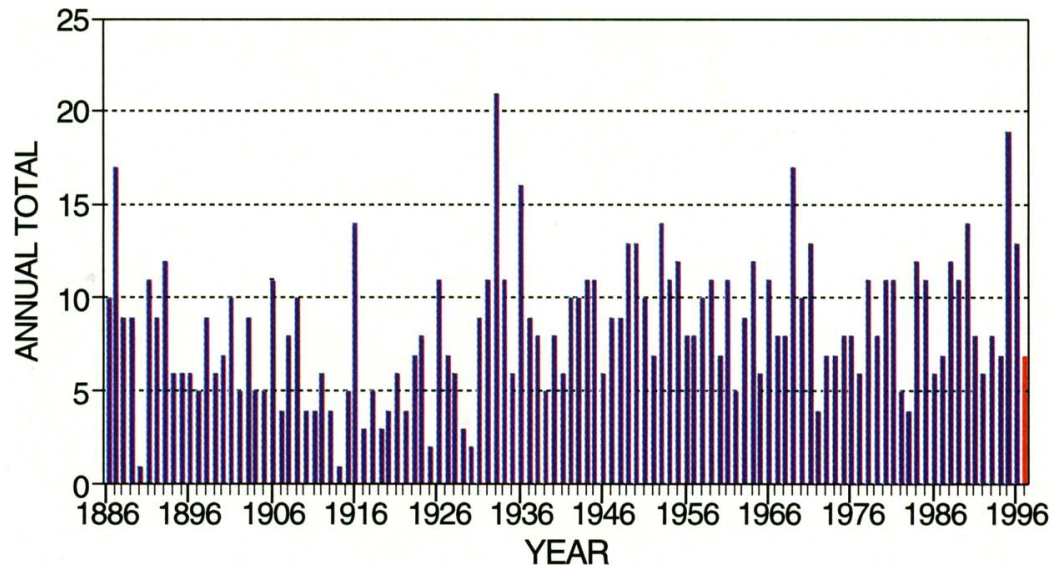

FIG. 38. Number of hurricanes and tropical storms for the North Atlantic basin: 1997 is shown in red. (Source: National Climatic Data Center.)

tivity over the North Atlantic by helping to maintain or enhance the normally high vertical wind shear. In contrast, he notes that Pacific cold episodes (La Niña) often favor enhanced tropical storm activity and increased intense hurricane activity by helping to reduce the vertical wind shear across most of the tropical North Atlantic. Extreme phases of ENSO often have an opposite impact on tropical storm and hurricane activity over the eastern North Pacific, with El Niño favoring an expanded area of tropical cyclone activity by reducing the vertical wind shear in that region,
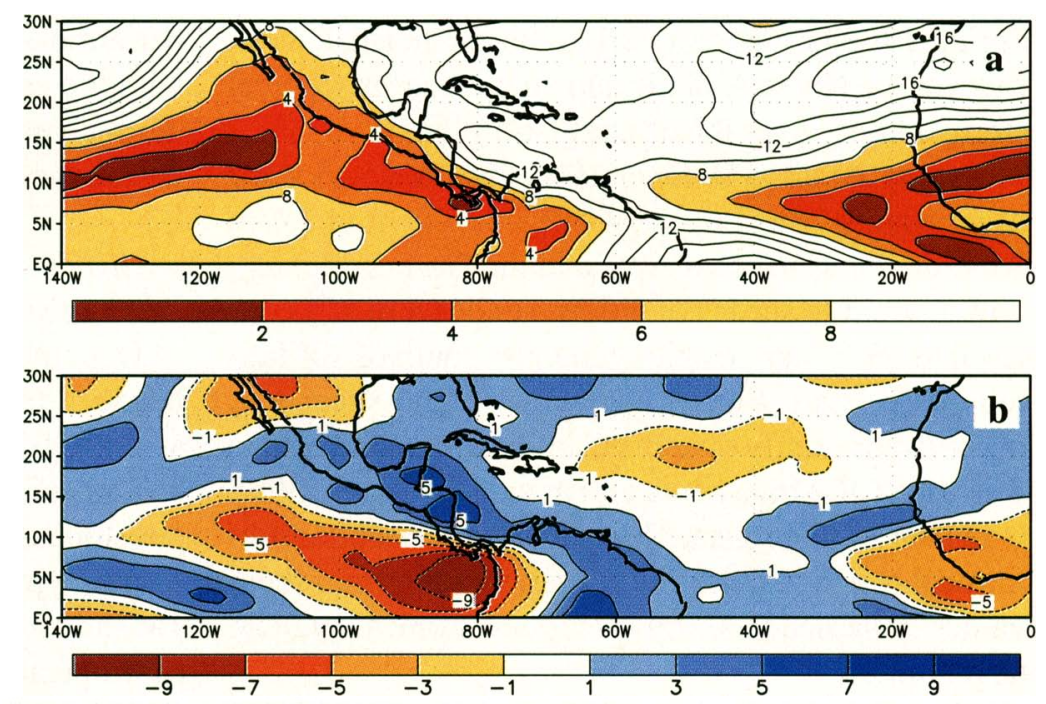

FIG. 39. (a) Vertical wind shear and (b) departure from normal during AugustOctober 1997. Wind shear is calculated as the difference in wind speeds between 200 and $850 \mathrm{hPa}$ (contour interval is $2 \mathrm{~m} \mathrm{~s}^{-1}$ ). Shaded areas in (a) indicate where the vertical wind shear is less than $8 \mathrm{~m} \mathrm{~s}^{-1}$ and are considered favorable for tropical 


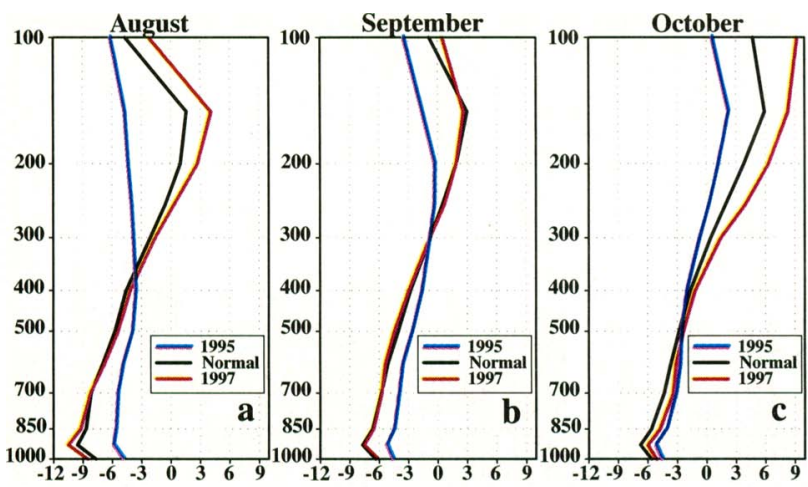

FIG. 40. Vertical profile of atmospheric zonal winds $\left(\mathrm{m} \mathrm{s}^{-1}\right)$ averaged over the Caribbean Sea sector during (a) August, (b) September, and (c) October. Negative values indicate easterly winds and positive values indicate westerly winds. The black curve indicates the 1979-95 normal conditions, the red curve indicates 1997 conditions, and the blue curve indicates 1995 conditions.

and La Niña favoring suppressed tropical cyclone activity by enhancing the vertical wind shear.

This ENSO influence on tropical storm and hurricane activity has been particularly prominent during the 1990s. The prolonged ENSO-like conditions during 1991-February 1995 were accompanied by extremely low Atlantic tropical storm and hurricane activity. In contrast, the cold episode years of 1995 and 1996 featured an increase in tropical storm activity over the North Atlantic and substantially reduced activity across the eastern North Pacific. Subsequently, the transition to very strong warm episode conditions during 1997 brought a return to below-normal activity over the North Atlantic and an increase in tropical storm activity over the eastern North Pacific.

During August-October 1997 large vertical wind shear covered most of the western and central North Atlantic, the Caribbean Sea, and the Gulf of Mexico, with favorable shear conditions (under $8 \mathrm{~m} \mathrm{~s}^{-1}$ ) confined to the eastern tropics generally south of $10^{\circ}$ latitude (Fig. 39a). Enhanced vertical wind shear was observed primarily over the Caribbean Sea and off the west coast of Africa between $10^{\circ}$ and $15^{\circ} \mathrm{N}$ (Fig. 39b), with near average shear observed over the central subtropical North Atlantic. However, these normal shear values remained too large to support tropical cyclone development.

A vertical profile of the atmospheric winds over the Caribbean Sea region (Fig. 40), where no tropical storms developed during the 1997 hurricane season, indicates enhanced vertical shear resulting primarily from an ENSO-related increase in the upper-level

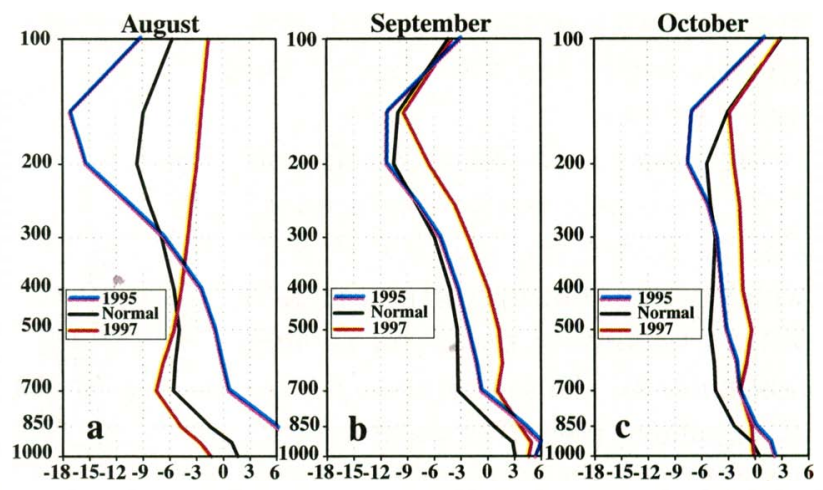

FIG. 41. Vertical profile of atmospheric zonal winds $\left(\mathrm{m} \mathrm{s}^{-1}\right)$ averaged over the eastern North Pacific sector during (a) August, (b) September, and (c) October. Negative values indicate easterly winds and positive values indicate westerly winds. The black curve indicates the 1979-95 normal conditions, the red curve indicates 1997 conditions, and the blue curve indicates 1995 conditions.

westerlies. In contrast, the near absence of vertical wind shear over the region during August-September 1995 (Fig. 40) resulted from weak easterly winds throughout the depth of the troposphere in association with La Niña conditions.

The entire eastern North Pacific featured low vertical wind shear during August-October 1997 (Fig. 39a), with generally reduced wind shear throughout the primary region of tropical storm formation between $10^{\circ}-17^{\circ} \mathrm{N}$ and $105^{\circ}-125^{\circ} \mathrm{W}$ (Fig. 39b). This reduced shear resulted primarily from an ENSO-related collapse of the normal easterly winds in the upper atmosphere (Fig. 41). These conditions contrast with the enhanced easterly winds and stronger-thannormal vertical shear observed throughout the region during the suppressed 1995 season.

\section{(iii) The African easterly jet and African wave disturbances}

Over the North Atlantic, another notable distinction between the inactive 1997 hurricane season and the active 1995 season was a marked difference in the percentage of tropical storms and intense hurricanes that developed from African easterly waves. These disturbances typically move across western Africa between $10^{\circ}$ and $15^{\circ} \mathrm{N}$, and then propagate westward across the subtropical North Atlantic. During the peak of the hurricane season in August-September these easterly waves are in many cases the very systems that eventually intensify into tropical storms. However, the potential for this intensification is heavily influenced by two factors: the vertical wind shear (discussed in the 
previous section) and the structure/location of the lowlevel African easterly jet within which the disturbances move and evolve (Reed et al. 1977).

The easterly jet normally extends westward from western Africa to the central subtropical North Atlantic (Figs. 42a,b) and reaches peak strength between the 600 and 700-hPa levels. This jet provides the "steering flow" for the easterly waves and is an important initial energy source for these disturbances as they propagate through the cyclonic shear zone (denoted by the region of red shading) along the southern flank of the jet (Reed et al. 1977). This cyclonic shear zone is normally well defined over the eastern tropical North Atlantic and western Africa between $8^{\circ}$ and $15^{\circ} \mathrm{N}$, and overlaps the area of low vertical wind shear (Figs. $43 \mathrm{a}, \mathrm{b})$. The overlap is normally most extensive in September (Fig. 43b) during the climatological peak in the Atlantic tropical cyclone activity.

During August and September 1997, the African easterly jet was centered $2^{\circ}-3^{\circ}$ south of normal near $11^{\circ} \mathrm{N}$. The jet was also broader than normal, with an abnormally weak meridional gradient in wind speed evident along its cyclonic-shear side (Figs. 42c,d). As a result, the primary region of cyclonic vorticity was displaced to south of $10^{\circ} \mathrm{N}$ in both months, a region generally considered too far south to favor efficient tropical cyclogenesis. Also during August 1997, the jet was weaker than normal and quite diffuse over the eastern tropical North Atlantic, with a relatively small region of cyclonic vorticity present. This area of weak cyclonic vorticity was displaced well south of the region of low vertical wind shear (Fig. 43c), with almost no overlap of the two features present. In September the easterly jet and accompanying cyclonic vorticity structure were better defined and extended farther west than normal (Fig. 42d). However, the overlap region of cyclonic relative vorticity and low vertical wind shear generally remained south of $10^{\circ} \mathrm{N}$ (Fig. 43d). Also during September, the vertical wind shear was much larger than normal across the central and western North Atlantic, further precluding any significant tropical development.

In contrast, during the active August and September 1995 period the African easterly jet was well defined and centered north of normal (approximately $1^{\circ}-$ $3^{\circ}$ latitude) to between $15^{\circ}$ and $18^{\circ} \mathrm{N}$ (Figs. 42e,f). Also, there was a strong meridional gradient in zonal wind in the region immediately south of the jet core in both months, resulting in large areas of cyclonic relative vorticity covering the entire eastern North Atlantic between $10^{\circ}$ and $15^{\circ} \mathrm{N}$. These conditions con- trast with the near absence of cyclonic vorticity at these latitudes during 1997. Also, August and September 1995 featured an extensive overlap of the regions of large cyclonic relative vorticity and low vertical wind shear between $10^{\circ}$ and $15^{\circ} \mathrm{N}$ across the central and eastern North Atlantic (Figs. 43e,f), compared with no overlap of these two features in this latitude band during 1997. This favorable location and horizontal structure of the African easterly jet during August-September 1995 , combined with its proximity to the extended region of low vertical wind shear, contributed to recurring tropical cyclogenesis and intense hurricane development from easterly waves throughout the period.

\section{b. Africa}

1) October-December 1997: Equatorial East AFRICA RAINY SEASON

Tropical eastern Africa has two rainy seasons, which occur during March-May and October-December (OND). The year-to-year variability of rainfall during the OND season shows a strong relationship to the ENSO (Ropelewski and Halpert 1987, 1989), with above-normal rainfall observed during Pacific warm episodes and below-normal rainfall observed during Pacific cold episodes.

During OND 1997, record rainfall (in many areas averaging 5-10 times the normal) was observed throughout the region in association with the ongoing strong El Niño conditions. Estimated rainfall totals during the period averaged more than $600 \mathrm{~mm}$ throughout Kenya, southern Somalia, the Ethiopian Highlands, and extreme northeastern Tanzania, with local maxima exceeding $1100 \mathrm{~mm}$ in northwestern Kenya and $900 \mathrm{~mm}$ in extreme southern Kenya (Figs. $44 \mathrm{a}$ and 22). Estimated precipitation anomalies averaged more than $500 \mathrm{~mm}$ across southern Somalia and the eastern half of Kenya, with the largest anomalies exceeding $700 \mathrm{~mm}$ observed in northern Kenya (Fig. $44 \mathrm{~b})$. The seasonal precipitation totals in both regions reached the 99th percentile, suggesting record amounts for the period (Fig. 44c). For the region as a whole, area-averaged rainfall totals exceeded the 90th percentile in all three months (Fig. 44d). This excessive rainfall is in marked contrast to the drier-than-normal conditions that prevailed during the OND 1996 wet season.

Accumulated rainfall and daily rainfall totals during OND 1997 are shown for two reporting stations in Kenya (Fig. 45). Mombasa (located in extreme southeastern Kenya), and Meru (located in central Kenya) each experienced precipitation totals of more than $1500 \mathrm{~mm}$ during the period (Figs. 45a,b, respec- 

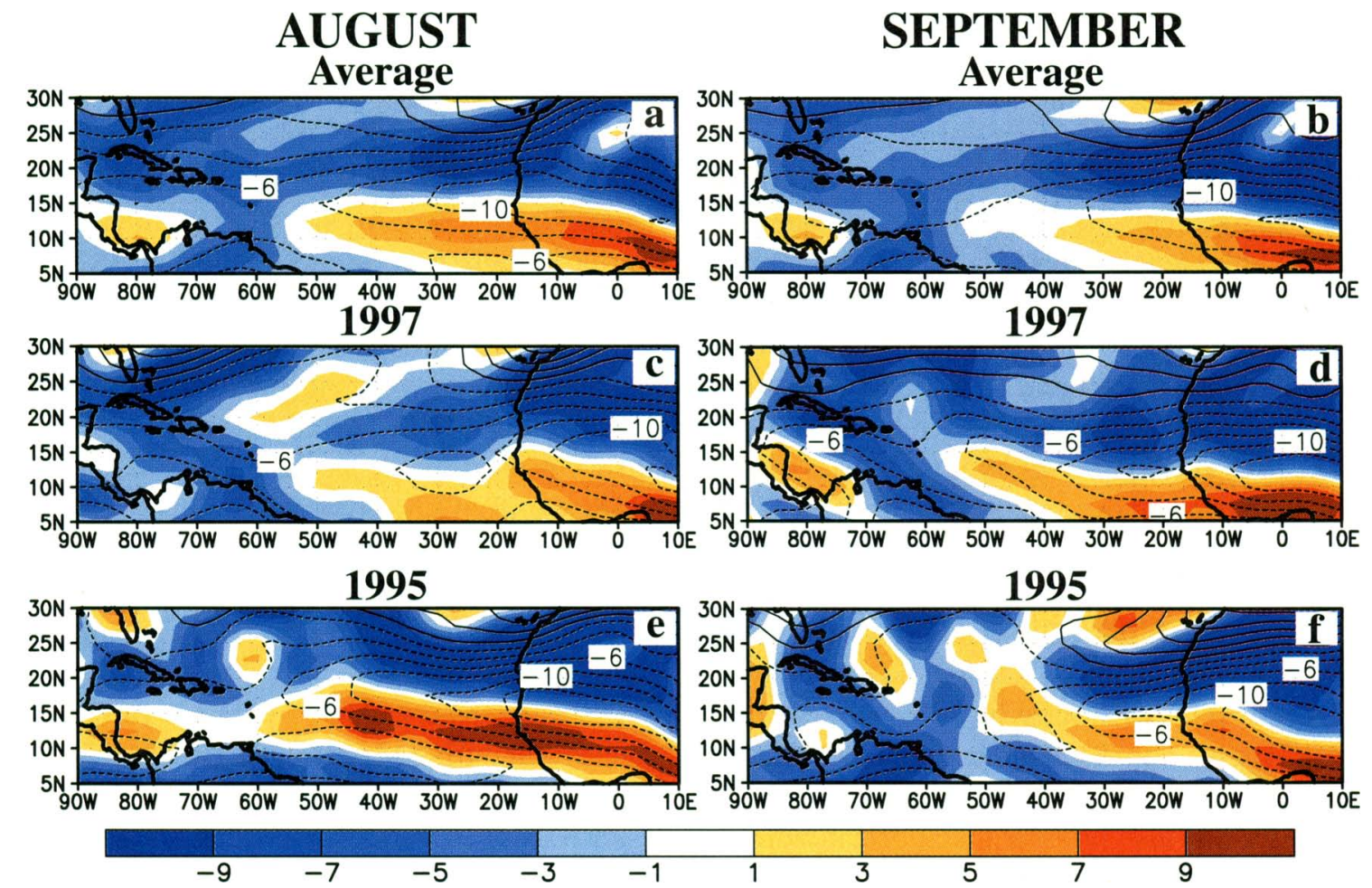

FIG. 42. August and September patterns of zonal wind (contours, interval is $2 \mathrm{~m} \mathrm{~s}^{-1}$ ) and relative vorticity (shaded, units are $10^{-6} \mathrm{~s}^{-1}$ ) at $600 \mathrm{hPa}$ during normal easterly jet conditions (a),(b), during the inactive 1997 hurricane season (c), (d), and during the active 1995 season (e),(f). Red (blue) shading indicates areas of cyclonic (anticyclonic) relative vorticity.
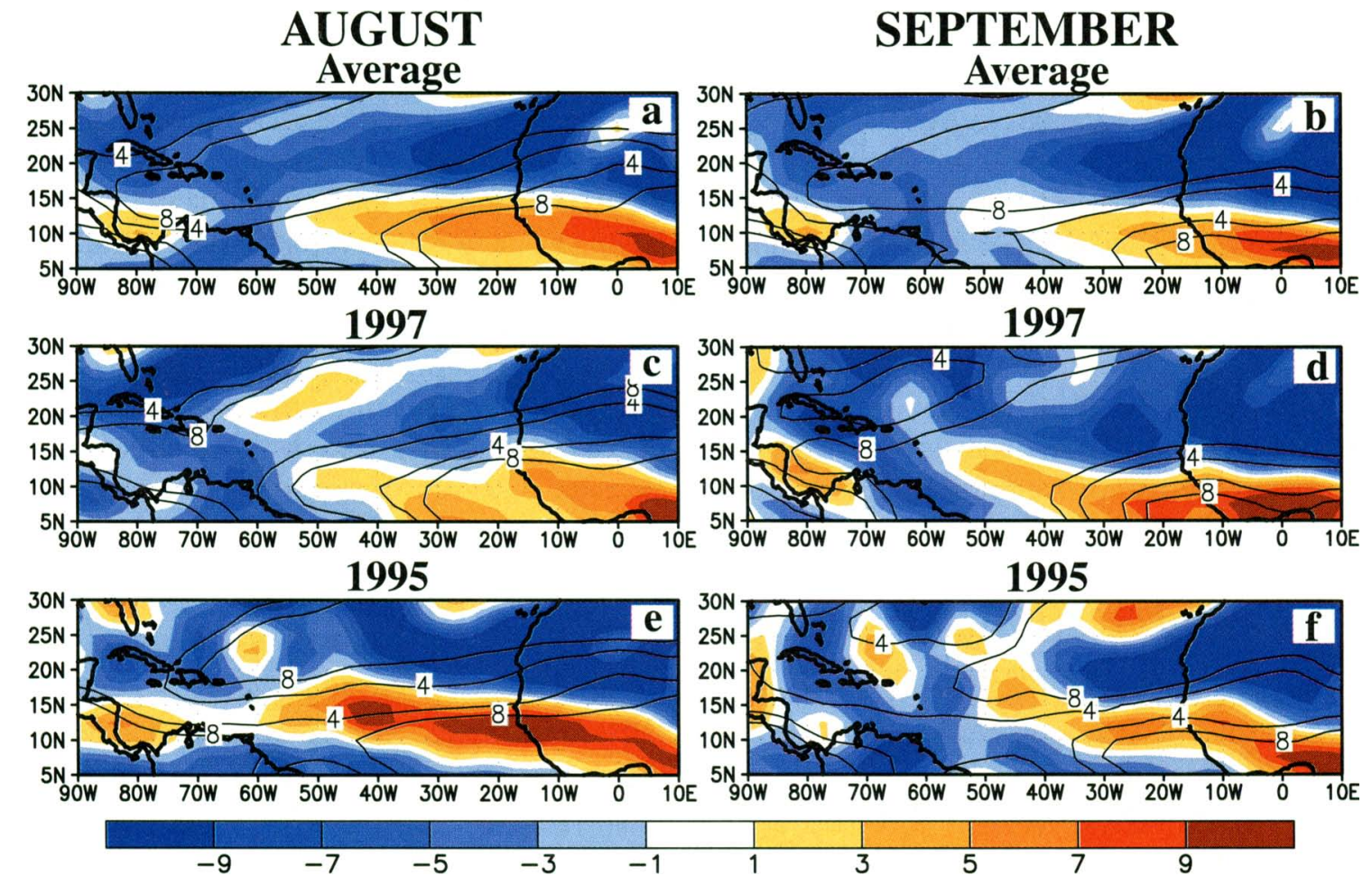

1995

FIG. 43. August and September patterns of vertical wind shear between 200 and $850 \mathrm{hPa}$ (contours for values less than the critical $8 \mathrm{~m} \mathrm{~s}^{-1}$ only, interval is $2 \mathrm{~m} \mathrm{~s}^{-1}$ ) and relative vorticity (shaded, units are $10^{-6} \mathrm{~s}^{-1}$ ) at $600 \mathrm{hPa}$ during normal easterly jet conditions (a),(b), during the inactive 1997 hurricane season (c),(d), and during the active 1995 season (e),(f). Red (blue) shading indicates areas of cyclonic (anticyclonic) relative vorticity. 

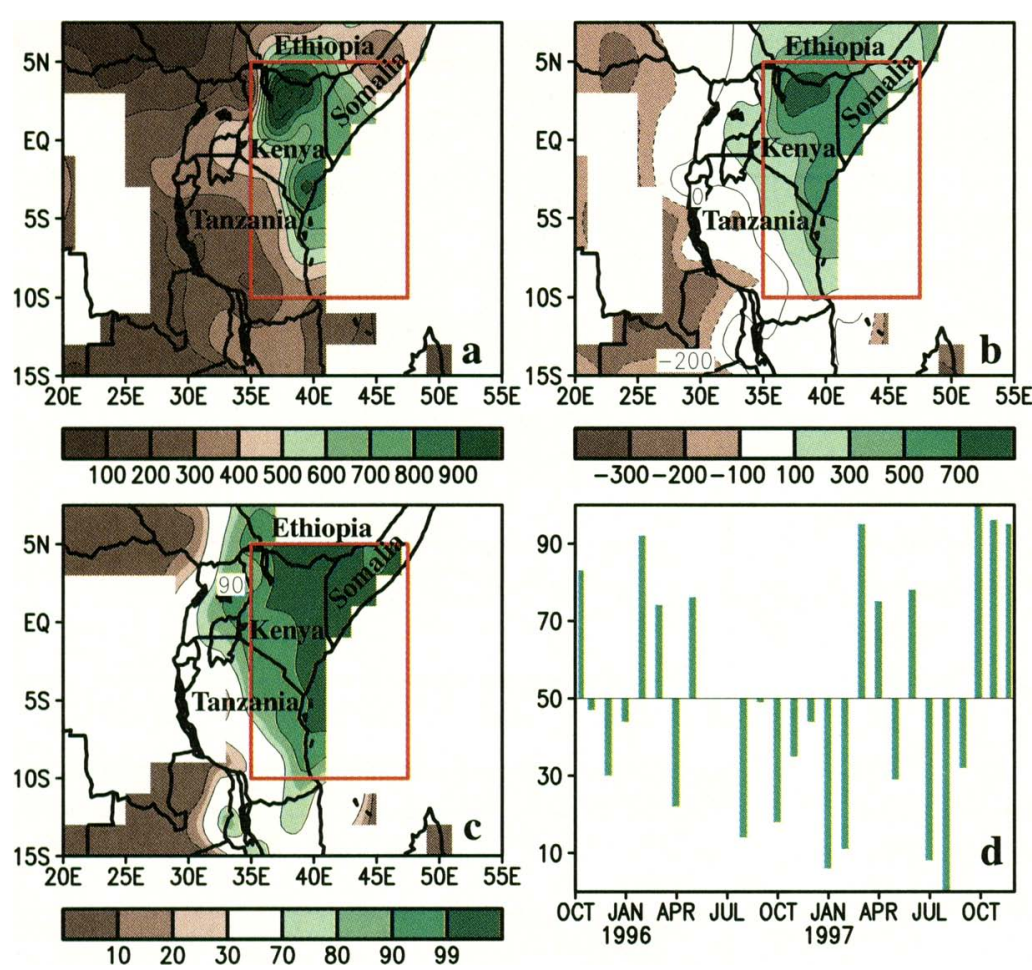

FIG. 44. October-December 1997 (a) total precipitation (mm), (b) precipitation anomalies ( $\mathrm{mm})$, and (c) precipitation percentiles based on a gamma distribution fit to the 1961-90 base period. (d) Monthly time series of precipitation percentiles, based on precipitation totals averaged over the boxed region depicted in (a)-(c).

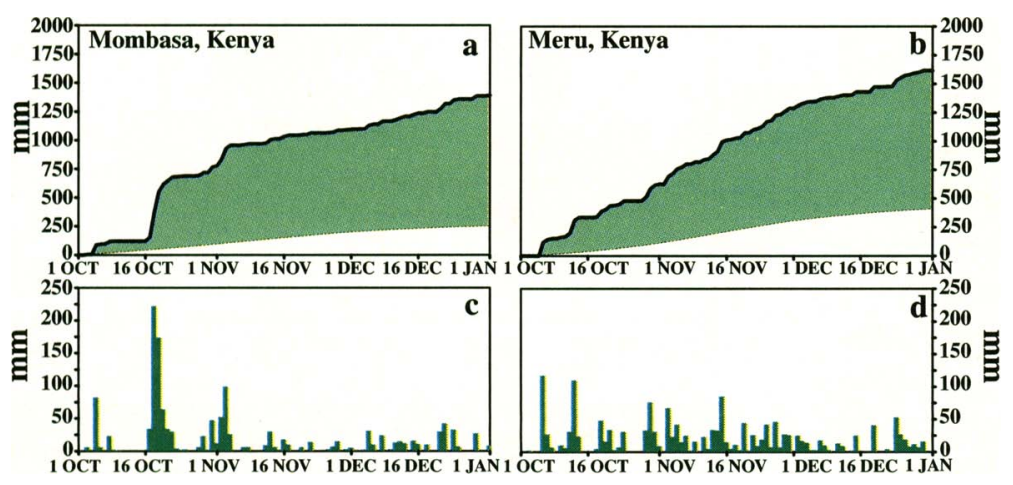

FIG. 45. (a),(b) Accumulated observed precipitation (solid curve) and accumulated climatological precipitation (1961-90 base period) (dashed curve) beginning 1 October 1997 and ending 1 January 1998 at (a) Mombasa, Kenya, and (b) Meru, Kenya. (c),(d) Daily precipitation totals during October 1997-1 January 1998 at (c) Mombasa, Kenya, and (d) Meru, Kenya. Green shading in (a),(b) indicates the difference between the observed and normal accumulated rainfall.

rains occurred from 31 October to 4 November, when totals reached $250 \mathrm{~mm}$. In addition to these extreme events, daily totals exceeded $12.5 \mathrm{~mm}$ on many days during OND, which further exacerbated conditions in the region. In Meru, totals exceeded $12.5 \mathrm{~mm}$ on 42 of the 92 days during OND. Heavier totals of $25 \mathrm{~mm}$ were observed on 26 days during the period, while totals exceeding $50 \mathrm{~mm}$ were recorded on six days.

Throughout equatorial eastern Africa, this repetitive and heavy rainfall resulted in disastrous flooding. In some areas, these conditions resulted in mass migration and destruction of property. According to the World Meteorological Organization, flooding in southern Somalia along the Juba and Shabelle Rivers claimed an estimated 2000 lives and forced hundreds of thousands of inhabitants from their homes. Extensive flooding along the Tana River in eastern Kenya also left thousands homeless and caused extensive property damage.

\section{2) OCTOBER 1996-APRIL 1997 :}

\section{SOUTHERn Africa RAINY SEASON}

The southern Africa rainy season typically lasts from October to April and reaches maximum strength between November and March. Most locations receive more than $75 \%$ of their annual rainfall during this seven-month period, with some parts in the northwest receiving more than $90 \%$ of their normal annual rainfall. The year-to-year variability in rainfall over southern Africa shows a strong relationship to the ENSO cycle (Ropelewski and Halpert 1987, 1989), with below-normal rainfall normally observed during Pacific warm episodes and above-normal rainfall observed during Pacific cold episodes.

tively), with measurable precipitation observed almost every day at both stations (Figs. $45 \mathrm{c}$,d). This compares to normal seasonal totals of approximately $250 \mathrm{~mm}$ at Mombasa and $450 \mathrm{~mm}$ at Meru. In Mombasa, the heaviest rains fell during 17-22 October, when six-day totals exceeded $500 \mathrm{~mm}$. A second period of heavy
Overall, southern Africa experienced an active and prolonged 1996/97 rainy season, with substantial rains beginning in October 1996 and continuing through July 1997 . The most abundant rains $(800-1000 \mathrm{~mm})$ fell across the climatologically wet region of eastern South Africa (not shown), with departures of 160-230 
mm observed across the region. Approximately 100 $150 \mathrm{~mm}$ of this surplus fell during the normal rainy season (Fig. 46a) with the rest $(60-80 \mathrm{~mm}$ ) falling during May-July (Fig. 46b). Southern and eastern Botswana also experienced a good rainy season, with totals averaging 500-600 $\mathrm{mm}$ throughout the region. The totals were $100-150 \mathrm{~mm}$ above normal in both areas during October-April (Fig. 46a), and 60-80 mm above normal in southeastern Botswana during MayJuly (Fig. 46b).

Elsewhere, western Zimbabwe and northeastern Namibia observed well above normal rainfall during their normal wet season, and near-normal rainfall during May-July. In contrast, precipitation was below normal across southern and eastern Mozambique during both periods, with totals averaging more than 200 $\mathrm{mm}$ below normal during October-April, and 40-80 mm during May-July. For the period as a whole, most of southern Mozambique recorded approximately $75 \%$ of normal rainfall, while most of the eastern region reported $50 \%-75 \%$ of average rainfall.

Three tropical storms contributed to the abundant rains over southeastern Africa during the 1996/97 wet season. The first of these systems, Tropical Storm Gretelle, brought heavy rainfall during January to eastern South Africa and southern Mozambique. Subsequently, Tropical Cyclones Josie and Lisette brought torrential downpours to southeastern Africa, and triggered extensive flooding in central and northern Mozambique.

The time series of area-averaged monthly mean rainfall for the boxed region $\left(18^{\circ}-33^{\circ} \mathrm{S}, 20^{\circ}-35^{\circ} \mathrm{E}\right)$ shown in Figs. 46a,b indicates that totals were above the 70th percentile in all months between October 1996 and July 1997, except for December and February (Fig. 47). In fact, February was the only month in which rainfall was substantially below normal during the season, as indicated by a drop in the area-mean value to the 15 th percentile.

During the subsequent 1997/98 wet season, rainfall was normal to above normal during October and November. However, totals were substantially below normal during December 1997 (Fig. 47), with almost no precipitation observed in parts of southern Mozambique, Zimbabwe, and eastern South Africa. This dryness is consistent with strong El Niño conditions

\section{3) June-SePtember 1997: Western Africa Rainy SEASON}

The Sahel region (bounded by $8^{\circ}-18^{\circ} \mathrm{N}, 17^{\circ} \mathrm{W}-$ $20^{\circ} \mathrm{E}$ and indicated by the boxed region in Fig. 48) re-
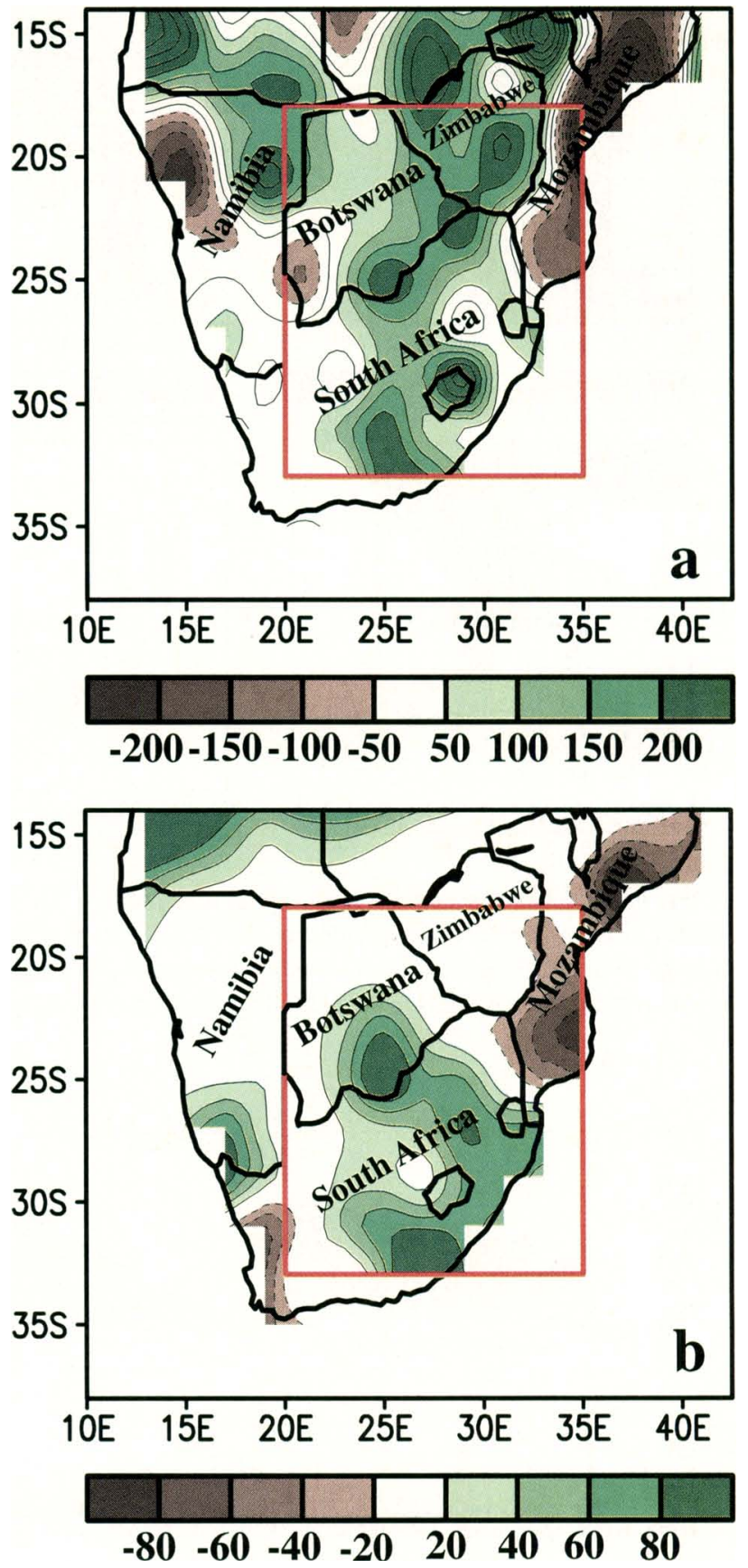

FIG. 46. (a) October 1996-April 1997 precipitation anomalies (mm) and (b) May-July 1997 precipitation anomalies (mm). Anomalies are departures from the $1961-90$ base period means.

ceives approximately $90 \%$ of its mean annual rainfall during the June-September period. This rainfall is closely related to the north-south movement of the ITCZ, which begins its northward movement in March and reaches its northernmost position (near $15^{\circ} \mathrm{N}$ ) in August. Rainfall during the wet season varies widely throughout the region, with the lowest to- 
tals of 100-300 mm observed in the north and the highest totals of $1300 \mathrm{~mm}$ and $800 \mathrm{~mm}$ observed in the southwestern and southeastern quadrants, respectively. Overall, the Sahel experienced a shortened and substantially below normal rainy season during 1997 (Fig. 48), with most of the rainfall deficits observed across the southern half of the region during July-September (Fig. 48b).

The season began with heavy rains during June across the northern half of the Sahel and across the Gulf of Guinea region (not shown). However, this beneficial rain was short lived, with July-September totals falling significantly below normal across the southern two-thirds of the Sahel (Fig. 48b). During July-September, the largest rainfall totals were observed in the climatologically wet region of the southwest, where totals ranged from 500 to $700 \mathrm{~mm}$ (Fig. 48a). However, these totals were $300-700 \mathrm{~mm}$ below normal (Fig. 48b), and in some areas were less than one-half the climatological mean. Farther east, JulySeptember totals averaged $300-500 \mathrm{~mm}$ across the heavy rainfall regions of the south-central and southeastern Sahel. These amounts were also significantly below normal, with deficits ranging from 100-200 $\mathrm{mm}$ in the central and south-central Sahel sectors to $200-400 \mathrm{~mm}$ in the southeast.

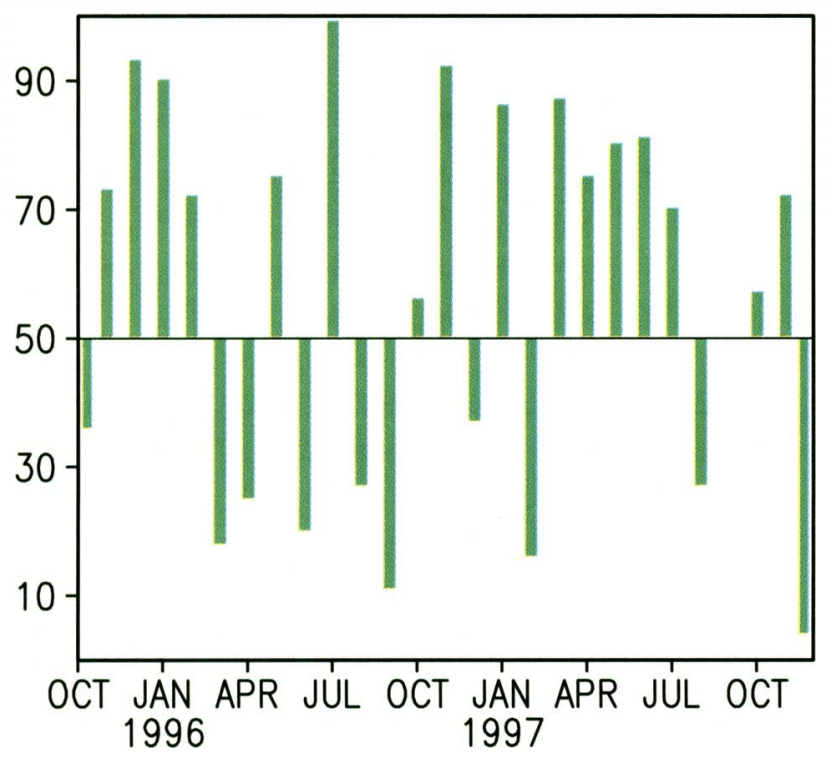

FIG. 47. Southern Africa monthly time series of precipitation percentiles based on a gamma distribution fit to the 1961-90 base period, calculated from precipitation totals averaged over the boxed region depicted in Fig. 46. c. Asia

1) INDIAN SUMMER MONSOON

The Indian summer monsoon typically lasts from June through September. During this period large areas of western and central India receive more than $90 \%$ of their total annual rainfall, while southern and northwestern India receive $50 \%-75 \%$ of their total annual rainfall. Overall, monthly rainfall totals average 200$300 \mathrm{~mm}$, with the largest values observed during the heart of the monsoon season in July and August.

According to the India Meteorological Department there was a slightly delayed onset to the 1997 monsoon season, with heavy rains beginning approximately one week later than normal. However, the monsoon covered most of the country by 19 July, only four days later than normal. This delay contrasts with conditions observed during 1996, when the monsoon rains covered India by 30 June, two weeks earlier than normal. Overall, area-averaged rainfall was slightly above normal during June-August (Fig. 49c) and slightly below normal in September.
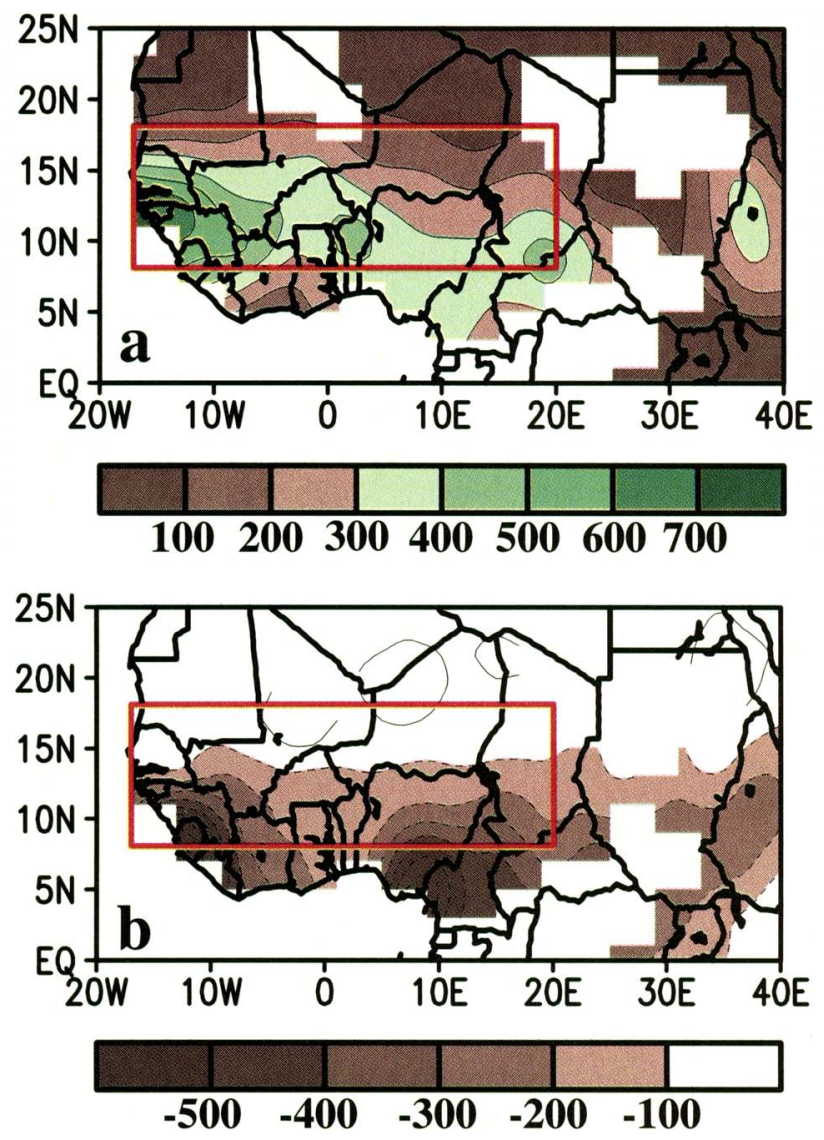

FIG. 48. July-September 1997 (a) total precipitation (mm) and (b) anomalies ( $\mathrm{mm}$ ) for the African Sahel region. The boxed region denotes the approximate boundaries of the African Sahel region. 
Regionally, the 1997 season featured abundant rains (1200-1600 $\mathrm{mm}$ ) in the typically heavy rainfall area of western India (Figs. 49a), which is $200-600 \mathrm{~mm}$ above the long-term mean (Fig. 49b). Elsewhere, rainfall was near normal over most of India, with below-normal totals confined to portions of the central and north-central sections. In northern India, beneficial rains were sometimes associated with strong midlatitude westerly disturbances moving across the region. These rains brought totals to near normal for the season as a whole, despite a weaker than normal and highly variable monsoon circulation during much of the period.

An extremely important component of the monsoon circulation is the upper-level $(200 \mathrm{hPa})$ monsoon ridge, which normally extends from the Middle East eastward to southeastern Asia at approximately $27.5^{\circ} \mathrm{N}$ (Fig. 50). This monsoon ridge normally develops during June and reaches full strength in July and August. Accompanying this evolution is a pronounced shift of the midlatitude westerly winds from south to north of the Tibetan Plateau by mid-June. During 1997 the anomalous monsoon circulation was apparent in both the upper-level monsoon ridge and the midlatitude westerlies (not shown), which exhibited substantial daily and weekly variability in their location and magnitude. This variability is summarized using a daily time-longitude section of upper-level relative vorticity centered on $30^{\circ} \mathrm{N}$ (Fig. 51).

In this analysis, large cyclonic relative vorticity anomalies over northern India indicate a weakening of the monsoon ridge, along with a southward shift of the mean westerly winds and strong westerly disturbances. The 1997 season featured several prolonged periods in which anomalous cyclonic relative vorticity prevailed over northern India (approximately $70^{\circ}-$ $90^{\circ} \mathrm{E}$ ), including the June through mid-July period when these conditions were evident nearly $50 \%$ of the time. During this period, there was a substantial impact on the northern part of the monsoon region from midlatitude westerly disturbances.

A more detailed analysis for the period indicates

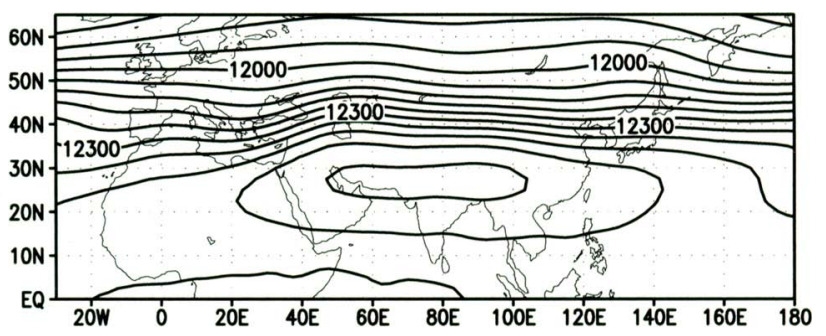

FIG. 50. June-August climatological mean 200-hPa geopotential height field $(\mathrm{m})$ calculated for the $1979-95$ period. Contour interval is $60 \mathrm{~m}$.

that during the first two weeks of June the monsoon ridge was displaced far southeastward from normal and was nearly absent across northern India (Fig. 52a). Large-scale midlatitude troughs were located along the western and eastern flanks of the ridge, with strong westerly geostrophic winds found across northern India and most of southern Asia. Thus, much of subtropical Asia was affected by extratropical flow features during this period.

During mid-July, there was a marked retraction in the eastward extent of the monsoon ridge, as well as a westward shift of the mean ridge axis to the area just 


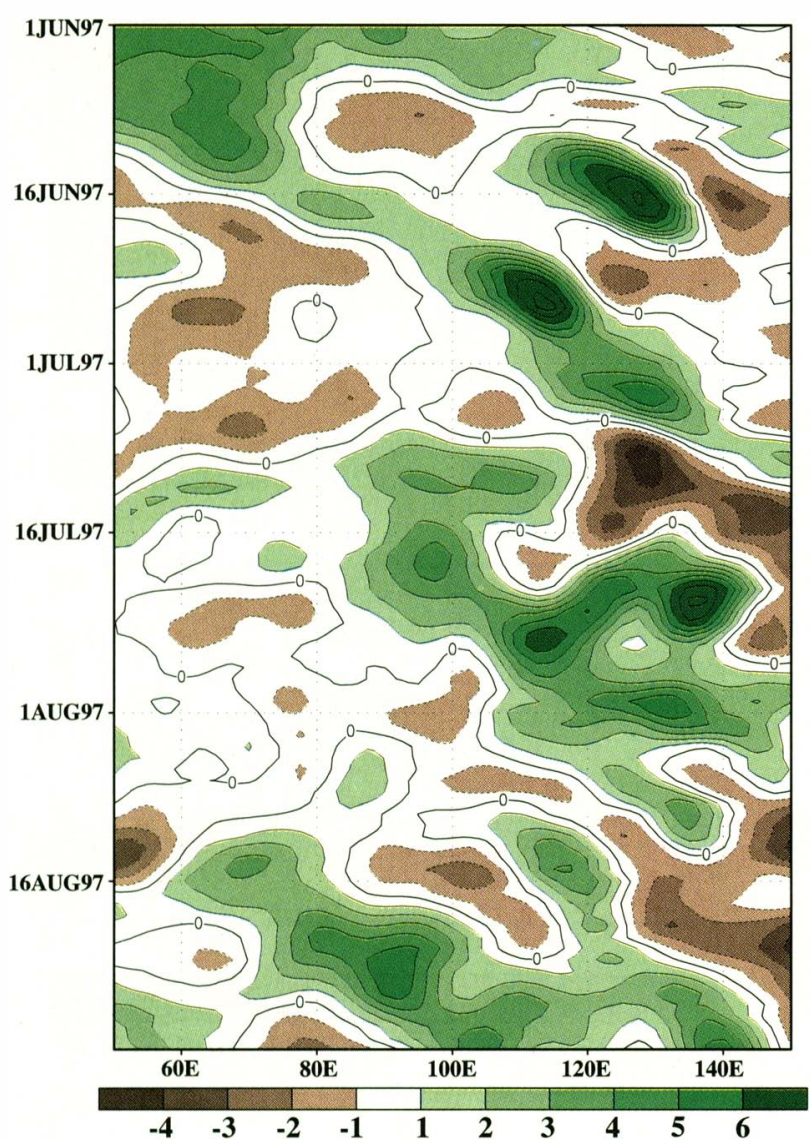

FIG. 51. Time-longitude section at $30^{\circ} \mathrm{N}$ of anomalous $200-$ $\mathrm{hPa}$ relative vorticity 1 June-31 August 1997 . Units are $1 \times$ $10^{-5} \mathrm{~s}^{-1}$. A five-day running mean smoother has been applied to the data. Anomalies are departures from the $1979-95$ base period daily means.

south of the Caspian Sea (Fig. 52b). This highly anomalous monsoon ridge was associated with a largeamplitude wave pattern extending from the Middle East to eastern Asia.

During late July the monsoon ridge became better defined across India (Fig. 52c), but remained ill defined across southeastern Asia. This flow pattern also suggested a continued substantial impact from extratropical disturbances on the large-scale monsoon circulation. These conditions finally lessened during August as the monsoon ridge became better defined.

\section{2) Southeastern Asia}

Rainfall across southeastern Asia is also monsoonal in nature, with the largest totals typically observed during May-September (Fig. 49d). Area-average totals normally reach $200 \mathrm{~mm}$ in each of these months, with seasonal totals of $1000 \mathrm{~mm}$ commonly observed. During 1997, seasonal rainfall totals averaged 1300-1500
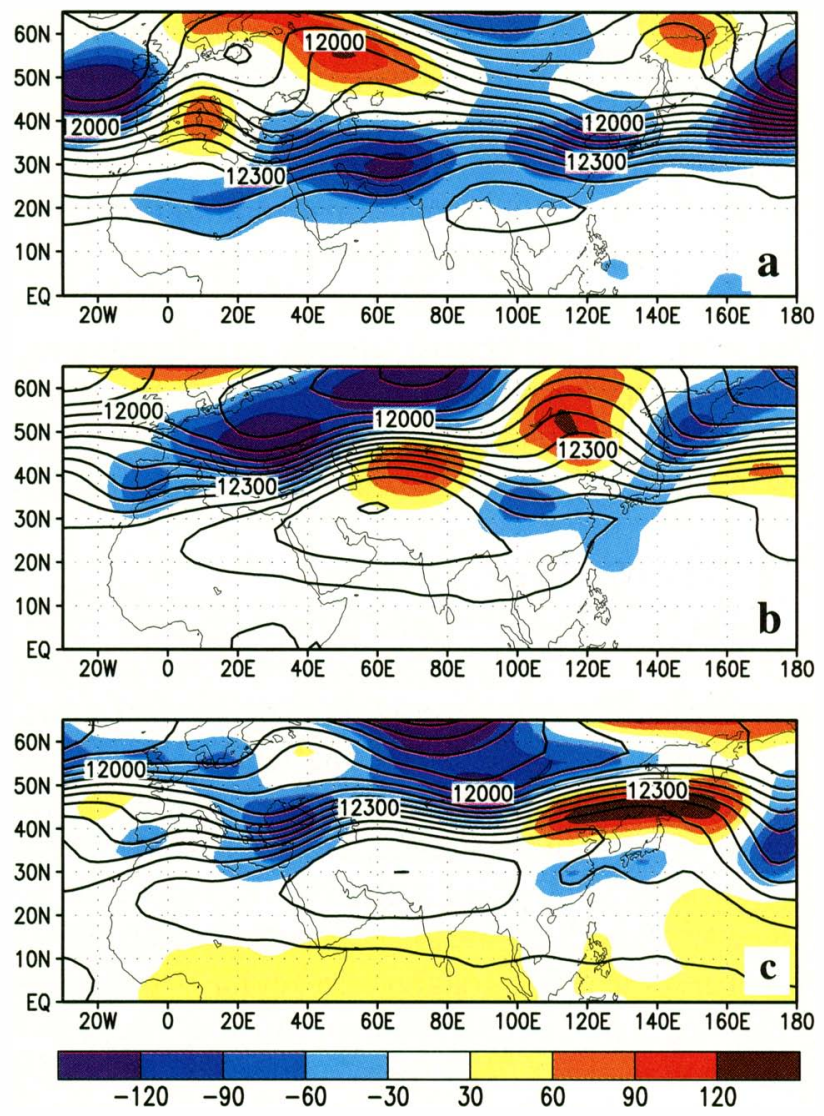

FIG. 52. The 200-hPa geopotential height (contours, units are $\mathrm{m}$ ) and anomalies (shaded) for (a) 1-16 June, (b) 10-21 July, and (c) 22-30 July 1997. Anomalies are departures from the 197995 base period daily means.

$\mathrm{mm}$ throughout the region (not shown). Most of this enhanced rainfall occurred during June-August, with area-averaged totals reaching $250 \mathrm{~mm}$ in June and 300 $\mathrm{mm}$ in July and August. In Hong Kong, monthly rainfall totals reached $700 \mathrm{~mm}$ during June, July, and August, with the three-month total exceeding $2400 \mathrm{~mm}$. This value is more the 2.2 times the average rainfall expected in that region for the period.

During June and July, the very large rainfall totals across southeastern Asia were related to an increased frequency of westerly wave disturbances, in association with the much weaker than average upper-level monsoon ridge (Figs. 51 and 52). For example, during 1-16 June when the monsoon ridge was extremely suppressed (Fig. 52a), Hong Kong received over 600 $\mathrm{mm}$ of rain compared to a mean of $200 \mathrm{~mm}$. Similarly during 10-21 July when the subtropical ridge axis was retracted to west of India (Fig. 52b), Hong Kong received almost $400 \mathrm{~mm}$ of rain compared to a mean of 
just over $100 \mathrm{~mm}$. Subsequently, rainfall was below average at Hong Kong during 22-30 July as the subtropical ridge extended eastward across southeastern Asia (Fig. 52c).

During August, above-normal rainfall continued across southeastern Asia, primarily in response to five tropical cyclones that moved across the region. Four of these systems affected southeastern China and one affected extreme southern China near Hong Kong. These systems brought flooding to much of the area, particularly in coastal southeastern China.

\section{d. Europe: Cold winter, wet summer}

Most of Europe recorded substantially below average precipitation early in the year (Fig. 53c), followed by substantially above average rainfall during the summer months (Figs. 53b,c). During January, the abnormally dry conditions were accompanied by excessive cold from England to Poland. This cold was linked to a high-latitude blocking pattern across the North Atlantic and Scandinavia, along with significantly diminished onshore flow throughout the region. During February much milder temperatures and very heavy precipitation returned to northern Europe, in association with a temporary reprieve from blocking activity and a return to strong onshore flow across the region.

The May-August period featured well above normal rainfall throughout Europe (Fig. 53b), much of which fell as a series of strong extratropical disturbances embedded within a very active low-latitude westerly flow affected the region (see section 5, Fig. 72). The largest totals during the period (exceeding $400 \mathrm{~mm}$ ) were observed across central Europe, the Czech Republic, and Poland (Fig. 53a). Totals also averaged $250-350 \mathrm{~mm}$ across western Europe and exceeded $200 \mathrm{~mm}$ over western Scandinavia.

The most substantial rainfall occurred in July, when regional totals averaged $200 \%-450 \%$ of normal over the eastern half of the Czech Republic, most of central and southern Poland, and portions of central Austria (Fig. 54). These excessive rains led to the "flood of the century" in the Czech Republic, and to significant flooding of the Oder River in Poland and eastern Germany. These floods resulted in more than 100 deaths and forced evacuations of more than 150000 people.

The floods resulted from two periods of very heavy rainfall: 4-7 July and 18-21 July. The first period featured excessive rainfall totals, which in some areas were $2-3$ times higher than the normal July total. This heavy rainfall was linked to a large-amplitude cyclonic
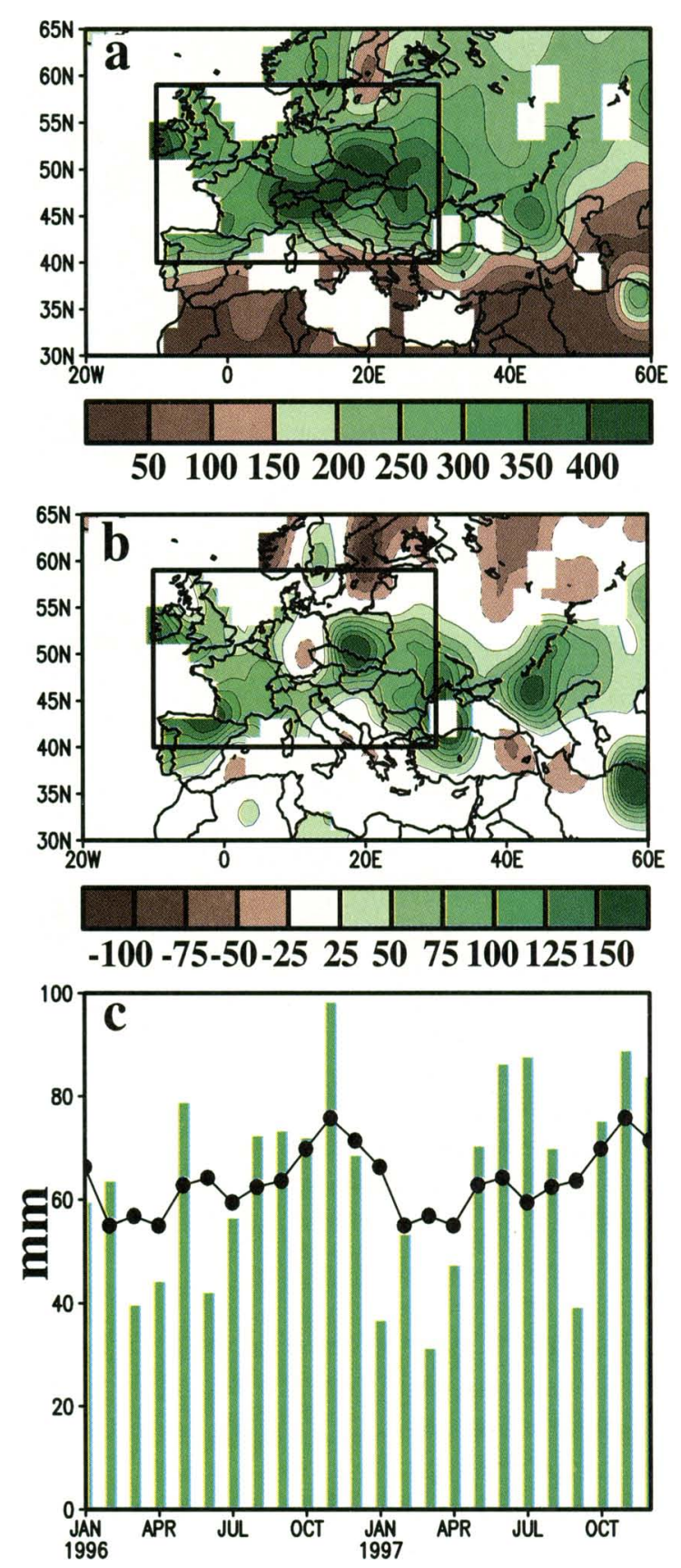

FIG. 53. (a) Total precipitation ( $\mathrm{mm})$, (b) precipitation anomalies (mm) for May-August 1997, and (c) monthly time series of total precipitation (mm, bars) and the 1961-90 mean ( $\mathrm{mm}$, line) averaged over the boxed region in (a),(b).

disturbance located immediately downstream of a blocking anticyclone (Fig. 55a).

This first period of heavy rainfall initiated flooding throughout the northern portions of the Oder River. However, the flood waters had not yet crested along the lower Oder River when, only two weeks later, another period of extremely heavy rainfall occurred. The 


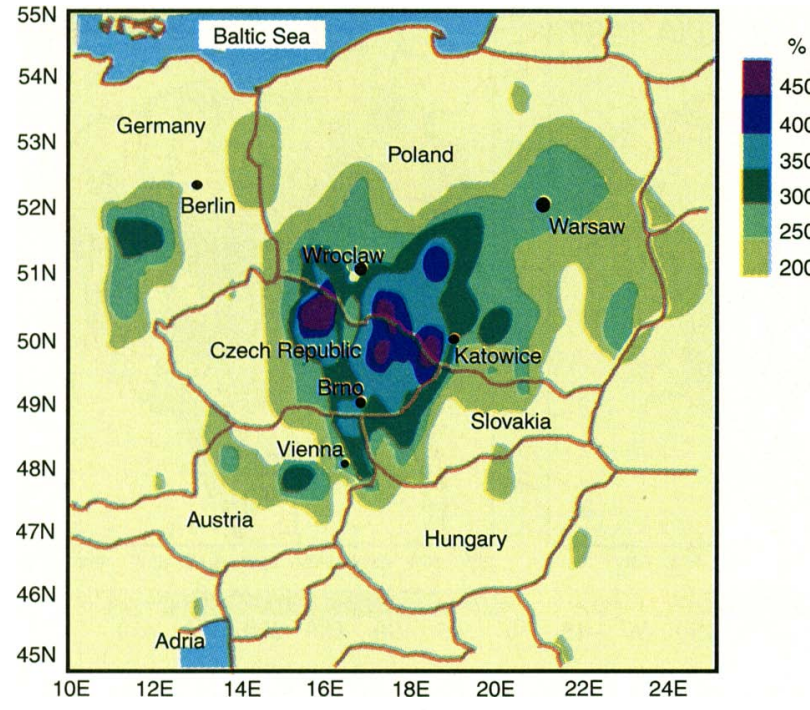

Fig. 54. July 1997 percent of normal rainfall relative to the 1961-90 base period means. (Source: Deutscher Wetterdienst, Hamburg, Germany).

resulting floods devastated thousands of homes and destroyed many dikes along the river's edge. Also during this period, excessive rains fell in the mountainous areas of Poland and the Czech Republic, with totals in many places reaching more than four times the normal monthly mean. This heavy rainfall was also linked to a very strong upper-level trough amplification and cyclogenesis in the region immediately downstream of a blocking anticyclone (Fig. 55b).

\section{e. South America}

The climate over large parts of South America is strongly influenced by the El Niño-Southern Oscillation. During warm episodes, drier-than-normal conditions are generally observed across northeastern South America during July-March, while enhanced precipitation tends to be observed throughout southeastern South America during November-February (Ropelewski and Halpert 1987), and throughout central Chile during the austral winter (Aceituno 1988). Also, above-average temperatures are typically observed along the west coast of South America from May to April (Halpert and Ropelewski 1992). During the very strong 1997 warm episode, all of these conditions were prominent aspects of the South American climate.

\section{1) BRAZIL WINTER AND SPRING HighlightS}

Precipitation was below normal across northern Brazil and parts of the Amazon Basin during June-
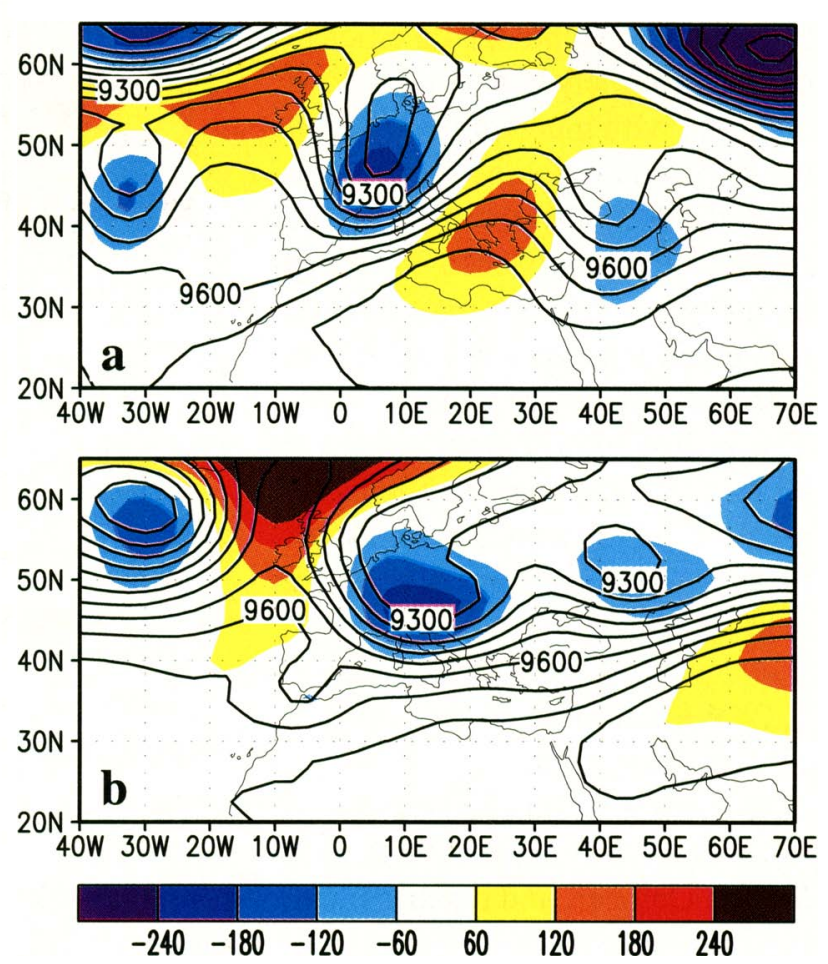

FIG. 55. The 300-hPa geopotential height (contours, units are m) and anomalies (shaded) for (a) 5 July and (b) 19 July 1997. Anomalies are departures from the $1979-95$ base period daily means.

November (Fig. 56), with accumulated seasonal deficits of 90-180 mm recorded throughout the Amazon during both seasons. Over northern Brazil, deficits of 180-360 mm were recorded during JJA (Fig. 56a), with smaller deficits observed during SON (Fig. 56b). These conditions caused a reduction in the level of many rivers throughout the region, which impacted the generation of hydroelectric power in the northern states of Brazil. The dryness was linked to anomalous large-scale subsidence, in association with a weakened upper-level anticyclonic circulation (Figs. 27c,d) and with a reduced low-level inflow of warm, moist air into the region.

In contrast, southern Brazil experienced well above normal precipitation during both JJA (Fig. 56a) and SON (Fig. 56b). Seasonal surpluses of 90-270 mm covered southern Brazil during JJA with larger anomalies up to $540 \mathrm{~mm}$ recorded during SON. During October, much of the heavy rainfall was associated with intense mesoscale convective systems triggered by extratropical frontal systems moving through the region. Time series of daily October precipitation are shown for two cities (Cruz Alta and Campos Novos) in the southern part of Brazil (Fig. 57). For 
the month as a whole, both cities recorded extremely large totals of over $500 \mathrm{~mm}$, with much of the rain falling during two distinct periods: 916 and 29-31 October. In the first period, totals approached $300 \mathrm{~mm}$ in both cities, while in the second period totals reached $130 \mathrm{~mm}$ at Cruz Alta and $180 \mathrm{~mm}$ at Campos Novos. These downpours were linked to larger-scale convective systems and resulted in numerous rivers overflowing their banks and flooding in many cities.

\section{2) WINTER PRECIPITATION IN CENTRAl ChILE}
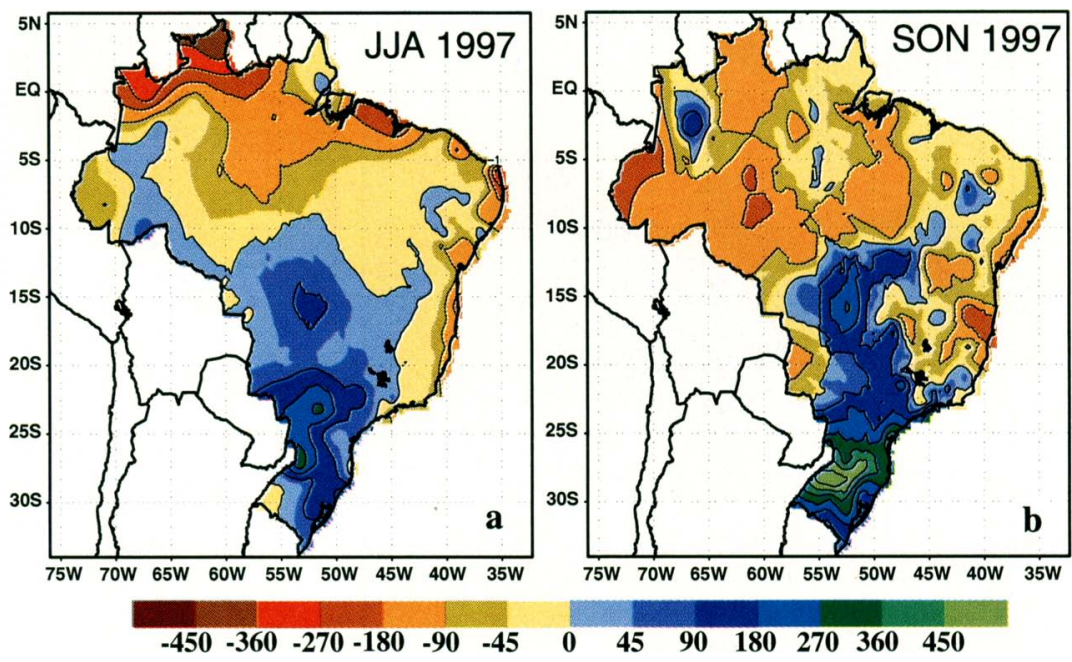

FIG. 56. Precipitation anomalies for (a) JJA 1997 and (b) SON 1997. Anomalies are departures from the 1961-90 base period means. [Source: CPTEC.]

In central Chile $\left(30^{\circ}-40^{\circ} \mathrm{S}\right)$, the rainy season typically lasts from May to October, and reaches maximum strength during June-July. Most of the region normally receives more than $75 \%$ of its annual rainfall during this rainy season, with totals in the north typically reaching $200-$ $300 \mathrm{~mm}$ and totals in the south exceeding $800 \mathrm{~mm}$ (Fig. 58a). During May-October 1997, precipitation totals ranged from $300-400 \mathrm{~mm}$ in the north to 900 $1000 \mathrm{~mm}$ in the south (Fig. 58b), averaging 100-300 $\mathrm{mm}$ above normal throughout the region (Fig. 58c). The area-mean precipitation was above average during every month except August, with 200\% of normal recorded across the region during June.

This above-normal precipitation contrasts with the 1996 season, when totals were substantially below average (Fig. 58d). This strong interannual variability of precipitation was linked to the extratropical atmospheric response to opposite extremes of the ENSO. During the 1997 season, the El Niño-related precipitation surpluses were linked to increased storminess from extratropical weather systems, in response to an abnormally strong South Pacific jet stream that was extended well east of normal [see section 3a(4)].

This link during 1997 between the increased precipitation and increased storminess is evident in the time series showing accumulated rainfall and daily rainfall at Santiago, Chile (Fig. 59). Santiago received nearly $700 \mathrm{~mm}$ of precipitation during May-October 1997, compared to a climatological mean of $290 \mathrm{~mm}$ (Fig. 59a). Nearly half of this total rainfall was observed during late May and June (Fig. 59b), when five major winter storms affected the region. This excessive precipitation resulted in flooding and led to large
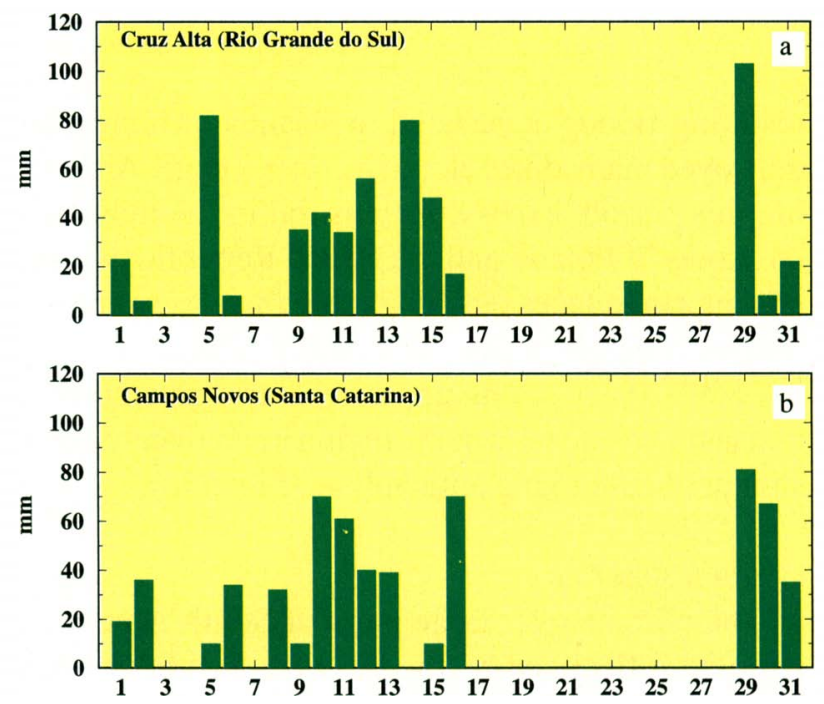

FIG. 57. Observed daily precipitation $(\mathrm{mm})$ during October 1997 for (a) Cruz Alta and (b) Campos Novos, both in southern Brazil. [Source: CPTEC.]

agricultural losses. Thereafter precipitation was substantial but more episodic, and again linked directly to major storm systems moving across the region. In fact, precipitation totals during August-October reached $240 \mathrm{~mm}$, which was $300 \%$ of normal for the period.

\section{3) Northwestern Peru warmth}

Surface air temperatures in northwestern coastal Peru and western coastal Ecuador exhibit a well-defined annual cycle that is controlled by the SSTs over 

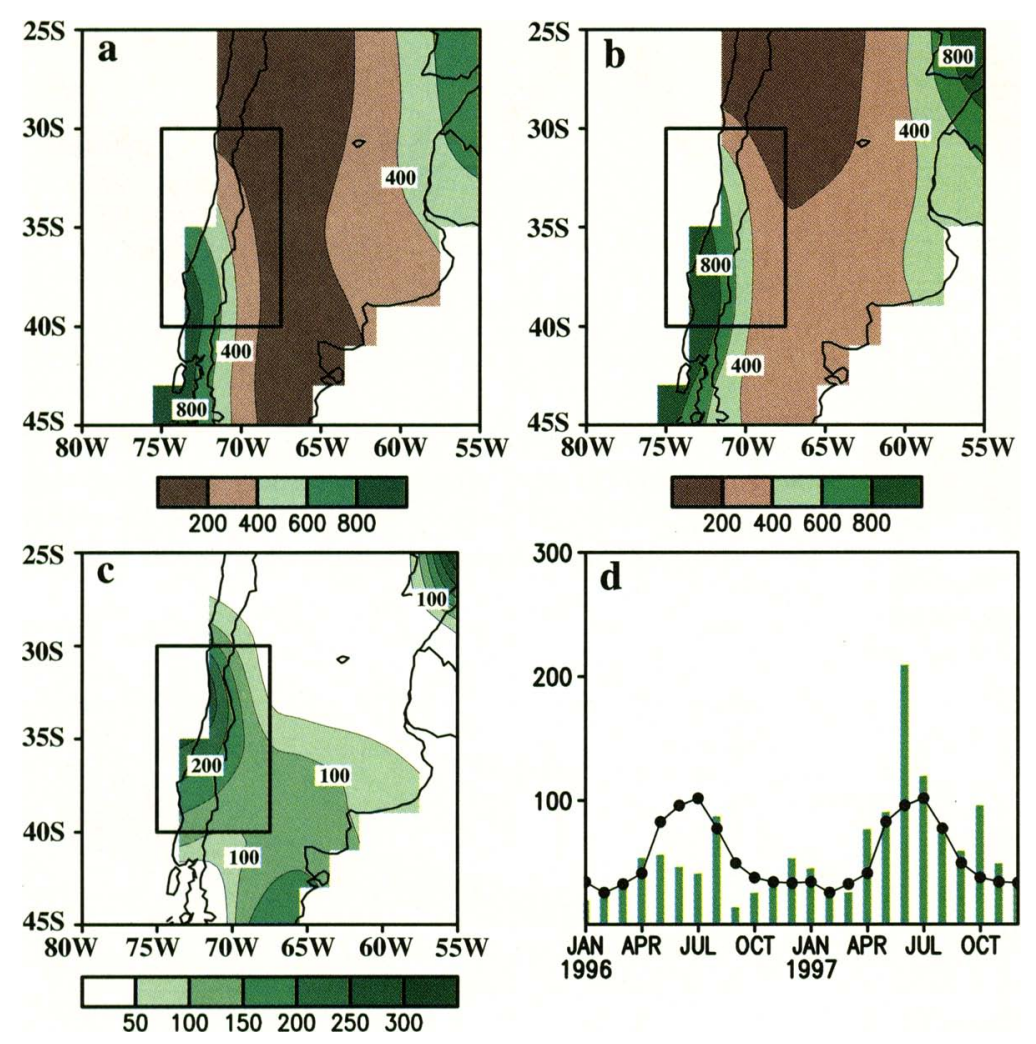

FIG. 58. May-October 1997 (a) average precipitation (mm), (b) total precipitation, (c) precipitation anomalies ( $\mathrm{mm}$ ), and (d) monthly time series of total precipitation (mm, bars) and the 1961-90 mean ( $\mathrm{mm}$, line) averaged over the boxed region in (a)-(c).
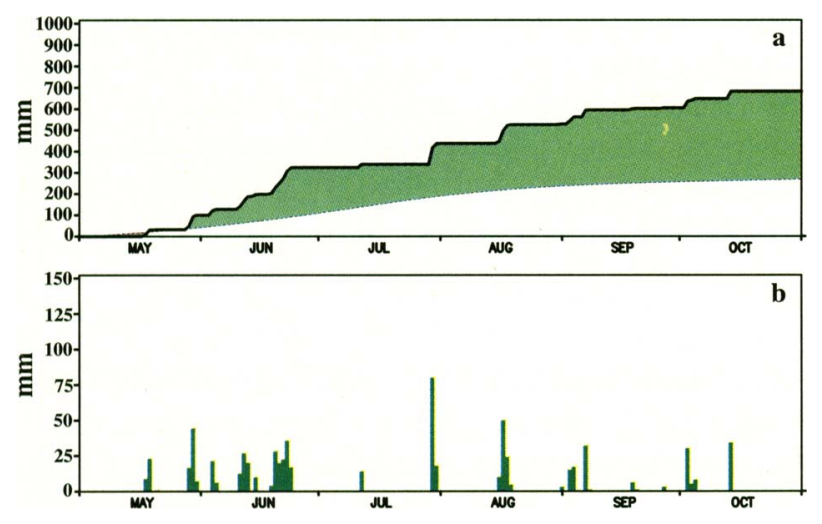

Fig. 59. Daily rainfall $(\mathrm{mm})$ at Santiago, Chile, during MayOctober 1997: (a) accumulated observed (thick line) and accumulated normal (1961-90 base period), and (b) observed daily total. Shading in (a) shows the accumulated departure from normal, with green shading indicating positive departures.

the extreme eastern Pacific. This annual cycle exhibits an August-October minimum and a March-April maximum. Interannual variations in surface temperature throughout the region are strongly controlled by the ENSO, with warmer (colder) than normal condi- tions observed during Pacific warm (cold) episodes.

During 1997, record or near-record warmth prevailed from May through December over most of the region, with temperatures averaging $3^{\circ}-6^{\circ} \mathrm{C}$ above average during the period. At Talara, Peru (Fig. 60a), daily mean temperatures averaged $26^{\circ}-28^{\circ} \mathrm{C}$ from April through December 1997, with almost no annual cycle evident. In effect, the region did not experience a cool season during 1997. These conditions are consistent with the greatly reduced annual cycle in SSTs over the eastern equatorial Pacific (see Fig. 24a) in response to very strong El Niño conditions. During this period, temperatures averaged $6^{\circ}-7^{\circ} \mathrm{C}$ above normal on most days (Fig. 60b), which set new monthly mean temperature records in every month from May through December.

\section{f. Indonesia/New Guinea}

In Indonesia, area-average rainfall totals normally range from 180 to $280 \mathrm{~mm}$ per month throughout the year (Fig. 61). The larger totals are normally observed during October-January when the primary region of tropical convection is centered on the equator. The smaller totals are typically observed during June-September as the tropical convection shifts northward to the Indian subcontinent and southeastern Asia. Rainfall across Indonesia is strongly modulated by ENSO, with above- (below-) normal rains occurring during Pacific cold (warm) episodes. This ENSO-related interannual variability is consistent with the enhanced (suppressed) equatorial Walker circulation typical of Pacific cold (warm) episodes.

During 1997 rainfall across Indonesia from March through December was significantly below average, with area-averaged totals less than $50 \%$ of normal throughout the period. For the region as a whole, the estimated total area-averaged rainfall during MarchDecember was $1145 \mathrm{~mm}$, compared to the mean of $2215 \mathrm{~mm}$. These very dry conditions were linked to the onset of El Niño conditions during March, and to the subsequent persistence of strong warm episode conditions during the remainder of the year.

The most significant dryness occurred during JuneNovember, when area-averaged totals reached only $30 \%-40 \%$ of normal. This below-average rainfall re- 

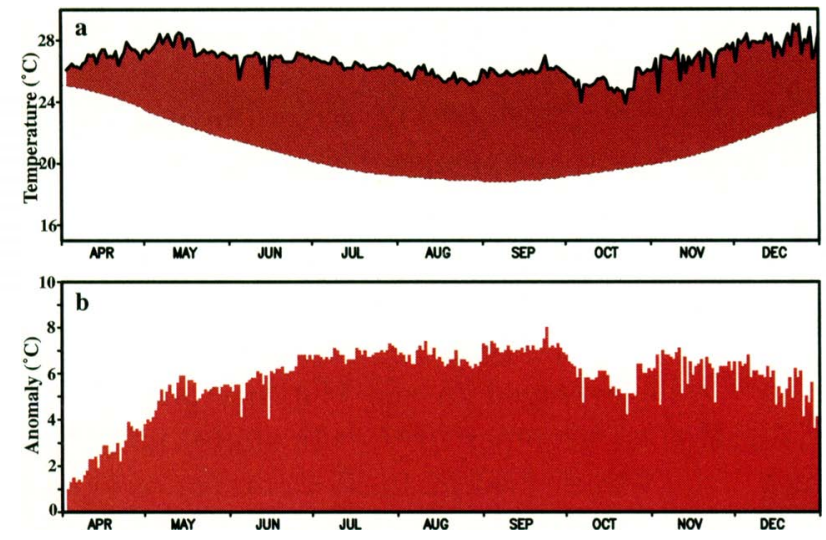

Fig. 60. Surface temperatures $\left({ }^{\circ} \mathrm{C}\right)$ at Talara, Peru, from 1 April-31 December 1997: (a) mean daily temperature (thick solid curve) and daily means (thin curve), and (b) anomalies. Anomalies are departures from the $1961-90$ base period means.

flected the previously noted dramatic shift of heavy tropical rainfall from Indonesia to the eastern half of the equatorial Pacific (see section 3a). By July and $\mathrm{Au}-$ gust drought conditions and continued well below normal rainfall contributed to vast uncontrolled wild fires in Sumatra and Borneo. Although dry-season burning takes place each year to clear land for planting crops, these fires during 1997 quickly created an ecological disaster as they burned out of control due to large-scale drought. By mid-August large areas of tropical rain forest were completely engulfed. In the following three months, uncontrolled fires destroyed massive areas of tropical rain forest and killed countless thousands of animals and other rain forest creatures. Vast areas of smoke from the fires reduced visibility at times to less than $100 \mathrm{~m}$, and caused serious respiratory problems hundreds of kilometers away from the smoke sources. The smoke also hindered, and sometimes completely stopped, traffic by land, sea, and air, and was a primary factor in several serious accidents.

At Menado, Celebes, total rainfall during the AprilDecember period only reached $1200 \mathrm{~mm}$, compared to a normal accumulation of $2100 \mathrm{~mm}$ (Fig. 62a). There were two prolonged periods in which no rainfall was observed. The first period of complete dryness lasted 45 days between mid-May and the end of June. The second period lasted an incredible 81 days from early July through the end of September. The time series of daily rainfall at Padana Tabing, Sumatra (Fig. 63), shows similar severe rainfall deficits, with many prolonged periods of dryness evident. In fact, daily rainfall totals at this location exceeded $25 \mathrm{~mm}$ on only

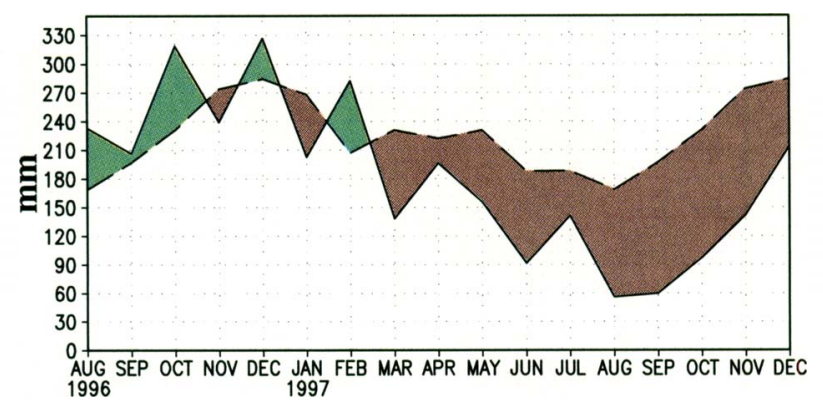

FIG. 61. Area-averaged monthly mean observed rainfall (solid line, $\mathrm{mm}$ ) and climatological rainfall (dashed line) over Indonesia $\left(5^{\circ} \mathrm{N}-5^{\circ} \mathrm{S}, 95^{\circ}-130^{\circ} \mathrm{E}\right)$ for the period August 1996-December 1997. Climatological values are calculated over the 1979-95 period.

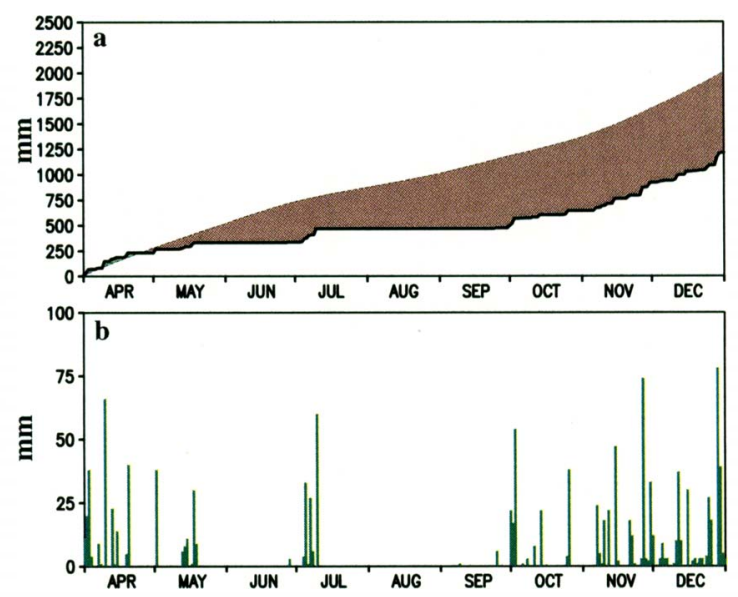

FIG. 62. Daily rainfall (mm) at Menado, Celebes, during AprilDecember 1997: (a) accumulated observed (thick line) and accumulated climatological mean (1961-90 base period), and (b) observed daily total. Shading in (a) shows the accumulated departure from normal, with brown shading indicating negative departures.

two days between mid-July and early November. Interestingly, in the area farther north, Kuala Lumpur, Sumatra, recorded slightly above normal rainfall (300 $\mathrm{mm}$ above normal) for the period (Fig. 64), with most of the enhanced precipitation occurring during November.

Severe drought, in combination with devastating frosts, also impacted New Guinea during 1997. These dry and cool conditions were linked to strong subsidence and clear skies in association with the an abnormally strong subtropical ridge over the country. By November, crop losses leading to malnutrition and in some cases starvation had affected hundreds of thousands of persons. These acute impacts continued during late November and December as significantly be- 


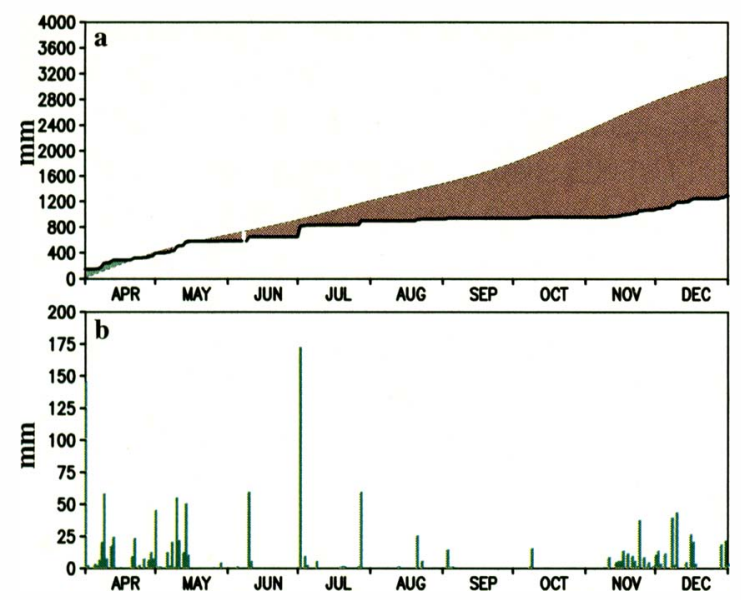

FIG. 63. Daily rainfall (mm) at Pedana Tabing, Sumatra, during April-December 1997: (a) accumulated observed (thick line) and accumulated climatological mean (1961-90 base period), and (b) observed daily total. Shading in (a) shows the accumulated departure from normal, with brown shading indicating negative departures.

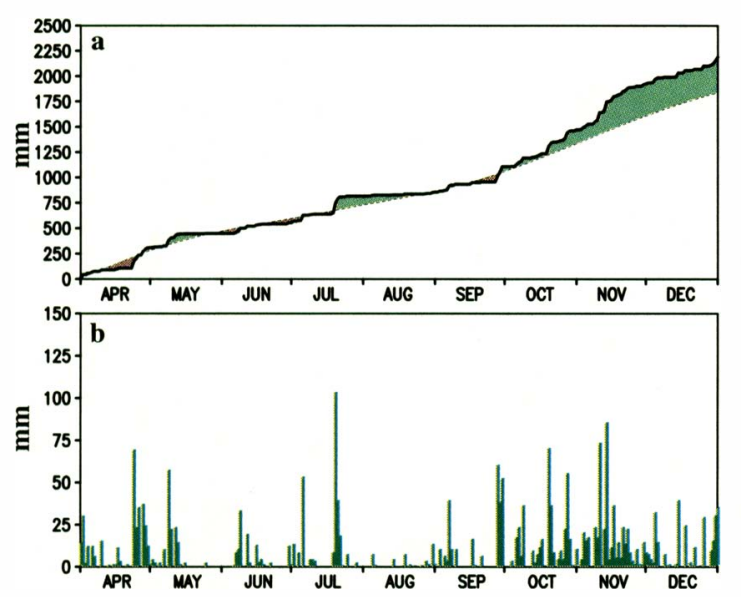

FIG. 64. Daily rainfall (mm) at Kuala Lumpur, Sumatra, during April-December 1997: (a) accumulated observed (thick line) and accumulated climatological mean (1961-90 base period), and (b) observed daily total. Shading in (a) shows the accumulated departure from normal, with green shading indicating positive departures.

low normal rainfall marked the onset of the 1997/98 wet season.

\section{g. Australia}

Northern Australia (indicated by the boxed area in Fig. 65a) experiences a tropical climate with a welldefined rainy season that typically begins during October and ends in April. Much of the area receives more than $75 \%$ of its mean annual rainfall during this seven-month period, with portions of extreme north-
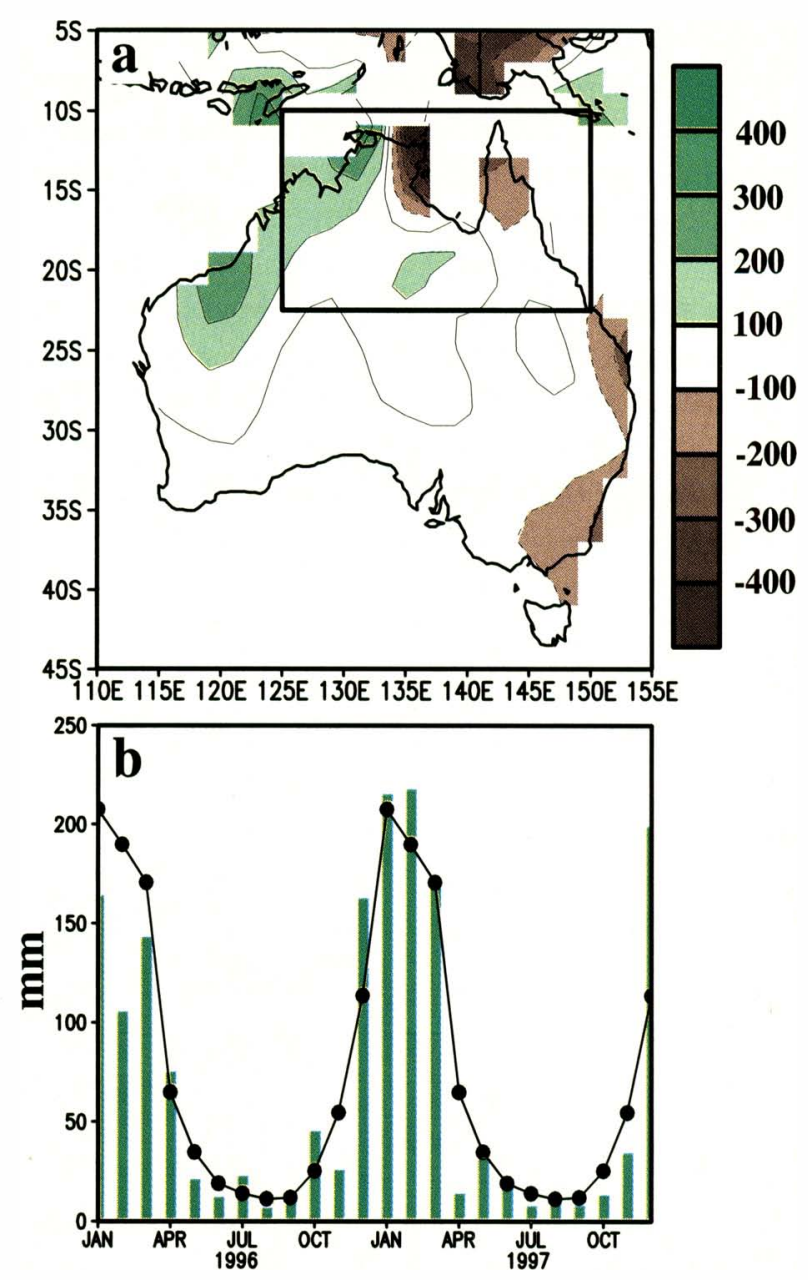

FIG. 65. (a) Precipitation anomalies (mm) for October 1996April 1997 and (b) monthly time series of total precipitation (mm, bars) and the 1961-90 climatological mean ( $\mathrm{mm}$, line) averaged over the boxed region in (a).

ern Australia recording more than $90 \%$. The annual cycle is strongly modulated by ENSO, with below(above-) normal rainfall typically observed during Pacific warm (cold) episodes (Ropelewski and Halpert 1987, 1989). The 1996/97 wet season featured abovenormal rainfall in the central and northwestern areas, which extended into the normally arid inland areas of western Australia. At Darwin, the seasonal rainfall total was $2374 \mathrm{~mm}$, just $8 \mathrm{~mm}$ below the record high total observed during the 1994/95 season (Halpert et al. 1996).

For the region as a whole, area-mean rainfall was near to above normal during the peak months (DJF) of the wet season (Fig. 65b), in association with continued weak cold episode conditions into early 1997. During this three-month period, rainfall totals were among the highest on record over extensive areas of 
central and northwestern Australia, with many places having their wettest season on record. The 1996/97 wet season also featured an abrupt end to the rains in late March, in association with the development of warm episode conditions in the tropical Pacific.

Elsewhere during the year, rainfall was below normal in southeastern Australia from March to November, with the largest deficits observed across southern Victoria and portions of eastern New South Wales (Fig. 66). In southern Victoria, dry conditions persisted from October 1996 through the end of the year. Within this region, Melbourne recorded its second driest January-November period in the 140-year record, with accumulated rainfall reaching only $355 \mathrm{~mm}$ (59\% of normal). Despite these dry conditions, the region experienced good rainfall during September and November, which occurred during a critical period in the growing cycle and in some cases turned imminent crop failure into good yields. These overall dry conditions during 1997 contrast with the previous year, when Melbourne recorded its second wettest January-September on record.

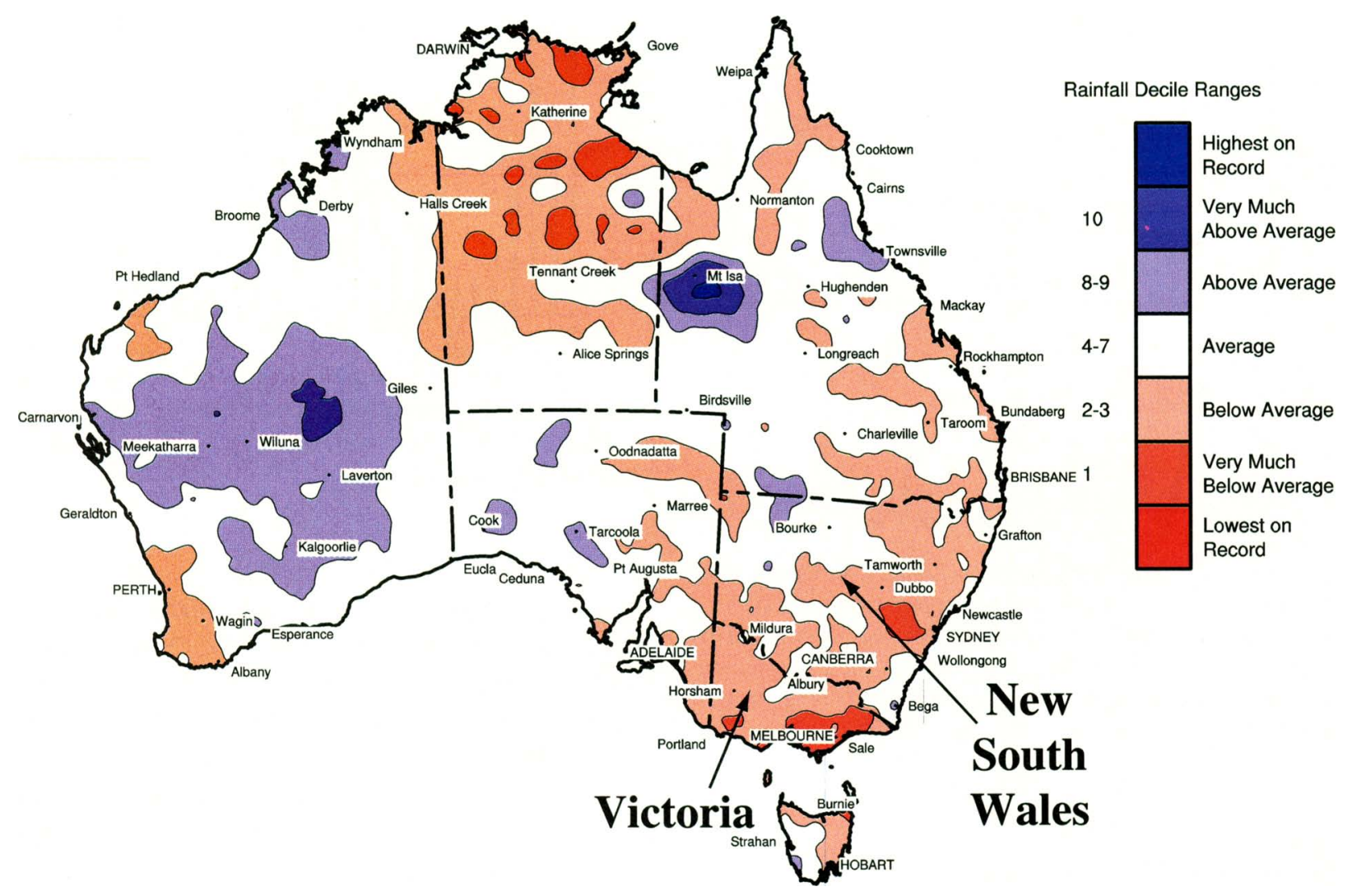

FIG. 66. March-November 1997 precipitation deciles. (Source: Australian Bureau of Meteorology.) 


\section{Seasonal summaries}
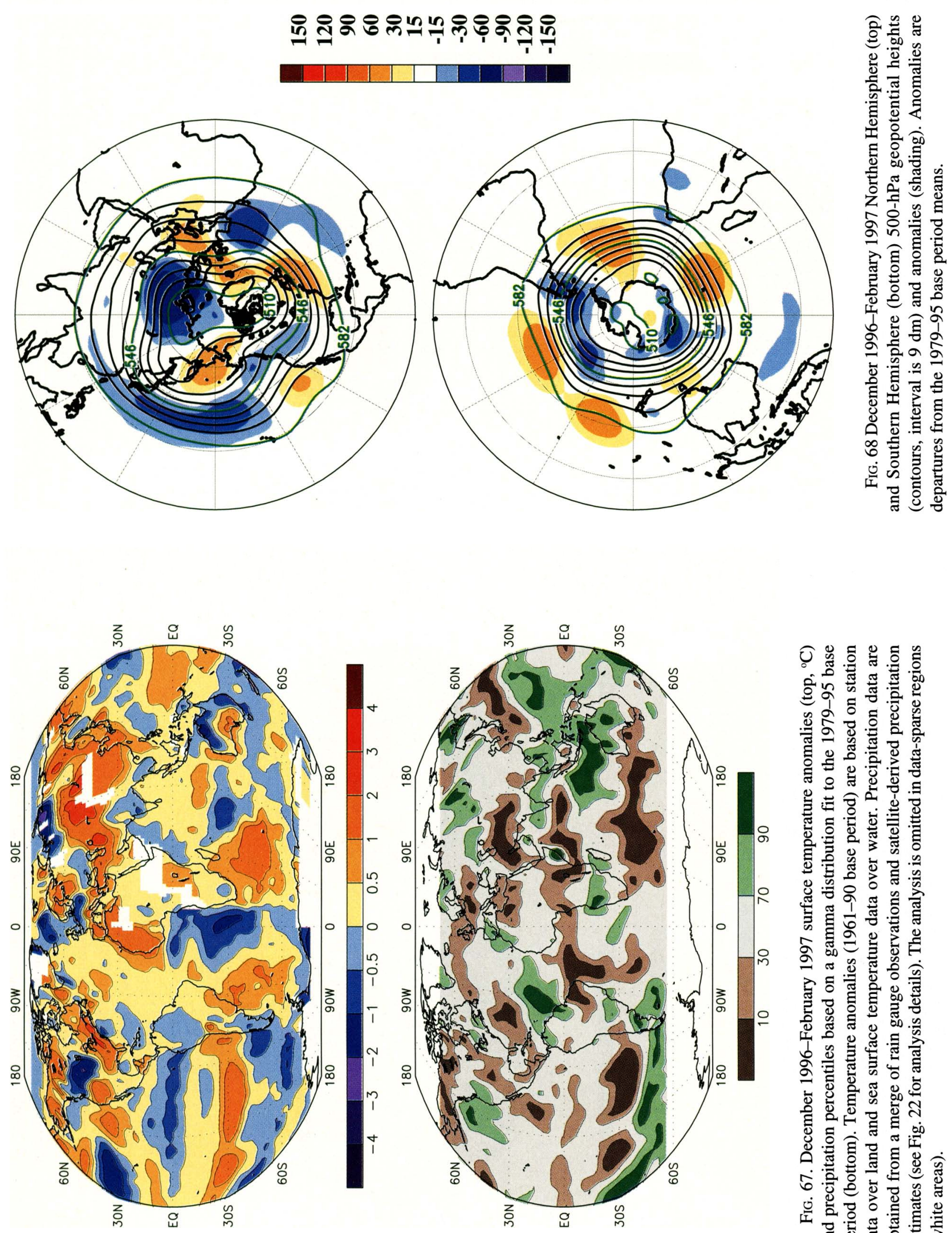

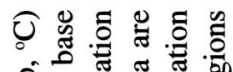

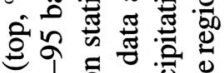

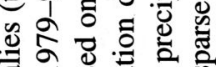
त 을 क्ज

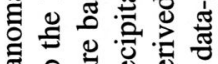
สิ

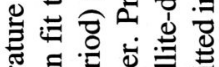

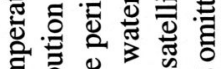

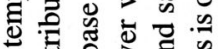
ญ.

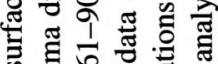

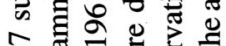

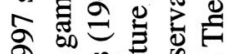
๙

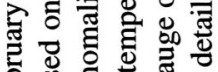

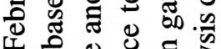
ปั

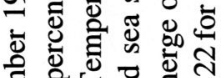
ถี่

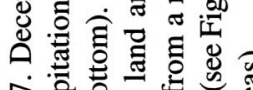
ஸे. :

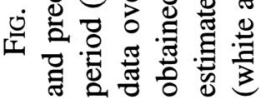




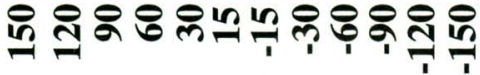
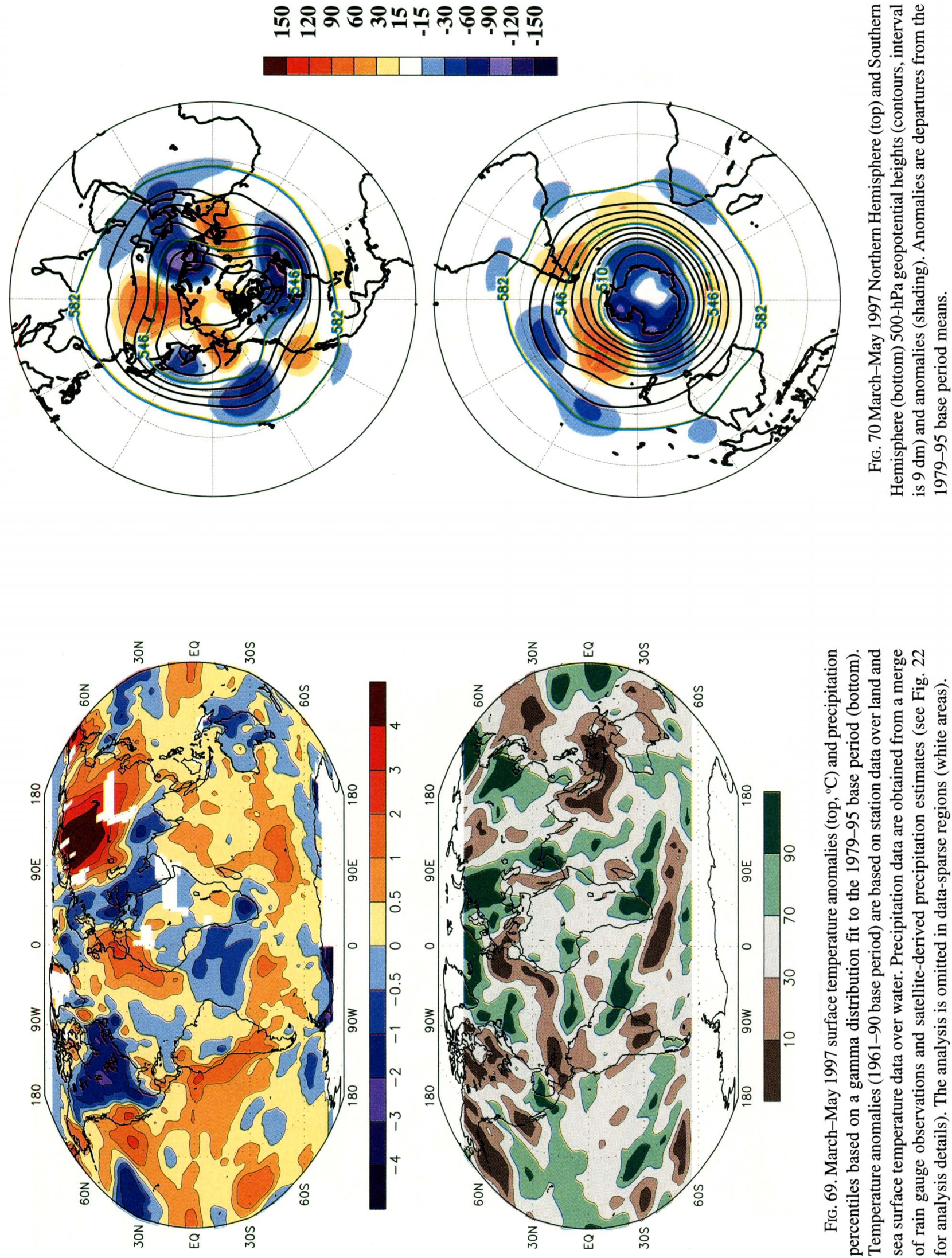


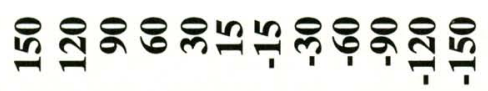
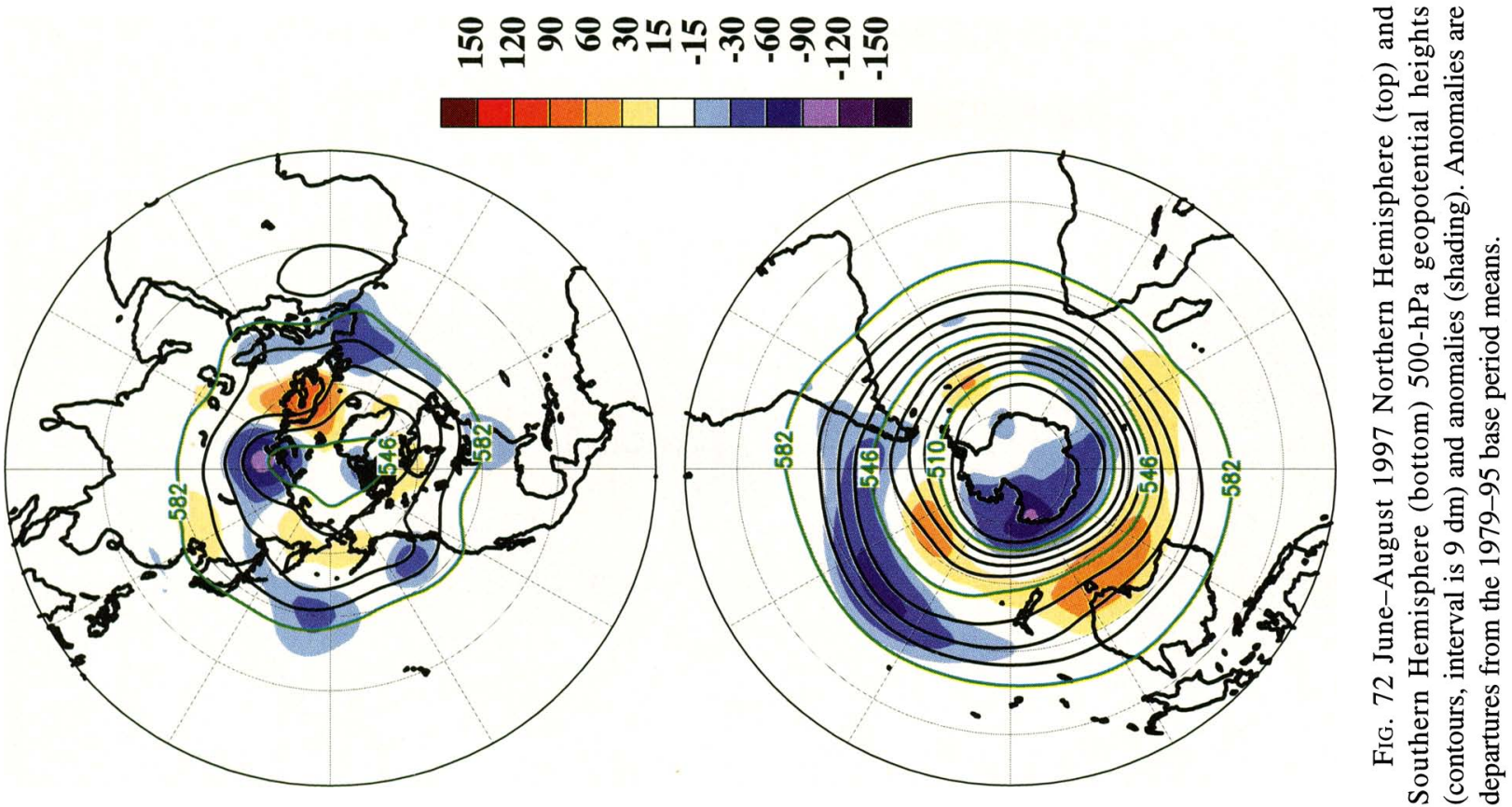

昰安

के 을

त्व

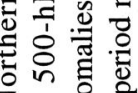

乙 $ิ$ สิ

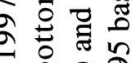

क हิ हो

का

$\int_{1}=2$

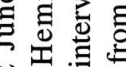

ㅍำ

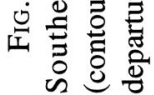
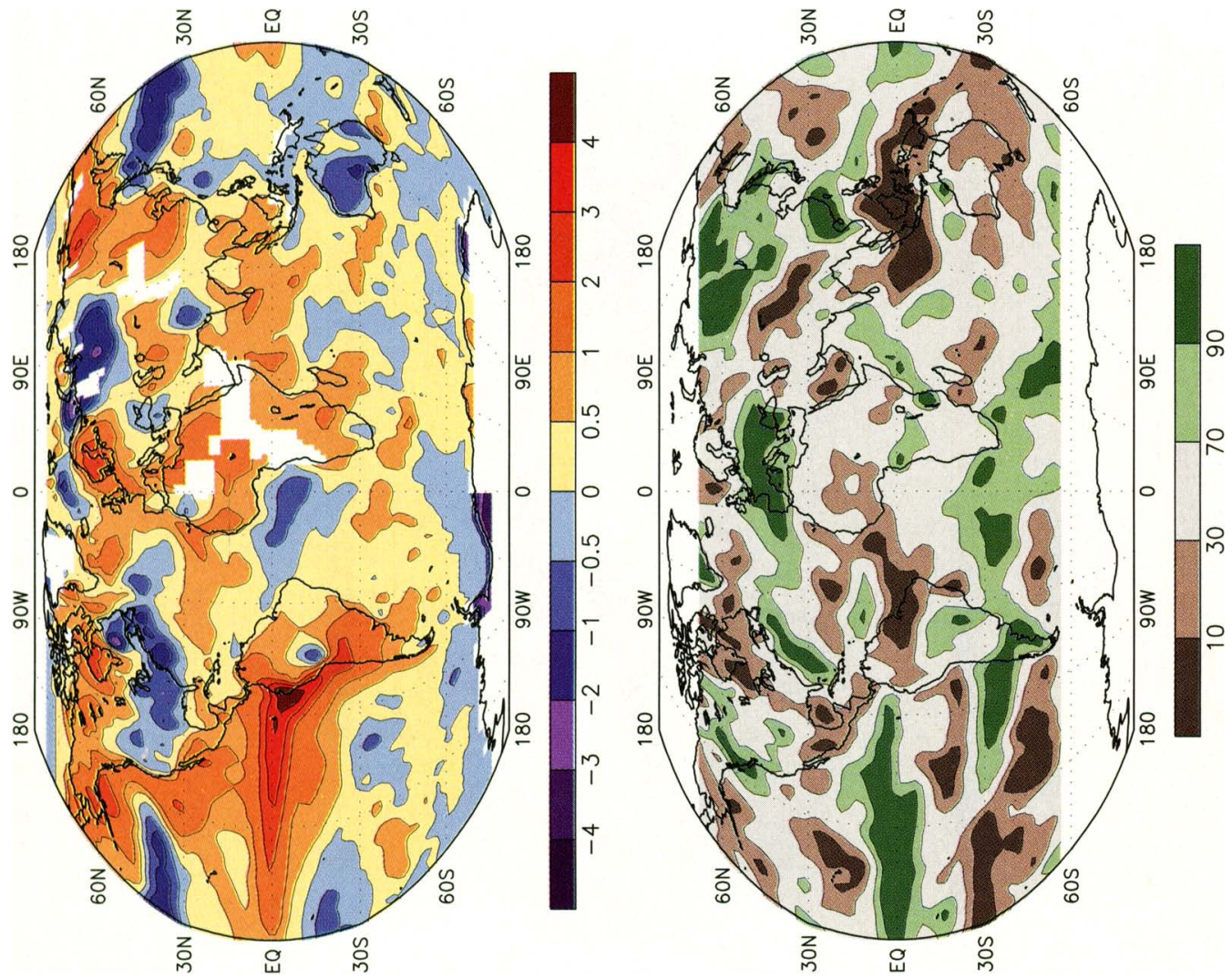

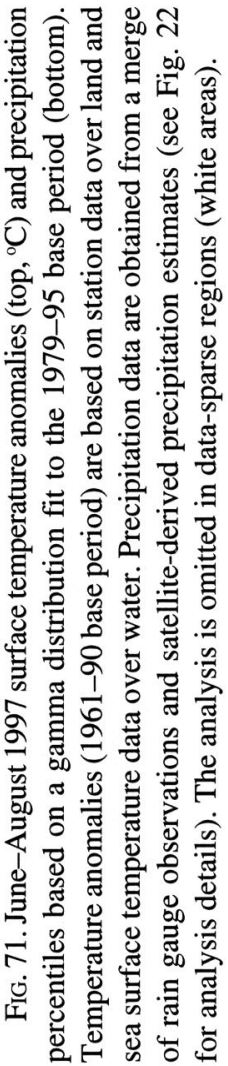



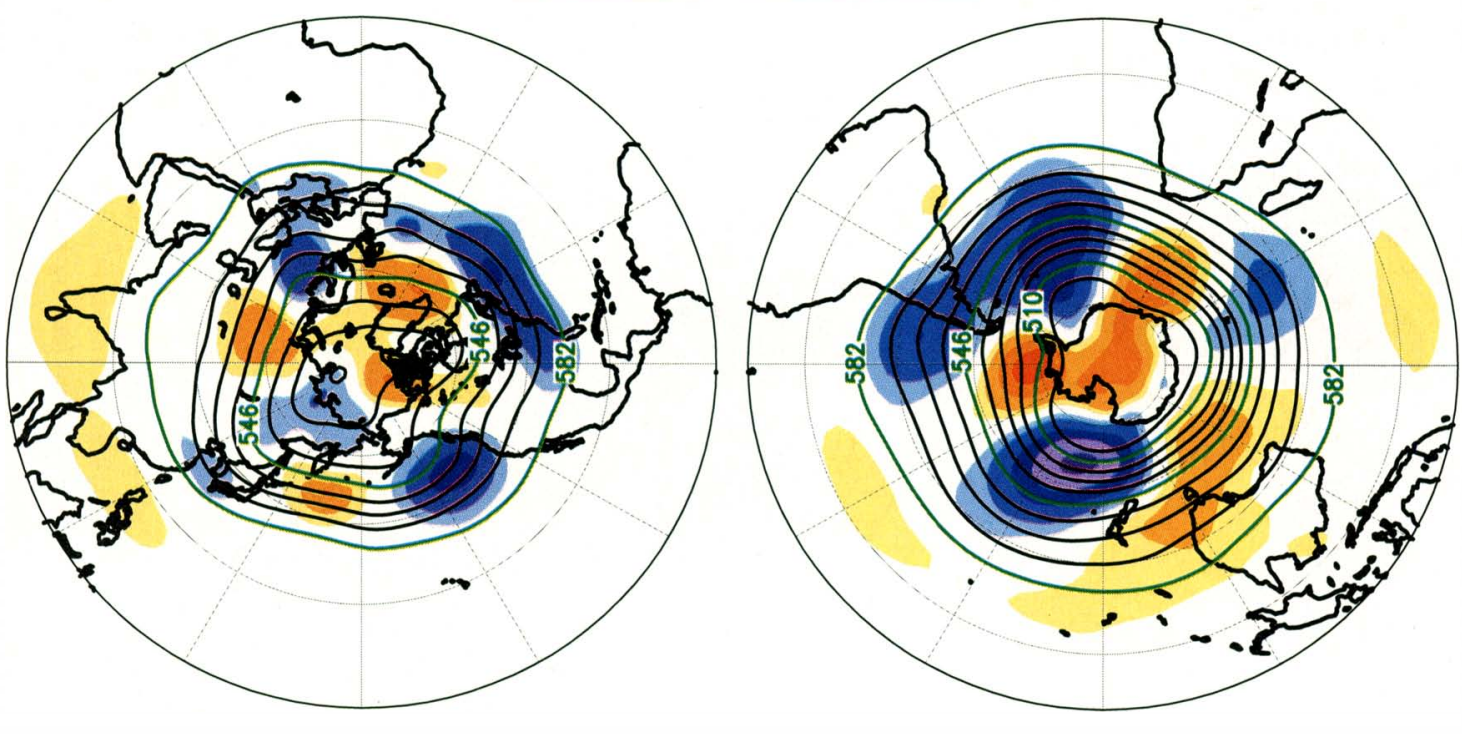

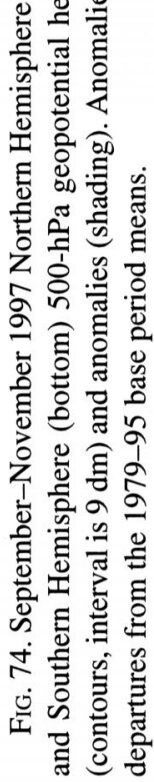
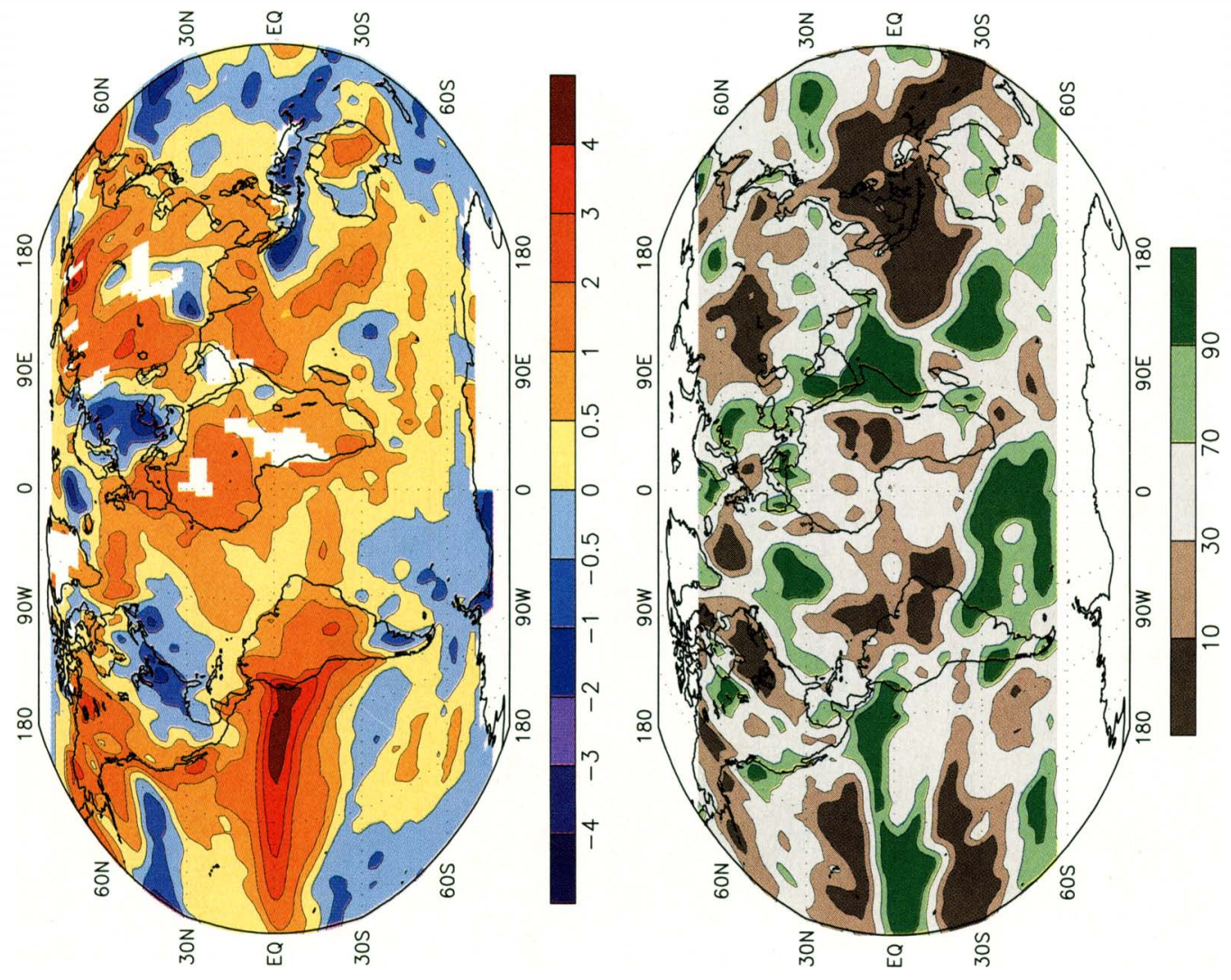

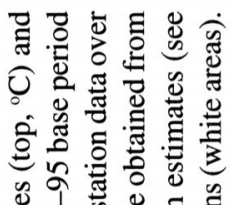

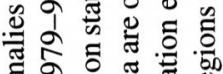
สิ๊

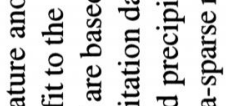
ฐٓ

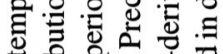
ญ :

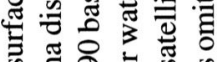
रิ

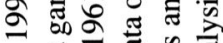

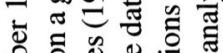

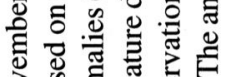

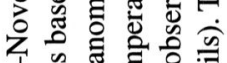

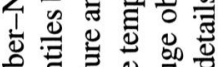

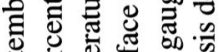

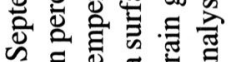
ஸ

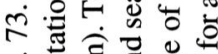

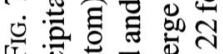

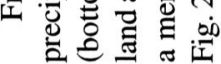




\section{Appendix: Contributors}

Australian Bureau of Meteorology, National Climate Centre, Climate Analysis Section

- W. Wright

Centro de Previsão de Tempo e Estudos Climáticos (CPTEC), Brazil

- I. Cavalcanti

Climate Prediction Center/NCEP/NWS/NOAA

- D. Garrett

- M. Gelman

- V. Kousky

- C. Long

- D. Miskus

- R. Nagatani

- W. Thiao

- R. Tinker

Climate Monitoring and Diagnostics Laboratory/ERL/NOAA

- J. Peterson

- P. Tans

Climatic Research Unit, University of East Anglia, United

Kingdom

- P. Jones

Department of Geography, Rutgers University

- D. Robinson

Deutscher Wetterdienst, Hamburg, Germany

- G. Rosenhagen

Hadley Centre for Climate Prediction and Research, United Kingdom

- B. Horton

- M. O’Donnell

- D. Parker

Indian Meteorological Department

- K. C. Sinha Ray

Japan Meteorological Agency

- K. Shida

National Climatic Data Center/NESDIS/NOAA

- W. Brown

- M. Crowe

Acknowledgments. This assessment would not have been possible without the cooperation and contributions from various scientists representing a cross section of the NOAA climate community. We also wish to acknowledge the contributions from the scientists outside of NOAA in other federal laboratories, at universities, and at several sites around the world. All of these scientists are in the contributors list (appendix) and we thank them for their timely and useful input. We are especially grateful to those international scientists who contributed their time and effort. In addition, we would like to thank C. Ropelewski, W. Higgins, J. Janowiak, V. Kousky, and D. Easterling for their comments that helped to strengthen the article. This assessment is supported by a grant from the NOAA Office of Global Program's Climate Change Data and Detection Program.

\section{References}

Aceituno, P., 1988: On the functioning of the Southern Oscillation in the South American sector. Mon. Wea. Rev., 116, 505525.

Arkin, P. A., 1982: The relationship between interannual variability in the $200 \mathrm{mb}$ tropical wind field and the Southern Oscillation. Mon. Wea. Rev., 110, 1393-1404.

Bell, G. D., and D. Keyser, 1993: Shear curvature vorticity and potential-vorticity interchanges: Interpretation and application to a cutoff cyclone event. Mon. Wea. Rev., 121, 76-102.

Bjerknes, J., 1969: Atmospheric teleconnections from the equatorial Pacific. Mon. Wea. Rev., 97, 163-172.

Chen, W. Y., and H. M. Van den Dool, 1997: Asymmetric impact of tropical SST anomalies on atmospheric internal variability over the North Pacific. J. Atmos. Sci., 54, 725-740.

Gadgil, S. J., P. V. Joseph, and N. V. Joshi, 1984: Ocean-atmosphere coupling over monsoon regions. Nature, 312, 141143.

Gray, W. M., 1984: Atlantic seasonal hurricane frequency: Part I: El Niño and 30-mb quasibiennial oscillation influences. Mon. Wea. Rev., 112, 1669-1683.

Groisman, P. Y., T. R. Karl, R. W. Knight, and G. L. Stenchikov, 1994: Changes of snow cover, temperature, and radiative heat balance over the Northern Hemisphere. J. Climate, 7, 16331656.

Halpert, M. S., and C. F. Ropelewski, 1992: Surface temperature patterns associated with the Southern Oscillation. J. Climate, 5, 577-593.

- , and G. D. Bell, 1997: Climate assessment for 1996. Bull. Amer. Meteor. Soc., 78 (5), S1-S49.

,-- V. E. Kousky, and C. F. Ropelewski, 1996: Climate assessment for 1995. Bull. Amer. Meteor. Soc., 77 (5), S1S44.

Higgins, R. W., and K. C. Mo, 1997: Persistent North Pacific circulation anomalies and the tropical intraseasonal oscillation. J. Climate, 10, 223-244.

Hofmann, D. J., S. J. Oltmans, J. M. Harris, B. J. Johnson, and J. A. Lathrop, 1997: Ten years of ozonesonde measurements at the South Pole: Implications for recovery of springtime Antarctic ozone. J. Geophys. Res., 102, 8931-8943.

Hoskins, B. J., I. Draghici, and H. C. Davies, 1978: A new look at the W-equation. Quart. J. Roy. Meteor. Soc., 104, 31-38.

Ji, M., A. Leetmaa, and J. Derber, 1995: An ocean analysis system for seasonal to interannual climate studies. Mon. Wea. Rev., 123, 460-481.

Jones, P. D., T. J. Osburn, and K. R. Briffa, 1997: Estimating sampling errors in large-scale temperature averages. J. Climate, 10, 2548-2568.

Kalnay, E., and Coauthors, 1996: The NCEP/NCAR 40-year reanalysis project. Bull. Amer. Meteor. Soc., 77, 437-471. 
Karoly, D. J., 1989: Southern Hemisphere circulation features associated with El Niño/Southern Oscillation events. J. Climate, 2, 1239-1252.

Keeling, C. D., R. B. Bacastow, and T. P. Whorf, 1982: Measurements of the concentration of carbon dioxide at Mauna Loa Observatory, Hawaii. Carbon Dioxide Review: 1982, W. C. Clark, Ed., Oxford University Press, 377-385.

Keyser, D., and M. A. Shapiro, 1986: A review of the structure and dynamics of upper-level frontal zones. Mon. Wea. Rev., 114, 452-499.

Madden, R. A., and P. R. Julian, 1971: Detection of a 40-50day oscillation in the zonal wind in the tropical Pacific. $J$. Atmos. Sci., 28, 702-708.

$\longrightarrow$, and — 1972: Description of global-scale circulation cells in the tropics with a 40-50 day period. J. Atmos. Sci., 29, 1109-1123.

$\longrightarrow$, and $\longrightarrow$ 1994: Observations of the 40-50-day tropical oscillation: A review. Mon. Wea. Rev., 122, 814-837.

Montzka, S. A., J. H. Butler, R. C. Myers, T. M. Thompson, T. H. Swanson, A. D. Clarke, L. T. Lock, and J. W. Elkins, 1996: Decline in the tropospheric abundance of halogen from halocarbons: Implications for stratospheric ozone depletion. Science, 272, 1318-1322.

Palmén, E., and C. W. Newton, 1969: Atmospheric Circulation Systems. Academic Press, 603 pp.

Reed, R. J., D. C. Norquist, and E. E. Recker, 1977: The structure and properties of African wave disturbances as observed during Phase III of GATE. Mon. Wea. Rev., 105, 317-333.
Reynolds, R. W., and T. Smith, 1995: A high-resolution global sea surface temperature climatology. J. Climate, 8, 1571-1583.

Ropelewski, C. F., and M. S. Halpert, 1987: Global and regional scale precipitation patterns associated with the El Niño/Southern Oscillation. Mon. Wea. Rev., 115, 1606-1626. , and 1989: Precipitation patterns associated with the high index phase of the Southern Oscillation. J. Climate, 2, 268-284.

Simpson, R. H., 1974: The hurricane disaster potential scale. Weatherwise, 27, 169-186.

Spencer, R. W., J. R. Christy, and N. C. Grody, 1990: Global atmospheric temperature monitoring with satellite microwave measurements: Method and results 1979-84. J. Climate, 3, 1111-1128.

Thoning, K. W., P. P. Tans, and W. D. Komhyr, 1989: Atmospheric carbon dioxide at Mauna Loa Observatory 2. Analysis of the NOAA/GMCC data, 1979-85. J. Geophys. Res., 94, 8549-8565.

WMO/UNEP, 1994: Scientific assessment of ozone depletion: 1994. WMO Rep. 37. [Available from the World Meteorological Organization, Case Postale 2300, 1211 Geneva, Switzerland.]

Xie, P., and P. A. Arkin, 1996: Analyses of global monthly precipitation using gauge observations, satellite summaries, and numerical model predictions. J. Climate, 9, 840-858.

$\longrightarrow$, and _ 1998: Global monthly precipitation estimates from satellite-observed outgoing longwave radiation. J. Climate, 11,137-164.

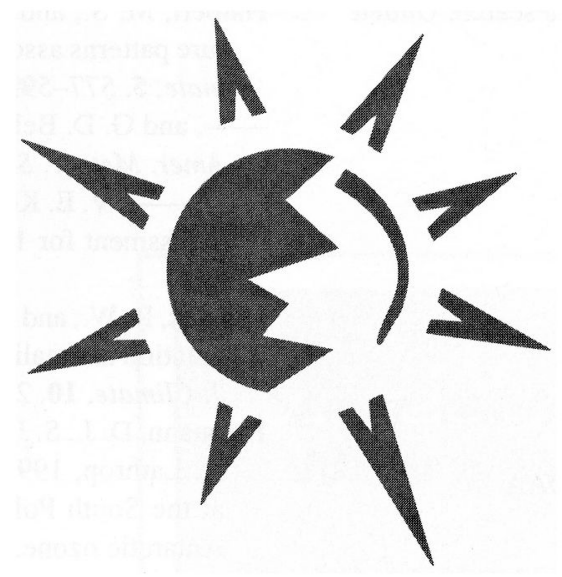

